\title{
UFRRJ
}

\section{INSTITUTO DE BIOLOGIA}

\section{CURSO DE PÓS-GRADUAÇÃO EM BIOLOGIA ANIMAL}

\section{DISSERTAÇÃO}

Anelídeos Polychaeta associados a bancos de corais de profundidade da Bacia de Campos - Rio de Janeiro, Brasil.

Vinícius da Rocha Miranda 


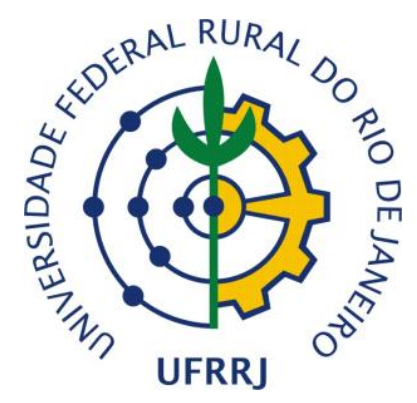

UNIVERSIDADE FEDERAL RURAL DO RIO DE JANEIRO

INSTITUTO DE BIOLOGIA

CURSO DE PÓS-GRADUAÇÃO EM BIOLOGIA ANIMAL

\title{
ANELIIDEOS POLYCHAETA ASSOCIADOS A BANCOS DE CORAIS DE PROFUNDIDADE DA BACIA DE CAMPOS - RIO DE JANEIRO, BRASIL.
}

\section{VINÍCIUS DA ROCHA MIRANDA}

Sob a Orientação da Professora

Ana Claudia dos Santos Brasil

\begin{abstract}
Dissertação submetida como requisito parcial para obtenção do grau de Mestre em Ciências, no Curso de Pós-Graduação em Biologia, Área de Concentração em Biologia Animal.
\end{abstract}

Seropédica, RJ

Junho de 2013 
578.7789

M672a Miranda, Vinícius da Rocha, 1987-

$\mathrm{T}$

Anelídeos Polychaeta associados a bancos de corais de profundidade da Bacia de Campos - Rio de Janeiro, Brasil / Vinícius da Rocha Miranda 2013.

105 f.: il.

Orientador: Ana Claudia dos Santos Brasil.

Dissertação (mestrado)

Universidade Federal Rural do Rio de Janeiro, Curso de Pós-Graduação em Biologia Animal.

Bibliografia: f. 87-104.

1. Biologia dos recifes de coral Teses. 2. Ecologia dos recifes de coral - Teses. 3. Corais - Teses. 4. Anelídeo - Teses. 5. Campos, Bacia de (RJ e ES) - Teses. I. Brasil, Ana Claudia dos Santos, 1965-. II. Universidade Federal Rural do Rio de Janeiro. Curso de Pós-Graduação em Biologia Animal. III. Título. 


\section{VINÍCIUS DA ROCHA MIRANDA}

Dissertação/Tese submetida como requisito parcial para obtenção do grau de Mestre em

Ciências, no Curso de Pós-Graduação em Ciências, área de Concentração em Biologia Animal.

DISSERTAÇÃO APROVADA EM 26/06/2013

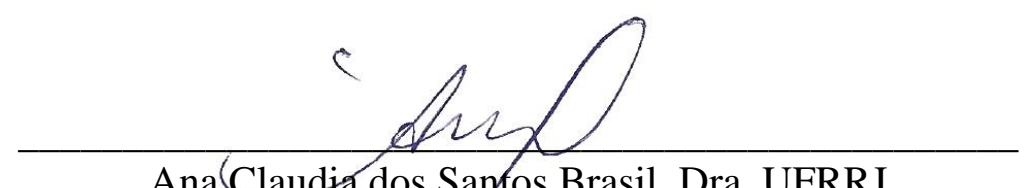

Ana Claudia dos Santos Brasil. Dra. UFRRJ
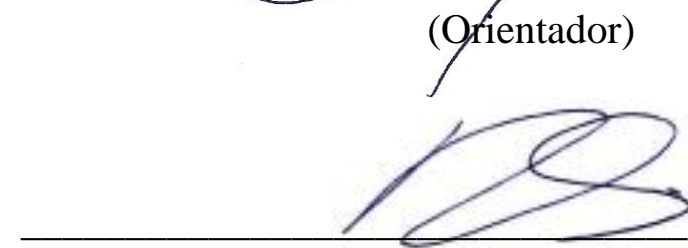

Paulo Cesar de Paiva. Dr. UFRJ
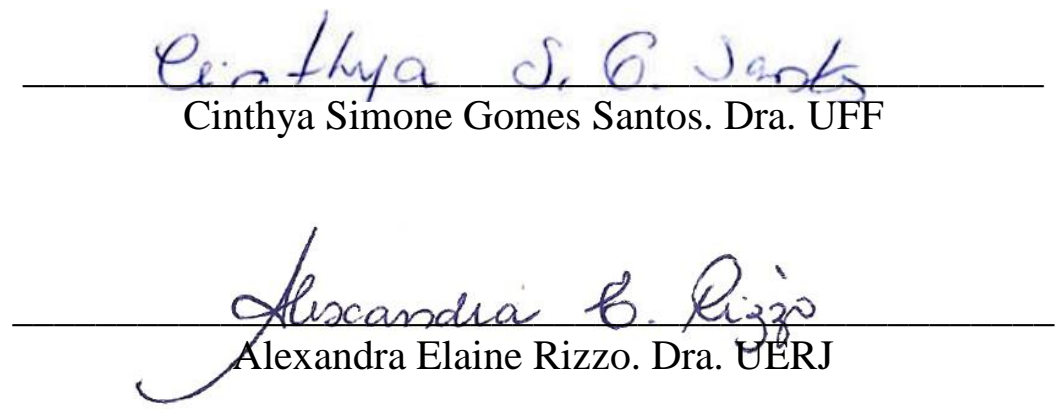


\section{AGRADECIMENTOS}

Primeiramente gostaria de agradecer à minha orientadora Ana Claudia dos Santos Brasil, por confiar em mim para ser seu primeiro aluno de pós-graduação e por me permitir realizar esse projeto tão legal e importante.

À minha família, meu pai Moacir e minha mãe Mirian, que sempre se preocuparam em me passar os preceitos de certo e errado, que se sacrificaram ao longo de todos esses anos para me possibilitar crescer e seguir em frente. Também foi deles o incentivo a nunca parar de estudar. Ao meu irmão Bruno que, apesar de todas as brigas, eu amo muito e que sempre esteve em casa me apoiando. Aos meus avós que me serviram como exemplo e que também sempre prezaram pela minha educação em primeiro lugar. Enfim, a todos os meus parentes que sempre me apoiaram com a sua companhia ao longo desta trajetória.

Agradeço também à minha namorada Rafaela Pedrosa, que muito aturou do meu mau humor nessa reta final e que sempre me alegrou com a sua companhia e tiradas engraçadas.

Agradeço ao meu professor a amigo Helio Ricardo da Silva, por me ajudar em vários momentos de dúvida e também pelos cafezinhos da tarde! Aos Doutores Alexandra Rizzo, Cinthya Santos e Paulo Paiva por aceitarem o convite para compor a banca avaliadora, mas também por estarem sempre amigavelmente acessíveis para quaisquer dúvidas e ajudas.

Aos meus amigos(as) de Petrópolis, Ricardo, Daniel, Cláudio, Guilherme, Rafael, Pedro, Francine, Emilio, Rodrigo, Marcelo, Alan, aos Trovadores Farofeiros (Marlan, Michele, Karina, Aline, Estevão, Eduardo e Natália), por compartilharem comigo esse clima chuvoso, essa cidade pacata, mas na qual sempre tivemos ótimos momentos juntos, estudando ou saindo, estávamos sempre rindo de alguma coisa.

Aos amigos e amigas dos tempos de graduação: Alex, Danielle, Enely, Fernandinha, Luiz, Nathalia e Taynara, com os quais enfrentei dias de sol até o DG ou dias de chuva e lama pelos gramados desta Universidade. Amigos os quais apenas a presença já bastava para que os dias fossem melhores nesses últimos seis anos! E também aos amigos de pós-graduação, Edicarlos, Marcia, Maíra, Rogério, Thiago e Adriana, que se tornaram tão queridos rapidamente e com os quais pude sempre contar pra discutir e conversar.

Por último, mas não em menor consideração, aos meus amigos do LAPOL, meus sinceros agradecimentos por aturarem meu mau humor, minhas piadas sem graças, minhas 
manias, dentre outras coisas mais, mas que me fazem rir durante os horários de estágio e pelas horas em que nos desesperávamos frente aos compromissos e à cafeteira tomando um cafezinho. Muito obrigado: Isabela, Tiago, Aline, Fernanda, Caroline, Guilherme, Tamires, Ayra, Joana, Mariana e também aos agregados incontáveis.

Agradeço também à PETROBRAS S.A, pela realização dos projetos, dos quais obtive o material, e também pela autorização por poder realizar esta pesquisa. Assim como ao Programa de Pós-graduação em Biologia Animal da UFRRJ e à CAPES pela bolsa recebida durante a realização desta dissertação. 


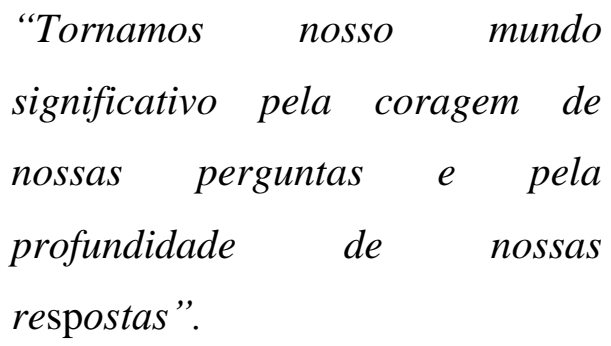

(Carl Sagan) 


\section{RESUMO}

MIRANDA, Vinícius da Rocha. ANELÍDEOS POLYCHAETA ASSOCIADOS A BANCOS DE CORAIS DE PROFUNDIDADE DA BACIA DE CAMPOS - RIO DE JANEIRO, BRASIL. 2013. 105p. Dissertação (Mestrado em Biologia Animal, Zoologia) Instituto de Biologia, Departamento de Biologia Animal, Universidade Federal Rural do Rio de Janeiro, Seropédica, RJ, 2013.

Recifes de corais de profundidade possuem uma grande importância ecológica, uma vez que podem abrigar uma grande diversidade de espécies associadas. Isso é possível graças à sua conformação tridimensional que proporciona uma alta hetereogenidade espacial, criando um ambiente protegido para muitas espécies. No Brasil, estudos sobre corais. de profundidade, são escassos e recentes. Muitos destes se limitam a descrever as espécies de corais encontradas e a sua distribuição pela costa brasileira assim como organismos bentônicos associados a eles. Recentemente foram realizados dois projetos coordenados pela CENPES/PETROBRAS, CAP-BC e ECOPROF com objetivo de realizar um levantamento dos recifes de corais de profundidade, bem como das espécies associadas a estes, na região da Bacia de Campos (noroeste do estado do Rio de Janeiro). Em cada um desses projetos foi utilizado um ROV para coletar amostras nas profundidades entre 300 e 1100 metros. Cinco espécies de corais formadores desse ecossistema foram coletadas: Solenosmilia variabilis Duncan, 1873, Lophelia pertusa (Linnaeus, 1758), Enallopsammia rostrata (Portualès, 1758), Madrepora oculata Linnaeus, 1758 and Errina sp., cada amostra foi fixada em uma mistura tamponada de formalina (10\%), para posterior triagem em laboratório. Aqui apresentamos o estudo dos poliquetas associados a estes corais na Bacia de Campos. A espécie Eunice prognatha McIntosh, 1885 foi a mais abundante, seguida por Harmothoe gilchristi (Day, 1960) e Nicon maculata Kimberg, 1866. O coral S. variabilis foi o que apresentou o maior número de espécies associadas, seguida dos corais E. rostrata e L. pertusa, já as espécies M. oculata e Errina sp. foram os corais com menos espécies de poliquetas encontrados. Foram reportadas cinco novas espécies de poliquetas Harmothoe sp. (Polynoidae), Pholoides sp. (Sigalionidae), Leocratides sp. (Hesionidae), Euchone sp. (Sabellidae), e Ophryotrocha sp. (Dorvilleidae). O total de oito espécies foram registradas pela primeira vez para a costa brasileira: Glycerella magellanica (McIntosh, 1885), Harmothoe gilchristi (Day, 1960), Eunice gracilicirrata (Treadwell, 1922), Eunice prognatha McIntosh, 1885, Pionosyllis procera Hartman, 1965, Haplosyllis ohma (Imajima \& Hartman, 1964), e Nicon maculata Kimberg, 1866. Duas outras espécies, 
Filogranula revizee Nogueira \& Abbud, 2009 e Notopygos crinita Grube, 1855, tiveram suas áreas de ocorrência ampliadas. Este é o primeiro estudo focando nos poliquetas associados aos corais de profundidade da costa brasileira. Novos estudos devem ser realizados para melhor compreender a distribuição das espécies descritas neste trabalho, assim como entender as possíveis associações destas com as espécies de coral desse ecossistema.

Palavras-chave: Corais de profundidade, Polychaeta, Bacia de Campos. 


\begin{abstract}
MIRANDA, Vinícius da Rocha. Polychaeta associated with deep-sea coral reefs from Campos Basin, Rio de Janeiro, Brasil. 2013. 105p. Dissertation (Master Science in Animal Biology, Zoology) Instituto de Biologia, Departamento de Biologia Animal, Universidade Federal Rural do Rio de Janeiro, Seropédica, RJ, 2013.
\end{abstract}

Cold-water coral reefs are of great ecological importance, they can support a great diversity associated with. They can offer a sheltered, three-dimensional, micro-habitat to many species. Studies involving the Brazilian deep-sea coral reefs, and the fauna which composes it, are recent and still scarce. These reefs were studied only in terms of the species of coral which composes it and their distribution in our coast, as the benthic fauna which are associated with this environment. Two projects, CAP-BC and ECOPROF, coordinated by CENPES/PETROBRAS, surveyed the Campos Basin (located at the northeast of Rio de Janeiro) with the objective of studying this environment and the associated fauna. On each project samples of the reef-building corals were collected with a ROV, at depths from 245 to $1100 \mathrm{~m}$. Five species of coral were surveyed: Solenosmilia variabilis Duncan, 1873, Lophelia pertusa (Linnaeus, 1758), Enallopsammia rostrata (Portualès, 1758), Madrepora oculata Linnaeus, 1758 and Errina sp.,and fixed in formalin $10 \%$ and sorted at the laboratory. Here in, we present the first, qualitative, results from the polychaetes found in association with the coral reefs in Campos BasinThe specie of Eunice prognatha McIntosh, 1885 were the most abundant, followed by Harmothoe gilchristi (Day, 1960) and Nicon maculata Kimberg, 1866. The majority of polychaetes were found associated to the coral $S$. variabilis, followed by E. profunda and L. pertusa, both $M$. oculata and Errina sp. were the corals with less associated polychaetes. Five new species of Polychaeta are reported: Harmothoe sp. (Polynoidae), Pholoides sp. (Sigalionidae), Leocratides sp. (Hesionidae), Euchone sp. (Sabellidae) and Ophryotrocha sp. (Dorvilleidae).Specimens identified as Glycerella magellanica (McIntosh, 1885), Harmothoe gilchristi (Day, 1960), Eunice gracilicirrata (Treadwell, 1922), Eunice prognatha McIntosh, 1885, Pionosyllis procera Hartman, 1965, Haplosyllis ohma (Imajima \& Hartman, 1964) and Nicon maculata Kimberg, 1866, are new occurrence for the Brazilian coast. Two other species, Filogranula revizee Nogueira \& Abbud, 2009 and Notopygos crinita Grube, 1855 had their range of occurrence extended. This is the first study aiming on the polychaetes associated with deep sea corals in the Brazilian waters, further studies should be conducted to better understand the distribution of species described here in, as well as to better understand the polychaete assemblage associated with each species of coral.

Key-words: Cold-water coral reefs, Polychaeta, Campos Basin. 


\section{LISTA DE FIGURAS}

Figura 1: (A) Mapa da America do Sul, com destaque para o estado do Rio de Janerio. (B) Mapa do estado do Rio de Janeiro com a localização da área de coleta (retângulo vermelho) na Bacia de Campos, entre os municípios de Cabo Frio de Campos dos Goytacazes.

Pág.6

Figura 2: Abundâncias relativas das principais espécies de poliquetas associadas aos corais de profundidade. Pág. 10

Figura 3: Riqueza relativa de poliqueta por espécie de coral. Pág. 10

Figura 4: Distribuição das espécies E. prognatha, H. gilchristi e Harmothoe sp.entre os corais amostrados.. Pág. 11

Figura 05: Harmothoe gilchristi MEV das neurocerdas: (A) ponta da neurocerda inferios; (B) ponta da neurocerda mediana; (C) ponta da neurocerda superior.... Pág. 18 Figura 6: Harmothoe gilchristi: (A) visão dorsal da região anterior; (B) escama mediana (lado direito); (C) Setigero mediano esquerdo; (D) micropapilas cônicas maiores; (E) microtuberculos conicos menores; (F) notocerda; (G) ponta da mesma; $(\mathrm{H})$ neurocerda bidentada; (I) ponta da neurocerda superior ( $\mathrm{J}$ ) ponta da neurocerda mediana $(\mathrm{K})$ ponta da neurocerdas inferior Pág. 19

Figura 7: Harmothoe sp MEV das cerdas: (A) ponta da notocerda; (B) ponta da neurocerdas superior; (C) ponta da neurocerda inferior. Pág. 22

Figura 8:. Harmothoe sp.: (A) visão dorsal da região anterior; (B) primeira escama do lado esquerdo; (C) escama mediana do lado direito; (D) parapódio mediano do lado direito; (E) detalhe das micropapilas; (F) notocerda;(G) ponta da mesma;(H) neurocerda bidentada (I) ponta da neurocerda superior;(J) ponta da neurocerda inferior Pág. 23 Figura 9: Pholoides sp.: (A) espécime no interior de uma cavidade na parte morta do coral Solenosmilia variabilis; (B): MEV da superficie dorsal da escama mediana e detalhes dos anéis concêntricos; (C): detalhe da ponta da notocerda de um parapódio mediano; (D) ponta da neurocerda superior; (E) ponta da neurocerda inferior Pág. 27

Figura 10 Pholoides sp.: (A) visão dorsal da região anterior; (B) escama mediana do lado direito; (C) primeira escama do lado direito; (D) parapódio cirróforo mediano ; (E) parapódio do segundo segmento (elitróforo); (F) parapódio do primeiro segmento (tentaculóforo), sem o cirro dorsal; $(\mathrm{G})$ ponta da neurocerda inferior; (H) ponta da 
neurocerda superior; (I) notocerda (J) ponta da mesma (K) cirro dorsal so primeiro segmento (tentaculóforo).:

Pág. 28

Figura 11: Leocratides sp.: (A) espécime no interior de esponja Hexactinellida; (B) vista dorsal da região anterior (seta apontando para o órgão nucal); (C) visão ventral da região anterior; (D) parapódio mediano; (E) cerda do parapódio 3; (F) cerda do parapódio 10; (G) cerda do parapódio 19 Pág. 33

Figura 12: Nicon maculata: (A) visão dorsal da região anterior; (B) visão lateral da região anterior; (C) espécimes em tubos na parte morta de E. rostrata; (D) parapódio mediano; (E) cerda heterogonfa falcígera; (F) cerda homogonfa espinígera ....... Pág. 38 Figura 13: Haplosyllis ohma: (A) visão dorsal da região anterior; (B) detalhes do prostômio; (C) acícula; (D) parapódio do setígero 10; (E) visão dorsal do estolão; (F) cerda; $(\mathrm{G})$ parapódio do setígero 32

Pág. 43

Figura 14: Pionosyllis procera: (A) visão dorsal da região anterior; (B) visão anteroventral da faringe; (C) Parapódio mediano; (D) cerda primeiro setígero; (E)cerda superior do setígero 49; (F) cerda inferior do mesmo; (G) cerda superior do setígero $101 ;(\mathrm{H})$ cerda inferior do mesmo

Pág. 48

Figura 15: Glycerella magellanica: (A) vista dorsal do espécime, com probóscide evertida; (B) visão lateral do prostômio; (C) papilla maior da probóscide; (D) papila menor da probóscide; (E) aileron; (F) parapódio do primeiro setígero; (G) cerda espinígera do mesmo; $(\mathrm{H})$ detalhe da mesma (I) parapódio da região posterior do corpo; (J) notocerda capilar do mesmo; (K) neurocerda espinígera do mesmo; (L) neurocerda falcígera do mesmo; (M) detalhe da haste da cerda falcígera do parapódio mediano; (N) parapódio mediano; $(\mathrm{O})$ neurocerda espinígera do mesmo; $(\mathrm{P})$ neurocerda falcígera do mesmo (Q) detalhe da haste da neurocerda falcígera do parapódio mediano

Pág. 53

Figura 16: Notopygos crinita:(A)visão dorsal da região anterior;(B) Prostômio.Pág. 57

Figura 17: Notopygos crinita: (A) visão dorsal da Região anterior; (B) parapódio anterior; (C) cerda superior recurvada; (D) detalhe da mesma; (E) cerda medianasuperior; (F) cerda mediana-inferior; (G) cerda inferior

Pág. 57

Figura 18: Ophryotrocha sp.: (A) visão dorsal do espécime inteiro (seta azul apontando para banda ciliar dorsal azul claro); (B) visão dorso-lateral da região anterior; (C) cerda capilar; (D) cerda homogonfa espinígera; (E) detalhe da mesma; (F) maxila P; (G) fórceps da maxila K; (H) placas dentárias da maxila K; (I) Mandibula; (J) MEV de um parapódio (seta laranja: lobo dorsal sobre o parapódio; amarela: lobo ventral sobre o parapódio; vermelha: cirro dorsal; verde: cirro ventral)

Pág. 62 
Figura 19: Eunice prognatha: (A) visão lateral do prostômio; (B) neurocerda composta; (C) ponta do gancho sub-acícular do setígero 54; (D) parapódio do setígero 11; (E) parapódio do setígero 31; (F) parapódio do setígero 54; (G) cerda pectinada do setígero 31; (H) notocerda capilar do setígero 31; (I) ponta da acícula Pág. 68

Figura 20: Eunice gracilicirrata: (A) visão lateral da região anterior; (B) visão dorsal da região anterior; (C) parapódio do setígero 12; (D) parapódio do setígero 32; (E) ponta das acículas do parapódio do setígero 33; (F) ganchos sub-acículares do mesmo; (G) detalhe da ponta dos mesmos; $(\mathrm{H})$ notocerda capilar do setígero 12; (I) neurocerda do setígero 31 Pág. 72

Figura 21: Euchone sp.: (A) espécime inteiro, visão ventral; (B) ponta do radíolo; (C) cerda limbada toráxica superior; (D) cerda limbada toráxica inferior; (E) cerda limbada toráxica superior; $(\mathrm{F})$ cerda limbada abdominal inferior; $(\mathrm{G})$ uncini acícular do tórax; (H) detalhe da ponta do mesmo; (I) uncini abdominal do setígero 9; (J) uncini abdominal do setígero 19 Pág. 77

Figura 12: Filogranula revizee: (A) região anterior, visão ventral; (B) uncini toráxico; (C) uncini abdominal; (D) cerda do colar; (E) cerda "fin and blade"; (F) cerda toráxica 


\section{LISTA DE TABELAS}

TABELA 1: Lista das espécies de poliqueta encontradas.. ............................... Pág. 9

TABELA 2: Distribuição batimétrica das espécies de poliqueta nos pontos amostrados na Bacia de Campos

Pág. 12 
1. INTRODUÇÃO

Pág. 1

2. OBJETIVOS

Pág. 5

2.1 OBJETIVO GERAL

Pág. 5

2.2 OBJETIVOS ESPECÍFICOS

Pág. 5

3. METODOLOGIA

Pág. 6

3.1AREA DE ESTUDO

Pág. 6

3.1 COLETA E TRATAMENTO DAS AMOSTRAS

Pág. 7

4 RESULTADOS

Pág. 9

4.1 Resultados

Pág. 9

4.2 Sistemática

Pág. 12

4.1 Harmothoe gilchristi Day, 1960

Pág. 14

4.2 Harmothoe sp.

Pág. 20

4.3 Pholoides sp.

Pág. 24

4.4 Leocratides sp.

Pág. 29

4.5 Nicon maculata Kimberg, 1866

Pág. 34

4.6 Haplosyllis ohma.(Imajima \& Hartman, 1964)

Pág. 39

4.7 Pionosyllis procera Hartman, 1965

Pág. 44

4.8 Glycerella magellanica (McIntosh, 1885)

Pág. 49

4.9 Notopygos crinita. Grube, 1855

Pág. 54

4.10 Ophyotrocha sp.

Pág. 58

4.11 Eunice prognatha McIntosh, 1885

Pág. 63

4.12 Eunice gracilicirrata (Treadwell, 1922)

Pág. 69

4.14 Euchone sp.

Pág. 73

4.15 Filogranula revizee Nogueira \& Abbud, 2009

Pág. 78

5 DISCUSSÃO

Pág. 81

6 CONCLUSÃO

Pág. 66

7 REFERÊNCIAS BIBLIOGRÁFICAS

Pág. 87

8 ANEXOS

Pág. 105 


\section{INTRODUÇÃO}

Antigamente acreditava-se que o assoalho oceânico abaixo dos 100 metros, assemelhava-se a um grande deserto, porém, com o aumento de projetos e apoios financeiros para pesquisas nesses ambientes, sabe-se hoje que existe uma grande diversidade de habitats e ecossistemas profundos. (Fossa et al., 2002; Glover \& Smith, 2003; Mortensen et al., 2008). Esse habitats abrigam uma grande biodiversidade, com diversas novas espécies sendo descritas nos últimos anos, em consequência do maior número de pesquisas nestes ambientes.

Há apenas dois séculos, foram descobertos os primeiros recifes de corais de águas profundas, um tipo de formação considerado restrito a águas mais rasas (Freiwald et al., 2004). Esse ecossistema coralíneo pode ser encontrado em todos os oceanos estando presentes tanto em plataformas continentais, quando em montes submarinos e regiões mais profundas. O ecossistema é formado por alguns táxons de Cnidaria, principalmente os corais pétreos da ordem Scleractinia, os Octocorallia (Alcyonaria) e os Hydrozoa (Hidrocorais -Stylasteridae). As espécies mais comumente encontradas são: Lophelia pertusa (Linnaeus, 1758), Solenosmilia variabilis (Ducan, 1873), Madrepora oculata Linnaeus, 1758 e Enallopsammia rostrata (Pourtalès, 1878), podendo estar associadas a outras espécies de cnidários que coocorrerem em um mesmo banco (Wienberg et al., 2009; Freiwald et al., 2009; Roberts et al., 2009). Essas espécies são as principais formadoras de estruturas recifais em ambientes de profundidade e, por possuírem uma forma tridimensional, propiciam uma maior complexidade espacial, formando um ambiente protegido de predadores e correntes marinhas abrigando diversas espécies de animais (Roberts, 2005).

Os recifes, ou bancos, de corais de profundidades são considerados, em alguns lugares do mundo, como "Hot Spots" de biodiversidade por serem um importante agregador de espécies sésseis e vágeis, que estão direta ou indiretamente relacionadas com o ambiente recifal. (e.g. sedimento formado por cascalhos de coral ("coral rubble"), no entorno dos bancos, e até mesmo o próprio banco) (Freiwald et al., 2004; Roberts et al. 2006; Fiege \& Barnich, 2009; Bongiorni et al., 2010). Apesar dessa importância ecológica, os recifes de corais são ameaçados no mundo inteiro por conta da pesca de arrasto (Fossa et al., 2002; Roberts et al., 2009; Kitahara, 2009). Kitahara (2009) observa que em um único lance de 
arrasto centenas de quilos de corais podem ser coletados, causando assim, um imenso estrago aos bancos recifais.

No Brasil, estudos envolvendo corais de profundidade ainda são escassos, em grande parte devido ao elevado custo e à dificuldade de acesso a infraestrutura necessária para esse tipo de trabalho (Arantes et al., 2009). No entanto, grandes projetos realizados em colaboração com agências do governo e empresas públicas, como por exemplo, o projeto REVIZEE (Avaliação do Potencial Sustentável de Recursos Vivos na Zona Econômica Exclusiva), CAP-BC (Projeto de Caracterização Ambiental de Águas Profundas da Bacia de Campos), ECOPROF (Ecossistemas de Mar Profundo) e OBSERVADORES DE BORDO (Projeto de avaliação ambiental da pesca de arrasto na costa brasileira), têm facilitado o acesso dos pesquisadores a esse ambiente, refletindo em um crescente número de artigos publicados nos últimos anos.

Os montes coralíneos são as formações mais comuns na Bacia de Campos (Cavalcanti et al., em prep.). Esse tipo de formação também é encontrado em outras partes do mundo, sendo tratada por diversos nomes (e.g. Bioherm, Carbonate knolls, carbonate mound, coldwater coral mound, coral mounds, coral bank, coral-topped mound, etc.) (Roberts et al., 2009). Esses bancos são formados a partir de recifes de corais que, ao se desenvolverem, se tornam suscetíveis a quebras e bioerosão, assim como podem morrer devido a alguma alteração ambiental, as partes mortas criam um ambiente protegido das correntes marinhas e, assim, propiciam o acumulo de sedimento. Ao longo do tempo o acumulo de sedimento pode sobrepor todo o recife, dando inicio ao crescimento e formação dos montes; essa camada de sedimento serve como substrato para a fixação de outros organismos (e.g. esponjas e outros corais), que em um dado momento poderão morrer ou se partir, formando novas áreas abrigadas das correntes que irão facilitar o depósito de sedimento e, assim, dando continuidade ao crescimento dos montes (Roberts et al., 2006).

Segundo Sumida et al. (2004) e Castro et al. (2006), os dois maiores bancos recifais em águas profundas no Brasil localizam-se na costa dos estados de Rio de Janeiro e São Paulo, respectivamente nas bacias petrolíferas de Campos e Santos. No entanto uma série de trabalhos vem ressaltando que os bancos de corais de profundidade se extendem mais ao sul dessas localidades, chegando até ao Rio Grade do Sul (Kitahara, 2006, 2007; Kitahara et al., 2009) e além, na costa do Uruguai (Carranza et al., 2012). 
Das espécies de corais que ocorrem em profundidade no mundo, L. pertusa é o que apresenta o maior número de estudos ecológicos e, por isso, é também a que apresenta uma maior quantidade de espécies associadas reportadas até o momento, sendo os poliquetas um dos grupos mais abundante e, algumas vezes, o mais diverso (Buhl-Mortensen \& Mortensen, 2004; Roberts, 2005; Mortensen \& Fossa, 2006; Cordes et al, 2008 e Fiege \& Barnich, 2009; Mastrototaro et al., 2010). Jensen \& Frederiksen (1992) em seu trabalho sobre a fauna associada aos bancos de L. pertusa do Atlântico Norte, registram a presença de espécies de poliquetas com quase $32 \%$ do total de animais encontrados. Fiege \& Barnich (2009) chegam ainda a citar que algumas espécies de poliqueta podem ser endêmicas de algumas espécies ou grupos de corais, destacando-se neste caso os gêneros de polinoídeos Gorgoniapolynoe spp. e Antipathipolyeunoa spp., que vivem em corais antipatharios, gorgonias, e stylasterideos (Pettibone, 1991 a,b). Algumas das espécies de poliquetas escamosos podem chegar a modificar o crescimento dos corais, fazendo com que tubos e/ou sulcos sejam formados sobre o esqueleto dos corais, por onde eles podem se locomover (Martin \& Britayev, 1998). Há também espécies de haplosylídeos (Syllidae) encontrados em íntima associação com espécies de gorgônias, capazes de formar canais no interior do esqueleto dos corais, podendo causar deformações nestes (Martin et al., 2002) e o de hesionídeos do gênero Leocratides, que são encontrados apenas no interior de esponjas de vidro as Hexactinellida também comumente associadas nesses ecossistemas de corais de profundidade (Horst, 1924; Pettibone, 1970).

Esses e outros tipos de interações envolvendo poliquetas com outros táxons (e.g. esponjas, cnidários, moluscos, etc.) vêm sendo estudadas nas últimas décadas (Britayev \& Zamishliak, 1996; Martin et al., 2002; Britayev et al., 2003; Buhl-Mortensen \& Mortensen, 2004; Martin et al., 2008; Di Camilo et al., 2010; Lattig \& Martin, 2011; Assis et al., 2012), com destaque para uma grande revisão realizada por Martin \& Britayev (1998), na qual são esclarecidas e exemplificadas todas as associações entre poliquetas e outros organismos, bentônicos (e.g. equinodermas e esponjas) ou não (e.g. peixes), conhecidas até aquele momento. Segundo esses autores pode haver dois tipos de associações, as livres, onde não há uma relação obrigatória entre os organismos, como espécies comensais, e a segunda são denominadas de fixas, onde os poliquetas não são encontrados sem estar associado àquele outro táxon como, por exemplo, em questões de simbiose e parasitismo. Segundo esses mesmos autores Cnidaria é um dos táxons que mais agrega poliquetas, no entanto muitas das interações reportadas entre esses dois grupos são do tipo comensalismo, ou seja relações 
livres, onde os poliquetas se aproveitam dos corais como abrigo e se alimentam dos restos não aproveitados por esses, sem necessariamente causar danos ou prejuízos.

Uma das associações mais reportadas para corais de profundidade com relação aos poliquetas é a de Eunice norvegica (Linnaeus, 1767) com o coral L. pertusa, essa interação possui uma elevada importância na manutenção dos bancos de corais, uma vez que atua como agente na agregação dos fragmentos de L. pertusa, levando à formação de pequenos novos recifes (Roberts, 2005). Essa associação não é restrita apenas à agregação de colônias, $E$. norvegica também atua como um cleptoparasita, ou seja, ao construir seu tubo entre os ramos dos corais, as saídas estão sempre próximas aos pólipos, assim o poliqueta rouba as partículas grandes de alimento capturadas pelos pólipos do coral (Buhl-Mortensen, 2001). A alimentação do coral não é prejudicada por conta deste comportamento, uma vez que os pólipos passam a se alimentar de partículas menores. Além disso, as colônias que apresentam os poliquetas associados também possuem taxas de calcificação quatro vezes mais altas que o normal, tornando assim a colônia menos suscetível à bioerosão (Mueller et al., 2013). Em contrapartida a essa relação benéfica, outros grupos de poliquetas, como alguns membros da família Spionidae, são considerados pragas, pois constroem seus tubos no interior dos esqueletos de calcário, tornando os corais suscetíveis a quebras e bioerosão (Wielgus et al., 2006).

No Brasil, são recentes os estudos sobre poliquetas de mar profundo e, em sua maioria, abordam apenas a descrição das espécies encontradas e nenhum deles trata de ambiente de corais de profundidade (e.g. Amaral et al., 2004a; Lavrado \& Viana, 2007; Barroso \& Paiva, 2008, 2009, 2011 a, b; Nogueira \& Abbud, 2009; Lavrado \& Brasil, 2010). Este é o primeiro estudo abordando tal ambiente, espera-se que com este trabalho seja possível elucidar um pouco mais sobre a importância desse habitat comum na nossa costa assim como conhecer e descrever melhor as possíveis associações existentes com os poliquetas. 


\section{OBJETIVOS}

\section{$2.1 \quad$ Objetivo geral:}

Identificar e descrever as espécies de poliquetas encontrados associados a corais de profundidade da região da Bacia de Campos no sudeste brasileiro.

\section{$2.2 \quad$ Objetivos específicos}

- Apresentar descrições taxonômicas de todas as espécies encontradas;

- Descrever possíveis novas espécies para a ciência,

- Reportar a distribuição geográfica e batimétrica das espécies encontradas

- Relacionar as espécies de poliquetas com os diferentes tipos de corais de profundidade 


\section{METODOLOGIA}

\section{1 Área de estudo:}

O material analizado neste trabalho foi coletado na Bacia de Campos, uma das mais importantes bacias petrolíferas brasileiras em mar aberto. Essa região, localizada no sudoeste do Oceâno Atlântico, possui mais de $100.000 \mathrm{Km}^{2}$, distribuídos entre o extremo de Vitória, ES $\left(20.5^{\circ} \mathrm{S}\right)$ e o de Cabo Frio, RJ $\left(24^{\circ} \mathrm{S}\right)$ (Figura 01). Nesta área o talude encontra-se a $100 \mathrm{Km}$ do litoral, com uma inclinação de $2,5^{\circ}$ e se estendendo por $40 \mathrm{Km}$ de encosta, desde a isóbata de 130m até a de 1.500m (em Vitória) e 2.000m (em Cabo Frio) (Viana et al., 1998).

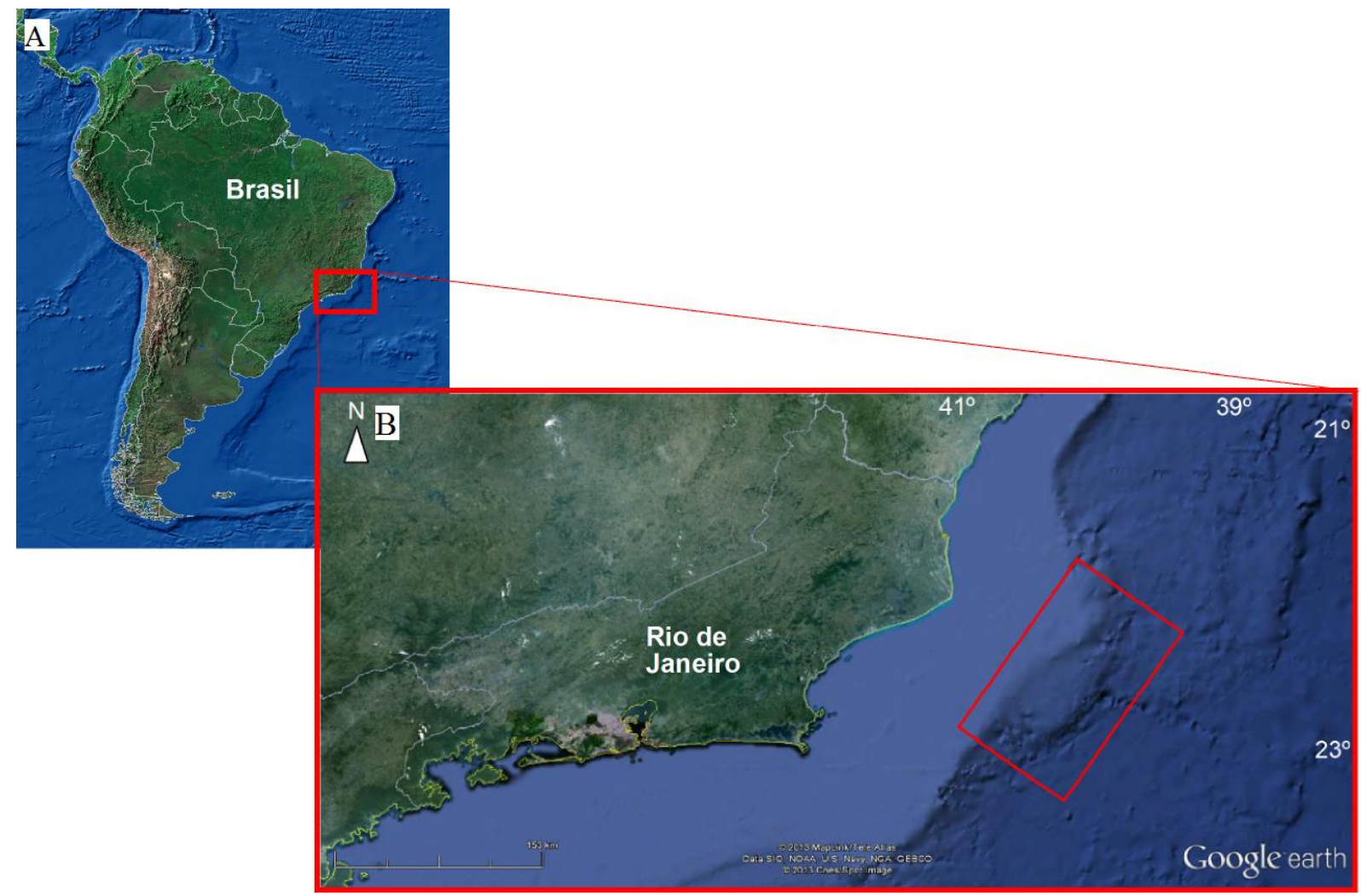

Figura 1: (A) Mapa da America do Sul, com destaque para o estado do Rio de Janerio. (B) Mapa do estado do Rio de Janeiro com a localização da área de coleta (retângulo vermelho) na Bacia de Campos, entre os municípios de Cabo Frio de Campos dos Goytacazes (Escala: $153 \mathrm{Km}$ ) 


\subsection{Coleta e tratamento das amostras:}

As amostragens do projeto de Caracterização de Águas Profundas da Bacia de Campos (CAP-BC) ocorreram entre 2004 e 2006 durante a realização deste sub-projeto dentro de um projeto mais amplo, o HABITATS. Nesse momento foram coletadas amostras aleatórias, tanto espacialmente quanto temporalmente, de diversos ambientes da Bacia de Campos, dentre eles os corais de profundidade. Essas amostras foram realizadas entre as profundidades de 200 até $1200 \mathrm{~m}$.

No projeto Ecossistemas de Profundidade (ECOPROF), foram realizadas coletas mensais entre os anos de 2008 e 2009, entre as profundidades de 100 e 770m. Em cada campanha foi utilizado um submersível operado remotamente (ROV) para coletar cinco fragmentos, de cinco espécies de corais formadores de recifes: Lophelia pertusa (Linnaeus, 1758), Solenosmilia variabilis Duncan, 1873, Enallopsammia rostrata (Portualès, 1878), Madrepora oculata (Linnaeus, 1758) e o hidrocoral Errina sp. Esses fragmentos, com toda a fauna associada, foram trazidos a bordo do navio e fixados com uma mistura de formalina a $10 \%$ tamponada com Borax.

Em laboratórios, os espécimes associados foram retirados, dos corais, cuidadosamente com o auxílio de pinças e colocados em vidros separados por famílias. Os poliquetas encontrados foram identificados em nível genérico com o uso de chaves taxônomicas e a determinação em nível de espécie foi realizada com base na literatura própria para cada gênero. Seguindo os procedimentos metodológicos para taxonomia de poliqueta os parapódios foram montados em lâminas permanentes, utilizando o meio Gray \& Wess (PVA) (Humason, 1979), e Hoyer, as lâminas foram depositadas junto com cada espécime na coleção científica Edmundo Ferraz Nonato, localizada no Instituto de Biologia da Universidade Federal do Rio de Janeiro.

Foram utilizados como fonte complementar de referência as bases de dados WoRMS - World Register of Marine Species (http://www.marinespécies.org), OBIS - Ocean Biogeographic Information System (http://iobis.org) e a lista de espécies de Polychaeta fornecida por Amaral et al. (2012).

Todos os desenhos foram feitos com o uso de câmara clara, anexada em um microscópio Wild M11 ou a um microscópio estereomicroscópio ZEISS Discovery V8. Imagens das cerdas e outros detalhes dos parapódios foram realizadas com câmera fotográfica 
Sony Cyber-shot DSCW210 adaptada para ser usada em um microscópio Olympus BX41; já fotografias dos espécimes inteiros foram feitas em um microscópio estereoscópico LEICA 250W. Posteriormente todas as ilustrações foram editadas no programa Adobe Photoshop CS5.

Os espécimes escolhidos para microscopia eletrônica de varredura foram preparados segundo o método descrito por Fitzhugh (com. pess.) (Anexo I). Neste método o material foi submetido à desidratação alcoólica, com concentrações de álcool variando, gradativamente, de $70 \%$ a $100 \%$ e permanecendo nestas diferentes gradações por, no mínimo, 15 minutos. Posteriormente o ponto crítico quimico foi realizado substituindo o etanol por um composto chamado Hexametildisilazano (HMDS), realizada em quatro etapas de, no mínimo, 15 minutos. Após esses procedimentos os espécimes foram recobertos com uma liga metálica de ouro-paládio (Au-Pd). Os espécimes metalizados foram analizados em microscópio eletrônico modelo Jeol - JEOL JSM-6390LV, do Centro de Microscopia Eletrônica do Museu Nacional (UFRJ). 


\section{RESULTADOS:}

Um total de 192 poliquetas foram encontrados associados aos corais. Estes estão distribuídos em 11 famílias e 14 espécies, destas cinco são novas espécies para a ciência, seis são novas ocorrências para a costa brasileira e duas já haviam sido reportadas para a costa brasileira e tiveram sua ocorrência ampliada (Tabela 1). Apenas cinco espécies apresentaram um grande número de indivíduos, sendo Eunice prognatha McIntosh, 1885 a espécie mais númerosa, com 34\% dos espécimes coletados, seguida por Harmothoe gilchristi Day, 1960 com $25 \%$. As demais espécies apresentaram menos de 20 indivíduos cada, ou seja, menos que $10 \%$ do total amostrado (Figura 02).

Tabela 1: Lista das espécies de poliqueta encontradas.

\begin{tabular}{ccc}
\hline Família & Espécie & $\begin{array}{c}\text { Número de } \\
\text { indivíduos }\end{array}$ \\
\hline $\begin{array}{c}\text { Amphinomidae } \\
\text { Dorvilleidae }\end{array}$ & Notopygos crinita Grube, 1855 & 1 \\
Eunicidae & Ophryotrocha sp. & 10 \\
& Eunice gracilicirrata (Treadwell, 1922) & 2 \\
Hesionidae & Eunice prognatha McIntosh, 1885 & 62 \\
Glyceridae & Leocratides sp. & 5 \\
Nereididae & Glycerella magellanica (McIntosh, 1855) & 1 \\
Polynoidae & Nicon maculata Kinberg, 1866 & 18 \\
& Harmothoe sp. & 15 \\
Sabellidae & Harmothoe gilchristi Day, 1960 & 47 \\
Serpulidae & Euchone sp. & 3 \\
Syllidae & Filogranula revizee Nogueira \& Abbud, 2009 & 3 \\
Sigalionidae & Pionosyllis procera Hartman, 1965 (Imajima \& Hartman, 1964) & 3 \\
\hline
\end{tabular}

O coral S. variabilis foi o que apresentou uma maior riqueza de poliqueta, $92 \%$ do material examinado, seguido por E. rostrata com 61\% (Figura 03). Algumas espécies foram exclusivas de S. variabilis, como Notopygos crinita Grube, 1855, Glycerela magellanica (McIntosh, 1885) e Haplosyllis ohma (Imajima \& Hartman, 1964). Ophryotrocha sp., por sua vez, só ocorreu em L. pertusa. A espécie Pholoides sp. ocorreu apenas nos corais S. variabilis e Errina sp., com dois indivíduos em cada um dos corais. Já E. gracilicirrata foi representada por dois espécimes, um associado a $S$. variabilis e o outro a L. pertusa. Euchone sp, teve duas 
espécies associadas a $E$. rostrata e apenas um em $L$. pertusa. A espécie $F$. revizee também ocorreu em apenas dois corais, com três indivíduos em $S$. variabilis e apenas um em $E$. rostrata; Leocratides sp. também ocorreu apenas nesses dois corais, porém com 4 indivíduos em S. variabilis e apenas um em E. rostrata. As demais espécies ocorreram em todos os corais, no entanto E. prognatha, H. gilchristi e Harmothoe sp, ocorreram em maior abundância em $S$. variabilis, enquanto que $N$. maculata e $P$. procera tiveram valores de abundância muito próximo entre os corais (Figura 04).

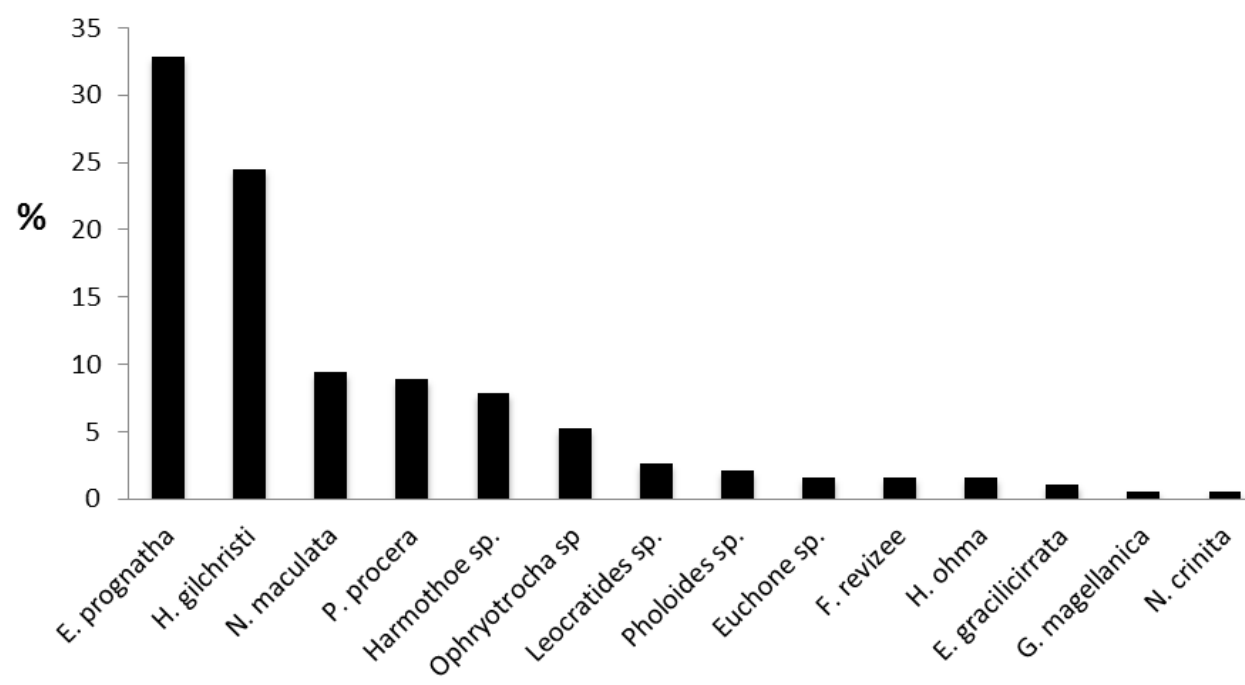

Figura 2: Abundâncias relativas das principais espécies de poliquetas associadas aos corais de profundidade.

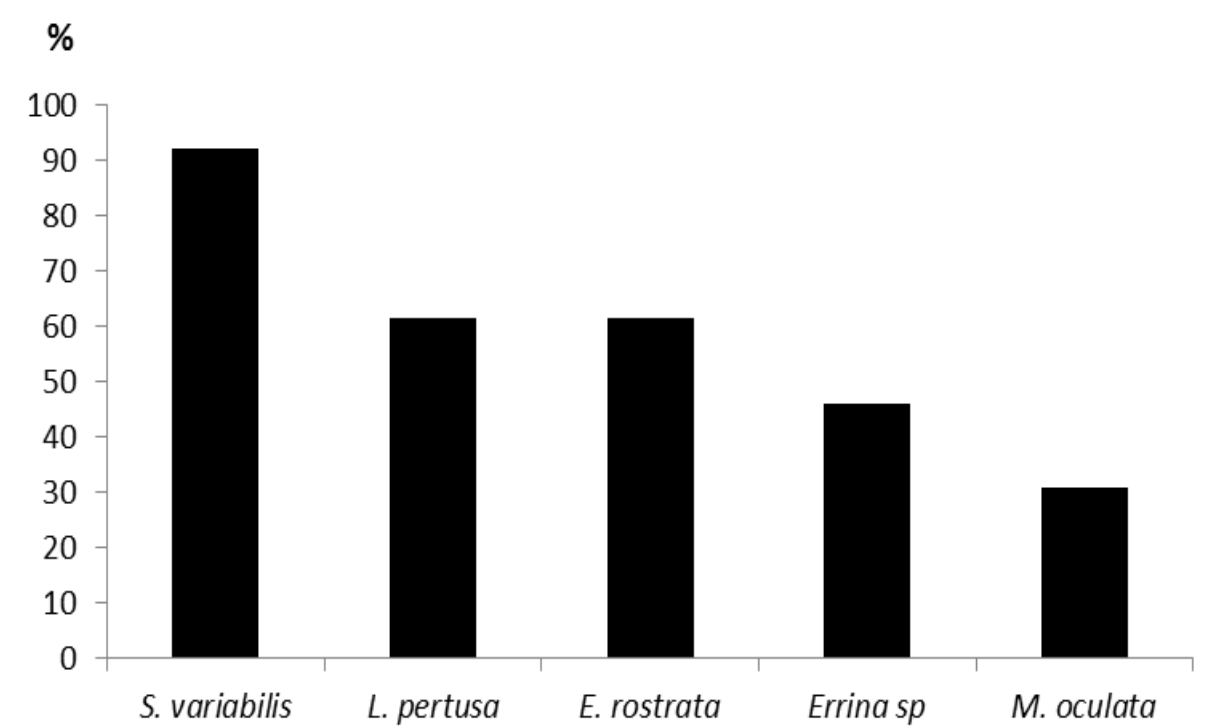

Figura 3: Riqueza relativa de poliqueta por espécie de coral 


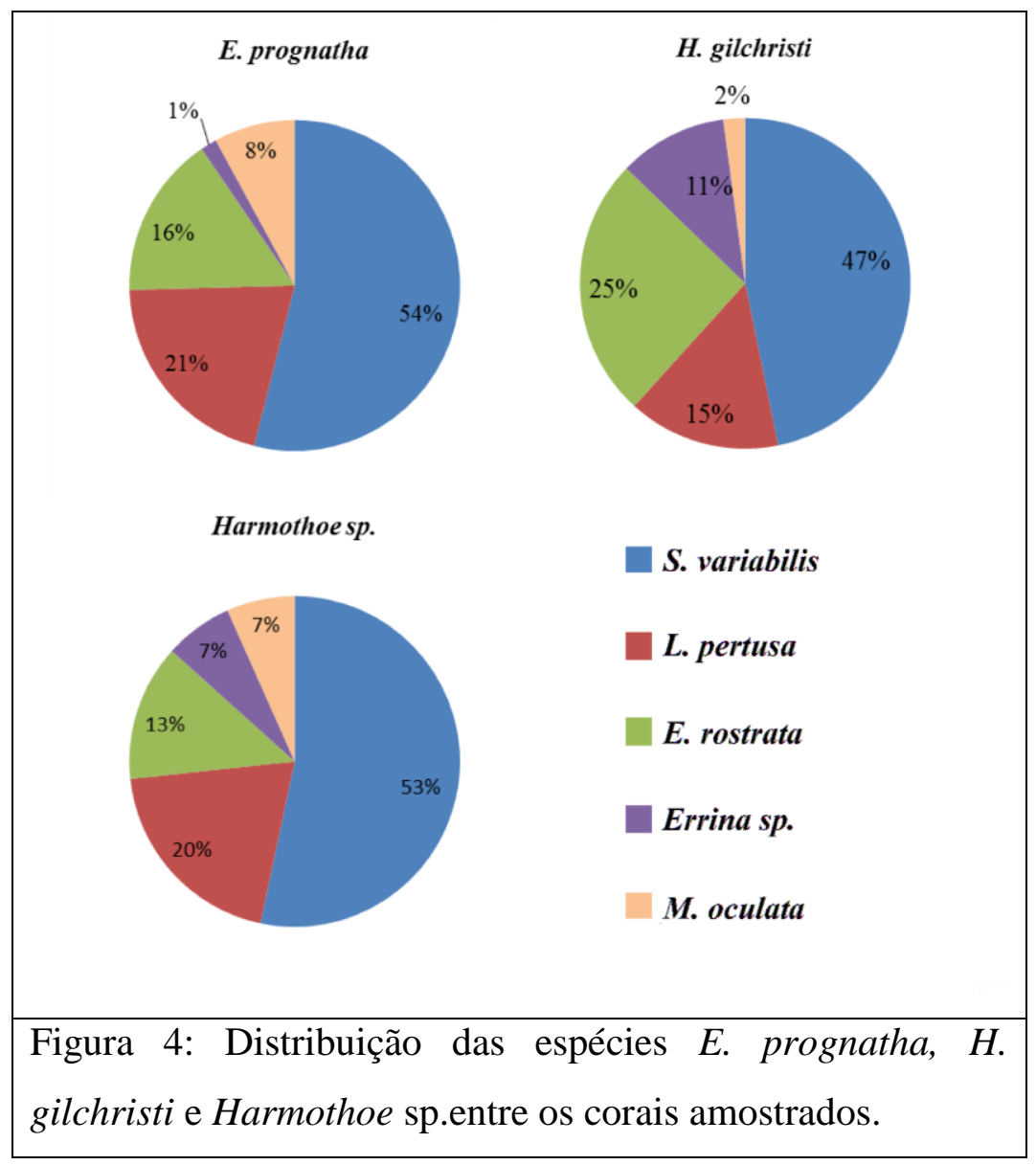

A maioria das espécies foi coletada entre 500 e 699m de profundidade, à exceção $F$. revizee e E. gracilicirrata, que neste trabalho só ocorreram abaixo dos $700 \mathrm{~m}$ e Ophryotrocha sp. que ocorreu entre 300 e 400m De todas as espécies, apenas E. prognatha ocorreu em todas as faixas batimétricas (Tabela 01). 
Tabela 2: Distribuição batimétrica das espécies de poliqueta nos pontos amostrados na Bacia de Campos

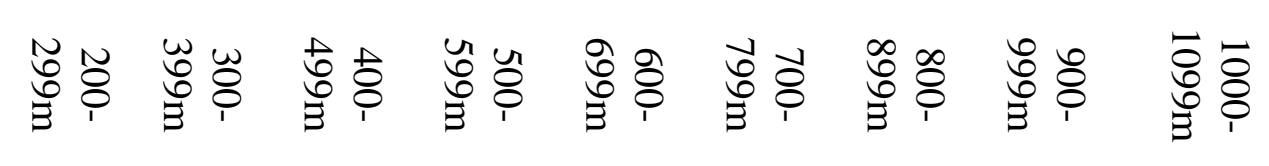

Euchone sp

E. gracilicirrata

E. prognatha

F. revizee

G. magellanica

H. ohma

H. gilchristi

Harmothoe sp

Leocratides sp.

N. maculata

N. crinita

Ophryotrocha sp

Pholoides sp.

$P$. procera

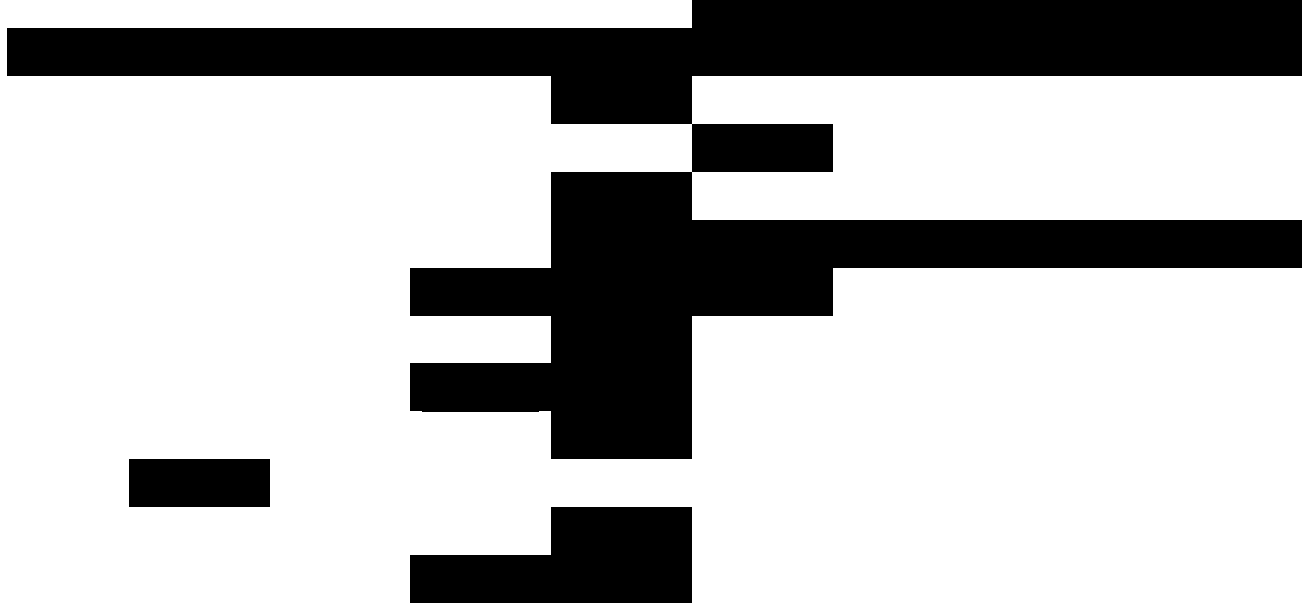

Sistemática:

Palpata,

Acículata

Phyllodocida

Aphroditiformia

Família Polynoidae Malmgren,1867

Harmothoe gilchristi Day, 1960

Harmothoe sp.

Família Sigalionidae Kinberg,1856

Pholoides sp.

Nereidiformia

Família Hesionidae Grube, 1850

Leocratides sp.

Família Nereididae Blainville, 1818

Nicon maculata Kimberg, 1866

Família Syllidae Grube, 1850

Haplosyllis ohma.(Imajima \& Hartman, 1964) 
Pionosyllis procera Hartman, 1965

\section{Glyceriformia}

Família Glyceridae Grube, 1850

Glycerella magellanica (McIntosh, 1885)

\section{Amphinomida}

Família Amphinomidae Lamarck, 1818

Notopygos crinita. Grube, 1855

Eunicida

Família Dorvilleidae Chamberlin, 1919

Ophyotrocha sp.

Família Eunicidae Berthold, 1827

Eunice gracilicirrata (Treadwell, 1922)

Eunice prognatha McIntosh, 1885

\section{Canalipalpata}

Sabellida

Família Sabellidae Latreille, 1825

Euchone sp.

Família Serpulidae Latreille, 1825

Filogranus revizee Nogueira \& Abbud, 2009 


\section{Família Polynoidae Malmgren, 1867}

Subfamília: Polynoinae Kinberg, 1856

Gênero: Harmothoe Kinberg, 1856

Espécie tipo: Harmothoe spinosa Kinberg, 1856.

Diagnose: Polinoídeos com corpo achatado dorso-ventralmente. Prostômio apresentando um sulco longitudinal, quatro pares de olhos, uma antena mediana e outras duas laterais. Na borda anterior de cada lobo prostomial há uma crista cefálica de tamanho variável. Corpo recoberto por ao menos 15 pares de escamas, geralmente inseridas sobre os setígeros 1, 3, 4, 6, 8, 10, 12, 14, 16, 18, 20, 22, 25, 28 e 31; estas podem ou não apresentar papilas sobre a superfície. Segmentos sem escamas apresentando um tubérculo dorsal e um cirro inserido sobre cirróforo. Parapódios birremes, com apenas um tipo de notocerdas e dois tipos diferentes de neurocerdas, um dos tipos apresentará sempre uma ponta bífida.

\section{Harmothoe gilchristi Day, 1960}

(Figuras: 5 a-c; 6 a-k)

Harmothoe gilchristi Day, 1960: 275, fig. 1a-f. Day (1967): 68, fig. 1.10a-e. Barnich \& Fiege (2000): 1922, fig. 17A-D. Barnich \& Fiege (2003): 43, fig. 19A-D.

Material examinado: 44 espécimes. CAP-BC (Caratinga), 1 espécime, 1040m, 3958'2,46"W-22²5'25,72"S, 23/07/2005, em Lophelia pertusa; CAP-BC (Caratinga), 1 espécime, 867m, 3959'17,32"W-22²1'54,38"S, 13/07/2005, em Lophelia pertusa.CAP-BC (Caratinga), 3 espécimes, 747m, 4049'49,47"W 22³0'52,33"S, 17/03/2006, em Lophelia pertusa; CAP-BC (Caratinga),4 espécimes, 870m, 39 59' 30,33"W 22 22' 17,79"S, 11/04/2004, em Solenosmilia variabilis; ECOPROF 1, 3 espécimes, 617m, 40 6' 5,13"W 22 22' 36,31"S, 28/01/2008, em Enallopsammia rostrata; ECOPROF 1, 5 espécimes, 659,2m, $40^{\circ} 10^{\prime} 33,33$ ” W 220 30' 16,96" S, 28/01/2008, em Errina sp.; ECOPROF 1, 7 espécimes, $626,2 \mathrm{~m}, 40^{\circ} 6^{\prime} 17,48^{\prime \prime} \mathrm{W} 22^{\circ} 22^{\prime} 34,34 " \mathrm{~S}, 29 / 01 / 2008$, em Enallopsammia rostrata; ECOPROF 2, 2 espécimes, 747m, 40¹0'33"W 22037'53"S, 10/06/2008, em Lophelia pertusa; ECOPROF 3, 1 espécime, 608m, 406'11,55"W 22²2'30,79"'S, 05/07/2008, em Madrepora oculata; ECOPROF 4, 1 espécime, 619m, 22²2'32,96"S 406'17,76"W, 01/08/2008, em Enallopsammia rostrata; ECOPROF 4, 3 espécimes, 612m, 40 6' 11,04"W 22²2' 33,53"S, 
05/08/2008, em Solenosmilia variabilis; ECOPROF 5, 1 espécime, 603m, 406'11,42"W 22²2'31,77"S, 01/09/2008, em Solenosmilia variabilis; ECOPROF 6, 2 espécimes, 608m, 407'21,81"W 22²2'59,31"S, 26/09/2008, em Solenosmilia variabilis; ECOPROF 7, 1 espécime, 609m, 406'18,81"W 22²2'24,43"S, 25/10/2008, em Solenosmilia variabilis; ECOPROF 8, 1 espécime, 606m, 22²2'24,44"S 406'17,87"W, 21/11/2008, em Solenosmilia variabilis; ECOPROF 9, 1 espécime, 639m, 405'45,06"W 22²2'41,48"S, 22/12/2008, em Solenosmilia variabilis; ECOPROF 10, 2 espécimes, 613m, 405'42,21"W 22²2'3,02"S, 17/01/2009, em Solenosmilia variabilis; ECOPROF 11, 1 espécime, 603m, 407'20,69"W 22²2'58,22"S, 14/02/2009, em Solenosmilia variabilis; ECOPROF 11, 2 espécimes, 608m, 407'35,34"W 22²4'13,33"S, 14/02/2009, em Solenosmilia variabilis; ECOPROF 12, 1 espécime, 628m, 406'47,32"W 22²2'53,31"S, 13/03/2009, em Solenosmilia variabilis; ECOPROF 13, 1 espécime, 626m, 406'45,87"W 22²2'59,21"S, 23/04/2009, em Enallopsammia rostrata.

Diagnose: Polinoídeo com escamas sub-reniforme, recobertas por micropapilas cônicas que aumentam de tamanho em direção à região posterior, porém não chega a atingir o tamanho de uma macropapila. Parapódios birremes, com notocerdas terminando em pontas obtusas e haste com varias coroas de espinhos delgados; neurocerdas bidentadas, também apresentando coroas de espinhos delgados, porém apenas na região terminal da haste.

Descrição: Maior indivíduo com 42 segmentos no total, menor com 23 segmentos. Prostômio bilobado, com cada lobo apresentando um pico cefálico bem distinto (figura $6 \mathrm{a}$ ). Antena mediana ausente, mas o ceratóforo encontra-se no sulco anterior; antenas laterais inseridas ventralmente à antena mediana, com estilódios apresentando umas poucas papilas, pequenas, espalhadas pela superfície e terminando afilando abruptamente para uma ponta filiforme. Primeiro par de olhos localizados na parte mais larga do prostômio e o segundo par na região posterior. Os palpos laterais inseridos do lado e ventralmente ao prostômio, afinando pra pontas finas (varia de acordo com o material fixado).

Tentaculóforos laterais ao prostômio, com 3 notocerdas capilares presentes em cada um; um cirro dorsal e outro ventral de formato semelhantes às antenas laterais, porém com mais papilas do que este e apresentando um leve inchaço subdistalmente. Segundo segmento apresentando o primeiro par de escamas, inseridas sobre elitróforos bulbosos; parapódios birremes com um longo cirro ventral cada. 
Escamas sub-reniformes (figura 6b), ocorrendo nos segmentos: 2, 4, 5, 6, 7, alternadamente até o segmento 23, depois nos segmentos, 26, 29 e 32; últimos 10 segmentos apresentando apenas cirros e pequenos tubérculos dorsais. Margem externa das escamas com papilas digitiformes, superfície recoberta por microtuberculos conicos (figura 6e), os quais se tornam maiores posteriormente e assumem um aspecto de clava (figura 6d). Nos segmentos sem escamas há um par de bulbosos tubérculos e cirros dorsais (que se destacam facilmente do cirróforo no material fixado) com pequenas papilas distribuídas espassadamente sobre os estilódios

Parapódios birremes (figura 6c), a partir do segundo segmento. notopódio e neuropódio com lobos acículares alongados; no lobo neuropodial há um pequeno processo digitiforme próximo à região final da acícula. Ambas as acículas penetrando a epiderme. Notocerdas mais robustas que as neurocerdas, com ponta obtusa e linhas de espinhos, em forma de cororas, bem distintas umas das outras ocorrendo ao longo da haste (figura $6 \mathrm{f}, \mathrm{g}$ ). Neurocerdas com coroas de espinhos ocorrendo a partir da metade da haste, pontas bidentadas variando de acordo com a posição no parapódio (figura 6h): feixe mais superior com o dente principal com ponta aguda e recurvada (figuras 5a, 6i), o feixe do meio também possui o dente principal recurvado, mas com ponta obtusa (figuras $5 \mathrm{~b}, 6 \mathrm{j}$ ), e nas inferiores ambas as pontas são paralelas (não recurvando) sendo que os dentes podem ter igual tamanho ou um ser maior que o outro (figuras $5 \mathrm{c}, 6 \mathrm{k}$ ). Todos os parapódios, com exceção do $2^{\circ}$ segmento, com um cirro ventral mais curto e afilado (figura $6 \mathrm{c}$ ).

Discussão: Este espécime foi identifado anteriormente como Lagisca floccosa Augener, 1906, por Brasil et al. (2007), mas uma revisão mais detalhada mudou a identificação para a atual. De acordo Pettibone (1953) e Barnich \& Fiege (2000) o gênero Lagisca deve ser sinonimizado com o gênero Harmothoe e, seguindo essa determinação, portanto trataremos aqui a espécie L. floccosa como H. floccosa. Ambas as espécies, H.floccosa e H. gilchristi, podem ser diferenciada pela ornamentação que ocorre sobre a superfície da escama; enquanto que $H$. floccosa apresenta micro- e macrotubérculos, $H$. gilchristi possui apenas microtubérculos. O fato de os microtubércuos nesta última se tornarem maiores próximo à margem posterior, pode ter levado ao erro de identificação da espécie, contudo de acordo com Barnich (com. pess.) os microtubérculos maiores em $H$. gilchristi não atingem um tamanho necessário e nem são escleratinizados, características necessárias para serem considerados um macrotubérculo. 
Dentre as espécies, do gênero, previamente reportadas para a costa brasileira por Amaral et al. (2012), nenhuma delas se parece com $H$. gilchristi, uma vez que $H$. floccosa, $H$. aculeata Andrews, 1981, H. ernesti Augener, 1931 e H. macginitiei Pettibone, 1955, todas possuem macrotubérculos nas escamas; H. lépida, por sua vez, as margens são lisas (Amaral \& Nonato, 1982).

De acordo com Barnich \& Fiege (2003) está espécie pode ser facilmente confundida com H. goreensis Augener, 1918. No entanto elas diferem, uma da outra, pelo fato de em $H$. gilchristi todas as neurocerdas serem bidentadas, os microtuberculos serem cônicos e tornarem-se maiores e em forma de clava na região posterior; já em H. goreensis há apenas microtuberculos cônicos e as neurocerdas são uni e bidentadas.

Esta espécie foi descrita originalmente na Africa do Sul por Day (1960; 1967) tendo ocorrências registradas, posteriormente, para o nordeste do Atlântico (Brito et al. 1991) e no Mar Mediterrâneo (Barnich \& Fiege, 2000). Neste trabalho é reportada, pela primeira vez parao oeste do Oceâno Atlântico, ocorrendo em profundidades entre 605 e 1040m na Bacia de Campos - Rio de Janeiro, Brasil.

Habitat: Esta espécie é descrita ocorrendo associada a corais como: Isidella sp., Cladocora caespitosa (Linnaeus, 1767) e Dendrophyllia ramea (Linnaeus, 1758), bem como em outros substratos (arenoso e lamoso). Na bacia de campos, foi encontrada em associação com os corais: L. pertusa, M. oculata, Errina sp., E. profunda e S. variabis.

Distribuição batimétrica: 1 - 1040m de profundidade.

Distribuição: sudoeste do Atlântico, Rio de Janeiro (Bacia de Campos) - Brasil., Nordeste do Atlântico (Mar do Norte), Noroeste do Atlântico (Golfo do Mexico) Sudeste do Atlântico (Africa do Sul) e Mar Mediterrâneo. 


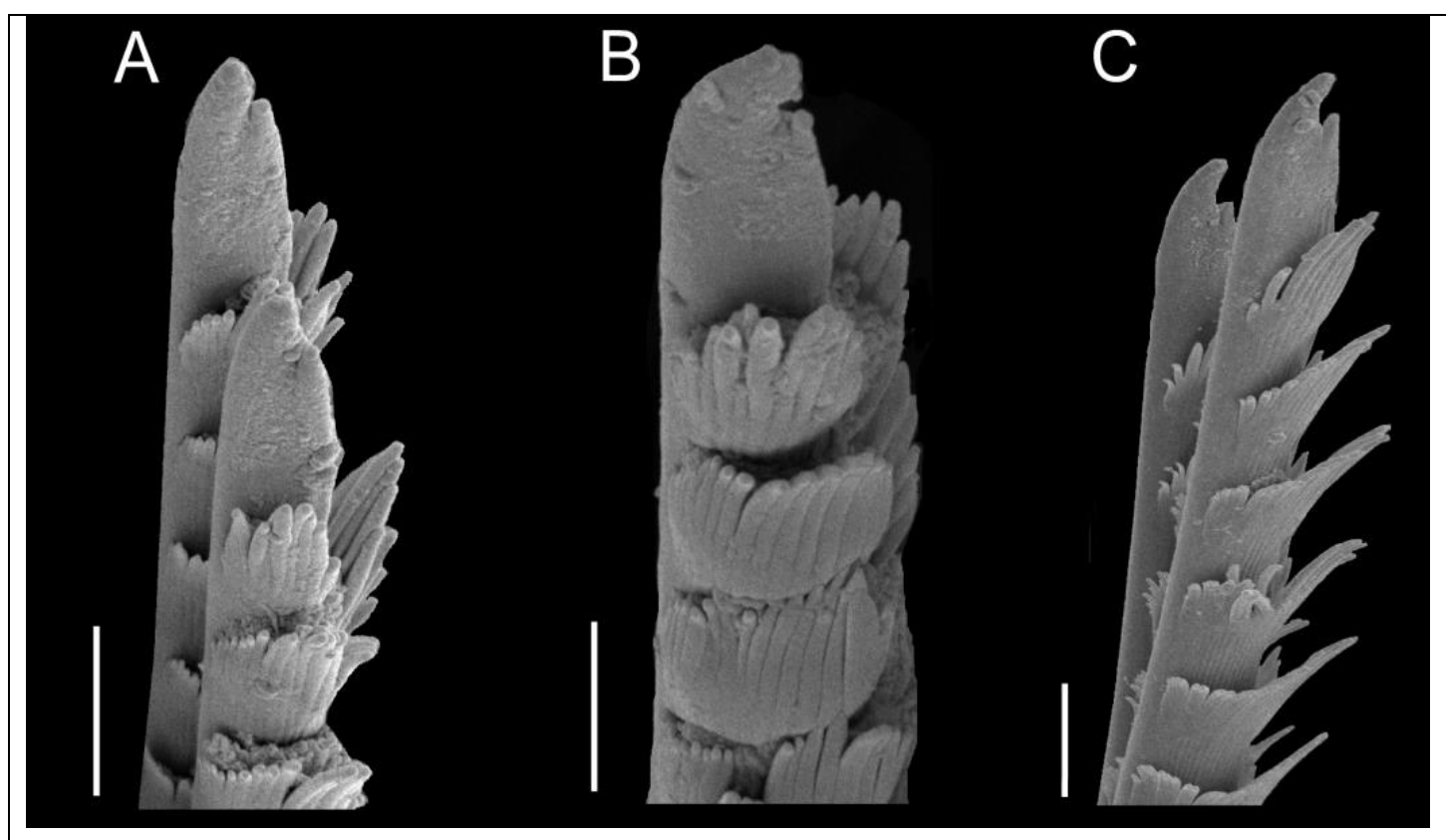

Figura 5: Harmothoe gilchristi MEV das neurocerdas: (A) ponta da neurocerda inferios; (B) ponta da neurocerda mediana; (C) ponta da neurocerda superior (Escalas: $\mathrm{A}, \mathrm{B}=10 \mu \mathrm{m} ; \mathrm{C}=20 \mu \mathrm{m}$ ). 


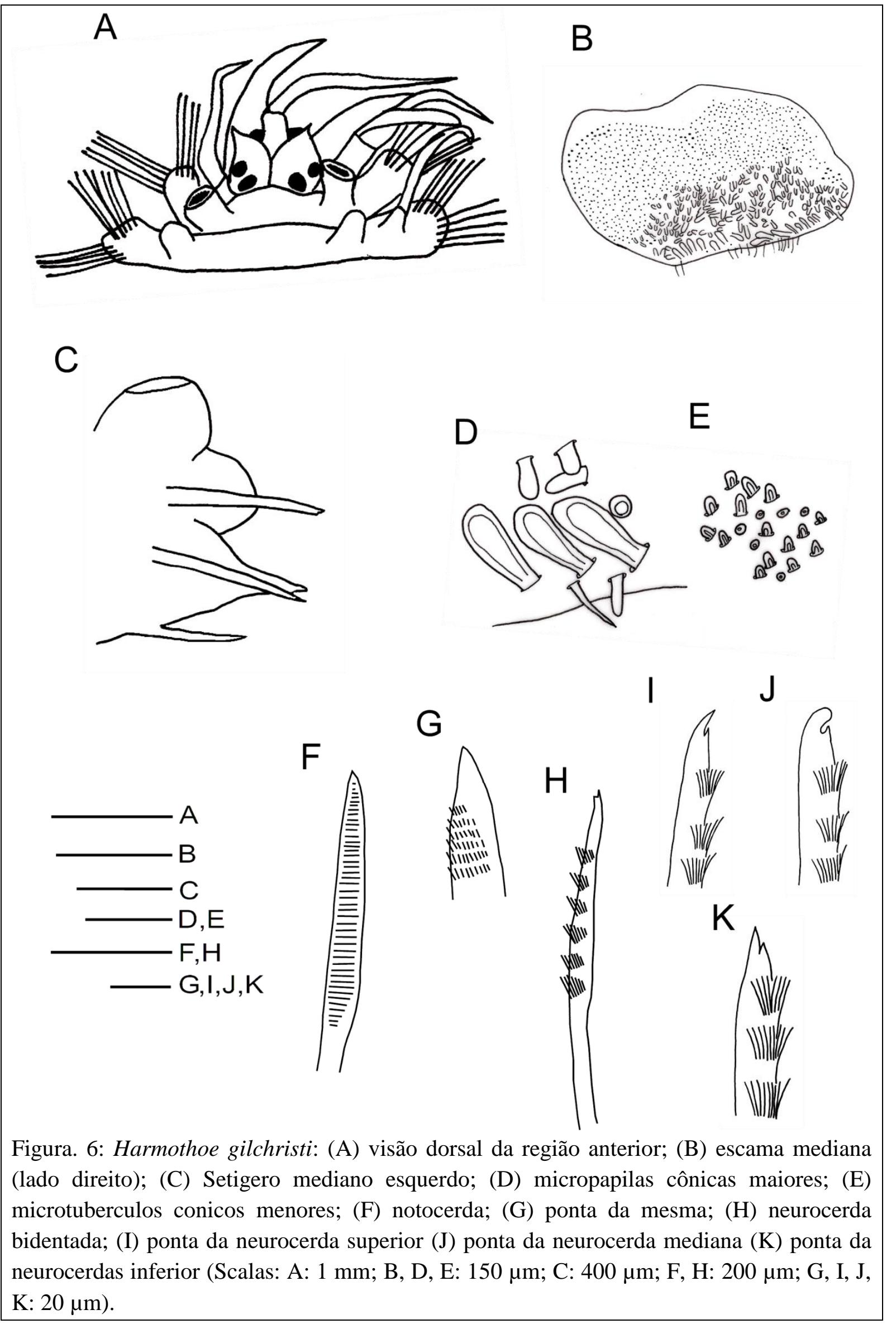




\section{Harmothoe sp.}

(Figuras: $7 \mathrm{a}-\mathrm{c} ; 8 \mathrm{a}-\mathrm{j}$ )

Material examinado: 16 espécimes. CAP-BC (Caratinga), 1 espécime, 746m, 40¹4'50,56"W 22³1'13,46"S, 17/03/2006, em Solenosmilia variabilis; ECOPROF 2, 1 espécime, 617m, 406'11,57"W 22²2'32,97"S, 10/06/2008, em Lophelia pertusa; ECOPROF 3, 1 espécime, 605m, 406'11,45"W, 22²4'31,12"S 05/07/2008, em Enallopsammia rostrata; ECOPROF 5, 1 espécime, 572m, 406'42,56"W 22²1'50,42"S, 01/09/2008, em Madrepora oculata; ECOPROF 5, 1 espécime, 612m, 406'10,36"W 22²2'29,95"S, 01/09/2008, em Lophelia pertusa; ECOPROF 5, 1 espécime, 620m, 406'16,16"W 22²2'33,75"S, 31/08/2008, em Solenosmilia variabilis; ECOPROF 5, 1 espécime, 622m, 406'16,26"W 22²2'33,43"S, 31/08/2008, em Solenosmilia variabilis; ECOPROF 7, 1 espécime, 599m, 406'20,74"W 22²2'7,74"S, 25/10/2008, em Errina sp.; ECOPROF 7, 1 espécime, 609m, 406'18,81 "W $22^{\circ} 22 ' 24,43$ "S, 25/10/2008, em Solenosmilia variabilis; ECOPROF 7, 1 espécime, 609m, $40^{\circ} 6^{\prime} 19,30 " \mathrm{~W}$ "22²2'16,24"S, 25/10/2008, em Solenosmilia variabilis; ECOPROF 9, 1 espécime, 636m, 405'46,88"W 22²2'41,33"S, 22/12/2008, em Lophelia pertusa; ECOPROF10, 1 espécime, 622m, 405'39,21"W 22²2'3,21"S, 17/01/2009, em Enallopsammia rostrata; ECOPROF 10, 1 espécime, 622m, 405'39,21"W 22²2'3,21"S, 17/01/2009, em Enallopsammia rostrata; ECOPROF 11, 1 espécime, 608m, 407'35,34"W 22²4'13,33"S, 14/02/2009, em Solenosmilia variabilis; ECOPROF 12, 1 espécime, 605m, 406'49,28"W 22²2'53,39"S, 13/03/2009, em Solenosmilia variabilis; ECOPROF 14, 1 espécime, 617,3m, 407'46,79"W 22²3'35,01"S, 23/05/2009, em Lophelia pertusa.

Diagnose: Polinoídeos com escamas sub-reniformes a ovaladas, recobertas por micropapilas cônicas, que se tornam maiores em direção à região posterior do corpo, ápices com pontas bífidas. Parapódios birremes, com notocerdas com ponta arredondada e coroas de espinhos delgados ao longo da haste; neurocerdas apresentando fileiras de espinhos a partir da metade da haste, o feixe supra-acícular com algumas cerdas de ponta simples e afinada, já o restante das neurocerdas apresentam pontas bífidas com dente levemente recurvado.

Descrição: Indivíduo maior com 40 segmentos, o menor com 27 segmentos; levemente comprimidos dorso-ventralmente. Prostômio bilobado com picos cefálicos distintos, ceratóforo da antena mediana inserido no sulco frontal, estilódio ausente; antenas laterais inseridas ventralmente à antena mediana, com estilódios lisos e afilando nas pontas (figura 8a). Par de olhos anteriores dorso-laterais, na região mais larga do prostômio, e o 
segundo par de olhos na região posterior do prostômio. Palpos inseridos latero-ventralmente, com superfície lisa e, gradativamente, afinando em uma ponta fina (alguns exemplares podem aparentar ter pontas obtusas por conta da fixação).

Tentaculóforos inseridos lateralmente ao prostômio, com duas notocertas surgindo atrás do cirro dorsal, cirro ventral também presente; ambos os cirros com estilódios lisos, gradualmente afinando para uma ponta filiforme. Segmento bucal, apresentando o primeiro par de escamas, com um parapódio birreme e um cirro bucal tão longo quanto os cirros tentaculares. Os outros segmentos apresentando um cirro ventral curto e afilado; papilas nefridiais surgindo no quinto ou sexto segmento.

Algumas escamas se soltaram, mas ao todo há inserção para 15 pares de escamas, nos segmentos: 2, 4, 5, 7, alternadamente até o segmento 23, 26, 29, 32, últimos 10 segmentos afinando e apresentando um par de pequenos tubérculos e cirros dorsais. Primeiro par de escamas quase totalmente circular (figura 8b), os demais apresentando um formato quase reniforme (figura 8c). No primeiro par as margens são lisas e a superfície recoberta por micotubérculos que se tornam ligeiramente maiores próximos à região posterior, não chegam a atingir o dobro do tamanho. Demais escamas apresentando papilas cirriformes na margem posterior, espassadas ou formando uma franja, superfície com microtubérculos que se tornam um pouco maiores na região posterior. Microtuberculos em todas as escamas com um formato ligeiramente cônico (embora alguns se pareçam com pinos de boliche), com pontas bífidas (figura 8e), alguns microtubérculos apresentam apenas uma ponta, o que pode ser explicado por ter sido gasta a outra ponta.

Parapódios birremes, notopódio e neuropódio com lobo acícular alongado e com acículas penetrando a epiderme; lobo pré-cerda do neuropódio maior do que o pós-cerda, com um processo digitiforme próximo à região final da acícula (figura 8d). Notocerdas mais robustas que as neurocerdas, em ambas as cerdas há fileiras distintas de espinhos, como que formando varias coroas paralelas, porém na notocerda essas fileiras surgem desde a base e nas neurocerdas a partir da metade da haste. Todas as notocerdas com pontas simples (figura 7a, 8 $\mathrm{f}$ - g) e, algumas poucas, afinadas; neurocerdas em sua maioria de pontas bífidas (figura 7c, 8 h -i) e dente principal levemente recurvado, algumas poucas cerdas superiores com pontas simples e afinadas (figura $7 \mathrm{~b}, 8 \mathrm{j}$ ).

Discussão: Devido ao fato de Harmothoe sp. só possuir microtubérculos com pontas bifidas nas escamas, a espécie se destaca das demais que ocorrem no Brasil, pois $H$. aculeata 
e H. ernesti apresentam macrotubérculos sobre as escamas; com relação a $H$. lépida, está apresenta microtubérculos com pontas simples e os de Harmothoe sp. são com pontas bífidas.

Espécies que também apresentam microtubérculos com pontas bíficas sobre as escamas, como H. macginitiei Pettibone, 1955, H. propínqua (Malmgren, 1867) e $H$. antilopes McIntosh, 1876, são diferentes de Harmothoe sp por apresentarem outros tipos de microtubérculos sobre as escamas. Em H. macginitiei também há a ocorrência de pontas simples e quádruplas, $H$. propínqua possui microtubérculos com pontas quádruplas, $H$. antílopes tem pontas duplas e também outras que aparentam uma coroa. $H$. discoberyae Pettibone, 1993, similarmente apresenta pontas duplas, mas em sua descrição a autora diz ocorrerem microtubérculos de diferentes tamanhos e com até cinco pontas, além disso, em $H$. discoveryae há manchas sobre as escamas, enquanto em Harmothoe sp. as escamas são translúcidas.

Habitat: Encontrado vivendo associado aos corais L. pertusa, S. variabilis, E. profunda M. oculata e Errina sp.

Distribuição batimétrica: 570 - 647m.

Distribuição: Atualmente possui distribuição conhecida apenas para a localidade tipo: Bacia de Campos, estado do Rio de Janeiro, Brasil.

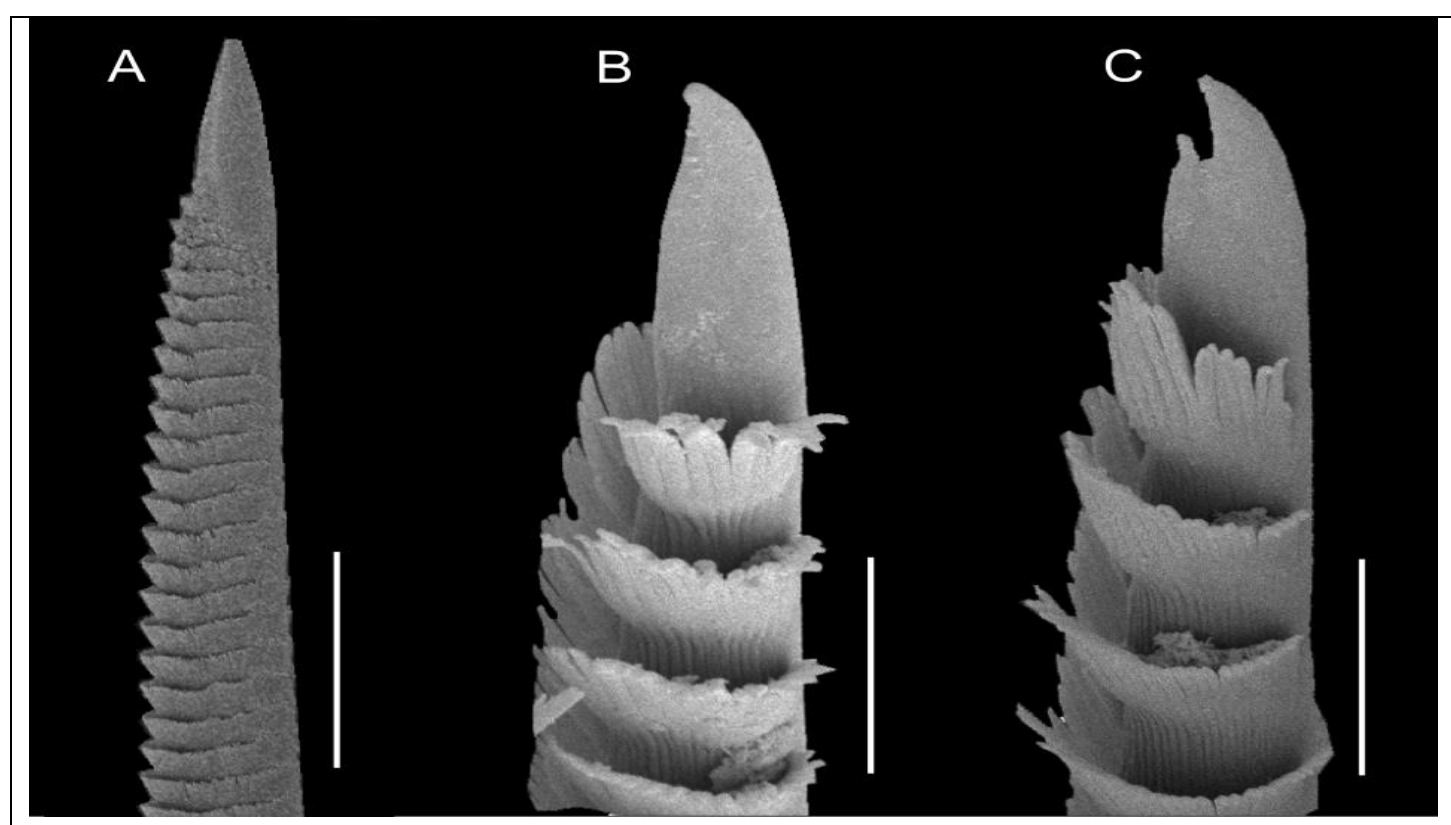

Figure 7: Harmothoe sp MEV das cerdas: (A) ponta da notocerda; (B) ponta da neurocerdas superior; $(C)$ ponta da neurocerda inferior (Scalas: $A=100 \mu \mathrm{m} ; \mathrm{B}, \mathrm{C}=$ $20 \mu \mathrm{m})$. 

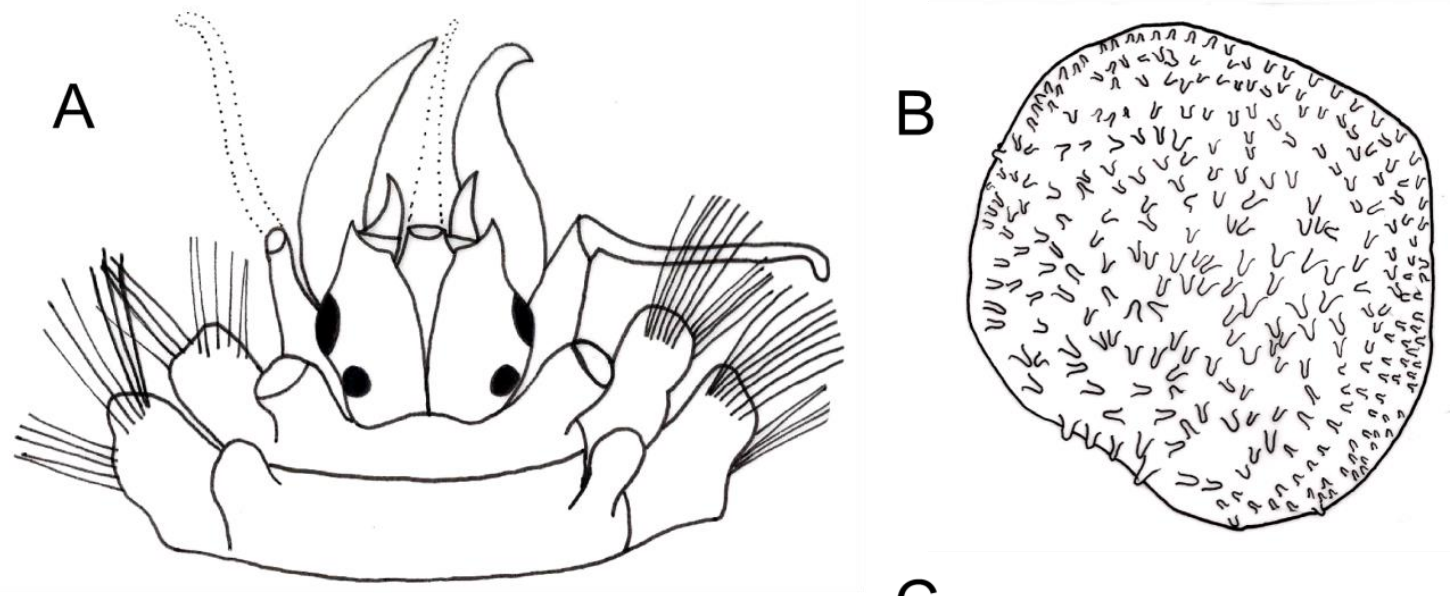

C
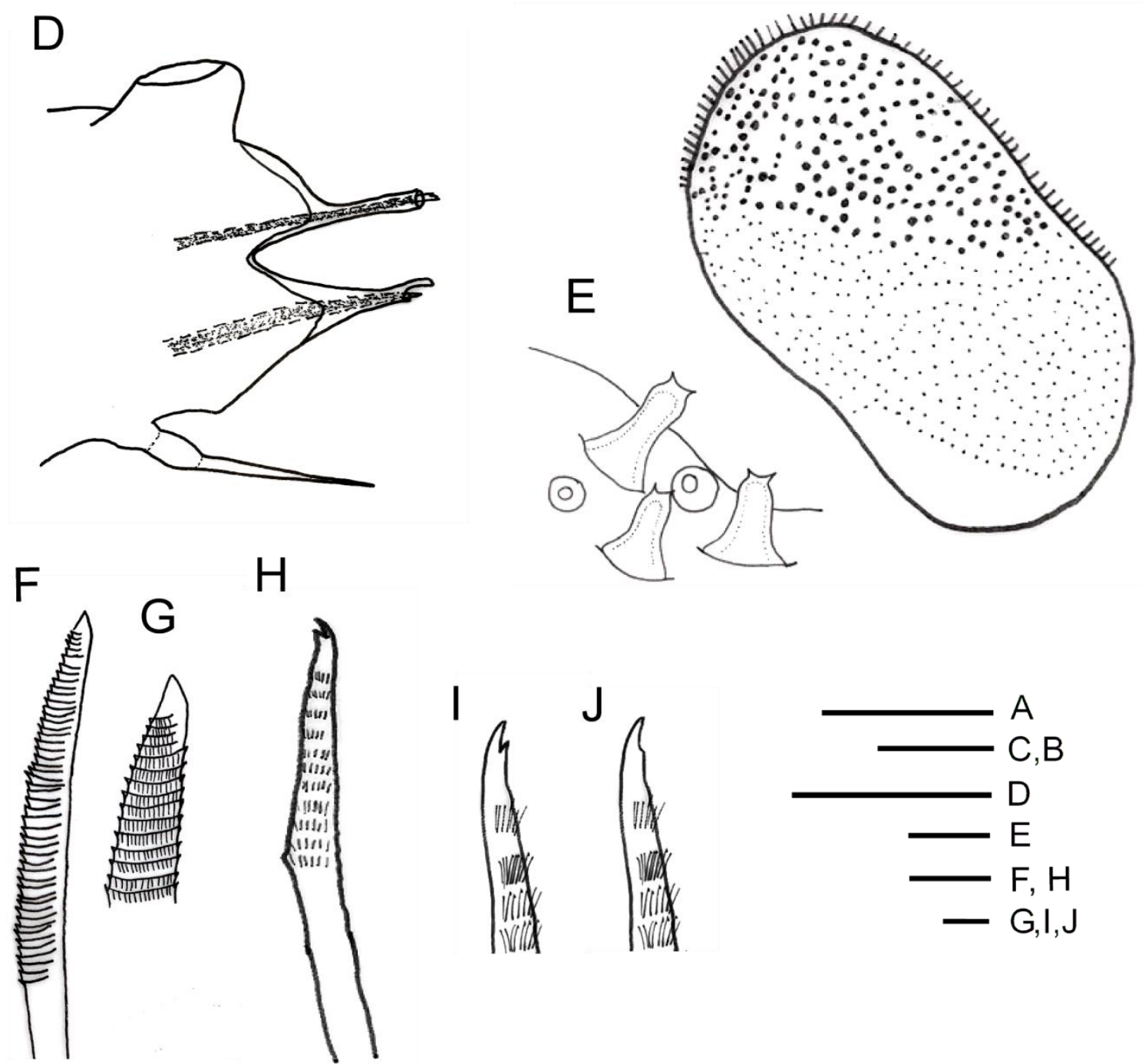

$\mathrm{H}$
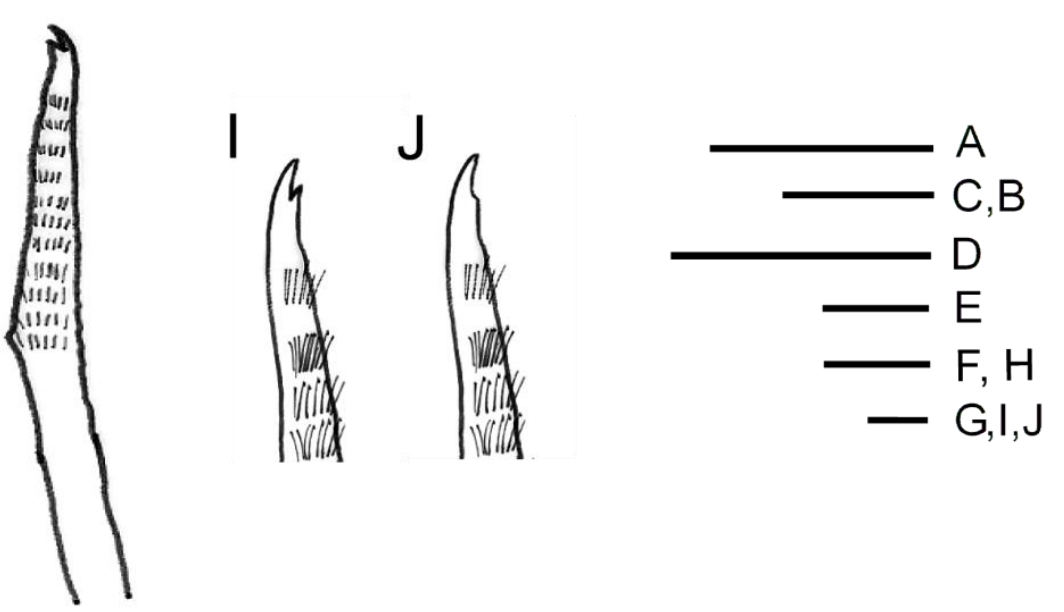

Figura 8: Harmothoe sp.: (A) visão dorsal da região anterior; (B) primeira escama do lado esquerdo; (C) escama mediana do lado direito; (D) parapódio mediano do lado direito; (E) detalhe das micropapilas; $(\mathrm{F})$ notocerda; $(\mathrm{G})$ ponta da mesma; $(\mathrm{H})$ neurocerda bidentada (I) ponta da neurocerda superior; $(\mathrm{J})$ ponta da neurocerda inferior (Scalas: $A=2 \mathrm{~mm} ; \mathrm{B}, \mathrm{C}=$ $200 \mu \mathrm{m} ; \mathrm{D}=500 \mu \mathrm{m} ; \mathrm{E}=15 \mu \mathrm{m} ; \mathrm{F}, \mathrm{H}=250 \mu \mathrm{m} ; \mathrm{G}, \mathrm{I}, \mathrm{J}=40 \mu \mathrm{m})$. 


\section{Família: Sigalionidae Kinberg, 1856}

Gênero: Pholoides Pruvot, 1895

Espécie tipo: Pholoe dorsipapillatus (Marenzeller, 1893) (por monótipo).

Diagnose: Sigalionideos com prostômio sub-rentangular, antena mediana inserida sobre um ceratóforo, que está localizado na borda anterior do prostômio. Sem antenas laterais. Tentaculóforo (primeiro segmento), com parapódio unirreme, portando um feixe de notocerdas e um cirro tentacular robusto. Demais parapódios birremes, com um feixe de notocerdas capilares e neurocerdas compostas. Região dorsal parcial ou totalmente recoberta pelas escamas; papilas adesivas podem ou não ocorrer sobre a superfície do corpo. Escamas ocorrendo nos parapódios 2, 4, 5, 7 e então alternadamente até o fim do corpo, retangulares ou reniforme, anéis concêntricos podem ser visualizados por transparência, as bordas são ornamentadas com franja de papilas.

\section{Pholoides sp.}

(Figuras: $9 \mathrm{a}-\mathrm{e} ; 10 \mathrm{a}-\mathrm{k}$ )

Material Examinado: 4 espécimes. ECOPROF 9, 2 espécimes, 405'45,06"W22²2'41,48"S, 22/12/2008, em Solenosmilia variabilis; ECOPROF 10, 2 espécimes, 405'39,24"W-22²2'3,21"S, 17/01/2009, em Errina sp.

Diagnose: Pholoídeo com escamas reniformes, apresentando anéis concêntricos (visíveis por transparência), superfície sem adornos e papilas em forma de franja na borda externa. Superfície dorsal e ventral lisa e sem papilas. Parapódios birremes, com neurocerdas compostas falcígeras, sendo o feixe superior com lâminas maiores que as do feixe inferior.

Descrição: Espécime completo, apresentando 37 segmentos, corpo achatado com ambas as superfícies (dorsal e ventral) sem papilas ou tubérculos. Prostômio e primeiro segmento (ou segmento tentacular) fusionados (figura 10a). Prostômio de formato subtriangular a arredondado, tão largo quanto longo. Um par de olhos presentes, antena inserida sobre um ceratóforo, localizada na borda anterior do prostômio; com estilos apresentando pequenos papilas digitiformes e um inchaço subdistalmente. Tentaculóforos, ou segmentos tentaculares, anteriores e laterias ao prostômio, com um tufo de notocerdas 
capilares levemente serrilhadas. Assim como um longo cirro dorsal semelhante à antena mediana (figura 10k) e um robusto palpo ventral (figura 10f).

Segundo segmento, ou segmento bucal, apresentando o primeiro par de escamas dorsalmente (figura 10c), assim como o primeiro parapódio birreme (figura 10e). Cada parapódio deste segmento apresentando um par de acículas que não chegam a penetrar a epiderme; um curto cirro ventral inserido sobre um cirróforo, laterais à boca e com pequenas papilas sobre a base. Inumeras notocerdas capilares (figura 9c, $10 \mathrm{i}$ - j), curvas e serrilhadas; neurocerdas compostas falcígeras, sendo as superiores menores (em comprimento) do que as inferiores, assim como apresentam as hastes e as lâminas lisas (figura 9d, 10h), ao passo que nas inferiores as hastes apresentam pequenos espinhos distalmente (próximo à articulação), já as lâminas são serrilhadas (figura 9e, 10g) e mais longas do que nas neurocerdas superiores.

Escamas inseridas sobre elitróforos bulbosos; estão presentes nos segmentos 2, 4, 5, 7, quando tornam a aparecer alternadamente nos segmentos até o final do corpo, apenas os dois últimos segmentos não apresentam escamas nem elitróforos. As escamas são bem finas, de formato subtriangular a reniforme (figura 9b, 10b); papilas digitiformes ocorrendo apenas na borda externa, superfícies dorsal e ventral lisas. Anéis concêntricos podem ser visualizados por transparência. Em todos os segmentos em que as escamas estão ausentes é possível visualizar um tubérculo dorsal. Não há ocorrência de cirro dorsal além do segmento tentacular.

Parapódios birremes ao longo do corpo, com notopódio de mesmo tamanho que o neuropódio (figura 10d); de formato arredondado a subcônico; notocerdas capilares e aparentemente serrilhadas, contudo ao serem observadas por MEV é possível visualizar que são em formato de espiga; notoacícula penetrando levemente a epiderme. Neuropodia mais cônico que arredondado (quando comparado com o notopódio); apresentam dois tipos de neurocerdas compostas falcígeras, as superiores menores em comprimento que as inferiores, com hastes e lâminas lisas ou fracamente serrilhadas, entretanto as lâminas são mais longas do que as das neurocerdas inferiores; enquanto que nas inferiores a haste apresenta uma região espinhosa distalmente e lâminas com ao menos a região inferior apresentando dentições. Neuroacícula bem próxima da epiderme, mas não chegando a perfura-la; lobo neuropodia com um pequeno processo digitiforme surgindo próximo à região posterior da acícula. Cirro ventral presente, inserido sobre um cirróforo, sobre o qual ocorrem umas poucas papilas. 
Discussão: Esta não é a primeira ocorrência do gênero em nossa costa, Sumida et al. (2004) já havia reportado a ocorrência da espécie P. asperus (Johnson, 1897) na Bacia de Santos (estado de São Paulo) em uma profundidade ainda maior do que Pholoides sp., 700m.

De acordo com a última revisão do gênero, Pholoides possui três espécies descritas: $P$. dorsipapillatus (Marenzeller, 1893) e P. asperus, a terceira P. mendeleevi (Averincev, 1978) foi considerada duvidosa por Pettibone (1992), por haver falhas na descrição, apesar de carecer de uma descrição mais detalhada essa espécie é considerada valida atualmente. Pholoides sp. difere destas espécies principalmente por possuir a região dorsal e ventral sem nenhuma papila ou tubérculos adesivos. O mesmo ocorre com relação à superfície bucal, enquanto que em $P$. dorsipapillatus possui papilas sobre o lábio ventral e $P$. asperus ambos os lábios contêm papila, Pholoides sp. não possui nenhuma papila sobre os lábios. Ainda com relação à ocorrência de papilas, Pholoides sp. não apresenta papilas sobre os tubérculos dorsais ou elitróforos, como ocorre nas duas espécies outras espécies do gênero.

Com relação às escamas, as duas espécies tidas como validas para o gênero, apresentam ao menos a superfície dorsal recoberta por papilas. Pettibone (1992) enfatiza o fato de $P$. asperus possuir papilas em formato de botão na região mediana e posterior. Pholoides sp., assim como $P$. dorsipapillatus possui os anéis concêntricos fracamente marcados, enquanto que em $P$. asperus os anéis são fortemente demarcados.

Não há diferenças em relação aos parapódios e as cerdas compostas entre Pholoides sp. e P. dorsipapillatus, em ambas as espécies o notopódio e o neuropódio são do mesmo tamanho, cerdas neuropodiais superiores menores em tamanho que as inferiores, porém com lâminas maiores. Já quando comparada com P. asperus, algumas diferenças podem ser observadas, como o fato de o notopódio desta ser menor que o neuropódio, bem como devido ao fato de haver um par de papilas no lobo pré-cerdal e o lobo pós-cerdal ser recoberto por papilas, características não encontradas na espécie aqui descrita; além destas distinções, $P$. asperus apresenta neurocerdas com lâminas mais largas e fortemente serrilhadas, além de hastes longas e espinhosas.

Outra forte distinção é o fato de Pholoides sp. só apresentar um par de olhos, enquanto P. asperus e P. dorsipapillatus possuem dois pares. Averincev (1978; Fig. 8:76-80 p.69) ilustrou sua espécie, $P$. mendeleevi, também com um único par de olhos, contudo Pettibone (1992) não faz nenhum comentário sobre esta peculiaridade. Assim sendo Pholoides sp. não seria a primeira espécie do gênero a possuir apenas um par de olhos, logo a condição de 
possuir apenas um par de olhos deveria ser reconhecida como uma característica que pode ocorrer no gênero e não um caráter distintivo entre espécies.

Habitat: Encontrado associado a dois tipos de corais: Solenosmilia variabilis e ao hidrocoral Errina sp.

Distribuição batimétrica: 600 - 640m.

Distribuição: Sudoeste do Oceano Atlântico, Bacia de Campos, Estado do Rio de Janeiro - Brasil.

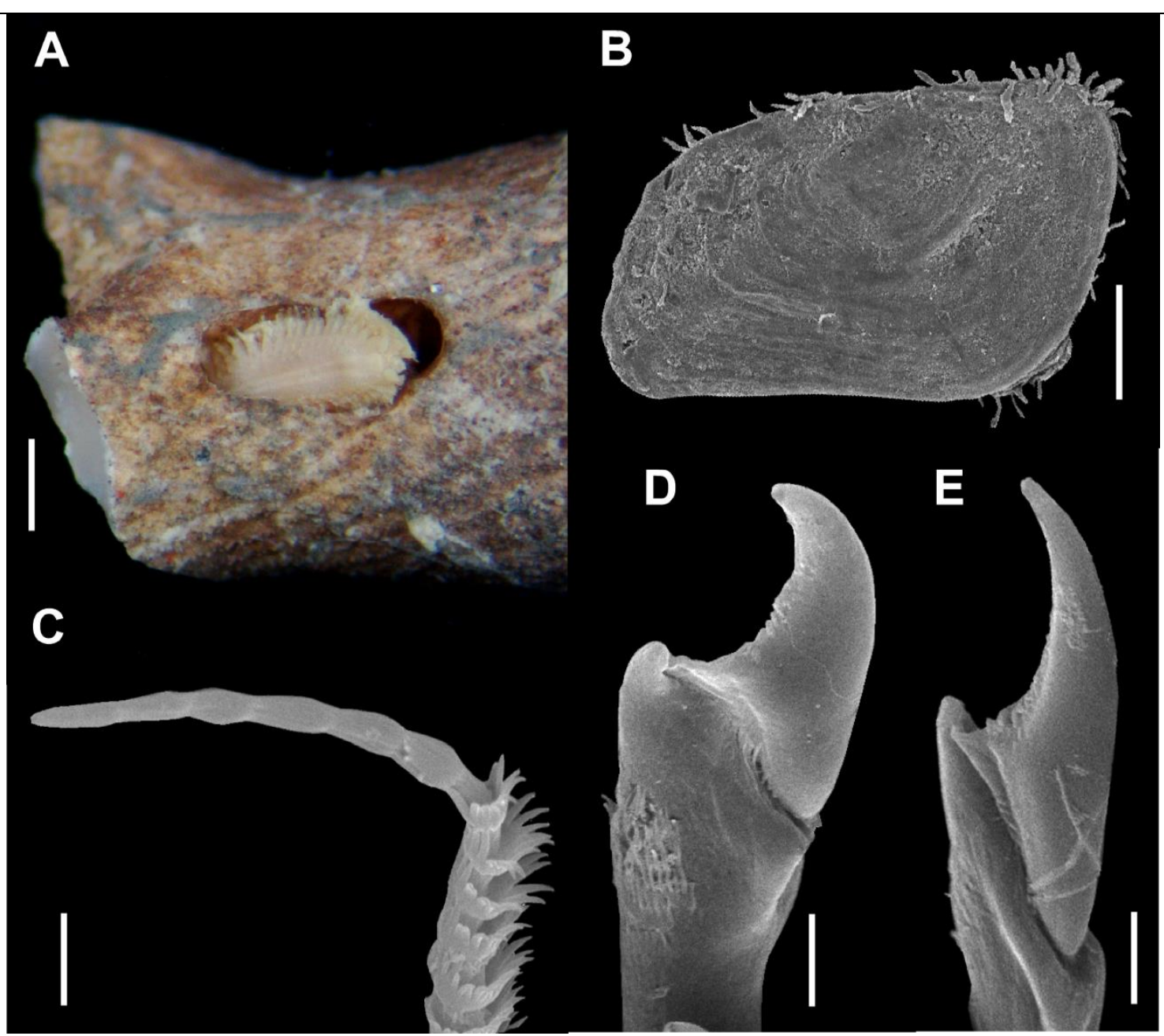

Figura 9: Pholoides sp.: (A) espécime no interior de uma cavidade na parte morta do coral Solenosmilia variabilis; (B): MEV da superficie dorsal da escama mediana e detalhes dos anéis concêntricos; $(\mathrm{C})$ : detalhe da ponta da notocerda de um parapódio mediano; (D) ponta da neurocerda superior; (E) ponta da neurocerda inferior. (Scalas: $\mathrm{A}=1 \mathrm{~mm} ; \mathrm{B}=200 \mu \mathrm{m} ; \mathrm{C}, \mathrm{D}, \mathrm{E}=10 \mu \mathrm{m})$. 

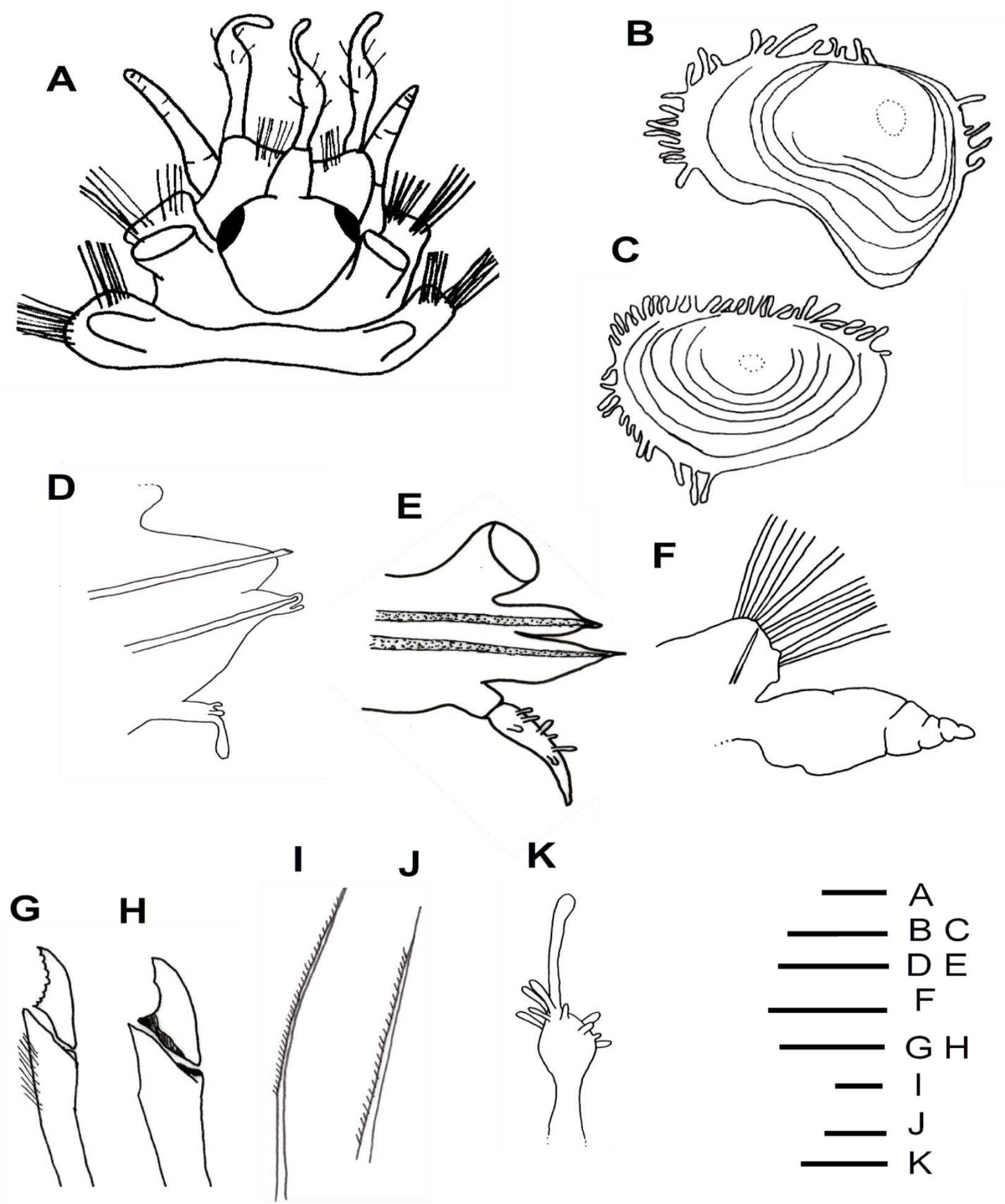

Figure 10: Pholoides sp.: (A) visão dorsal da região anterior; (B) escama mediana do lado direito; (C) primeira escama do lado direito; (D) parapódio cirróforo mediano ; (E) parapódio do segundo segmento (elitróforo); (F) parapódio do primeiro segmento (tentaculóforo), sem o cirro dorsal; (G) ponta da neurocerda inferior; $(\mathrm{H})$ ponta da neurocerda superior; (I) notocerda $(\mathrm{J})$ ponta da mesma $(\mathrm{K})$ cirro dorsal so primeiro segmento (tentaculóforo). (Scalas: $\mathrm{A}=500 \mu \mathrm{m} ; \mathrm{B}, \mathrm{C}, \mathrm{D}$ and $\mathrm{E}=300 \mu \mathrm{m} ; \mathrm{F}=$ $250 \mu \mathrm{m} ; \mathrm{G}$ and $\mathrm{H}=150 \mu \mathrm{m} ; \mathrm{I}=50 \mu \mathrm{m} ; \mathrm{J}=150 \mu \mathrm{m} ; \mathrm{K}=75 \mu \mathrm{m})$. 
Família Hesionidae Grube, 1850.

Gênero Leocratides Ehlers, 1908.

Espécie tipo: Leocratides filamentosus Ehlers, 1908.

Diagnose: Hesionídeos com número de segmentos fixo em 21, sendo que destes 16 são setígeros. Prostômio quadrangular, com a porção anterior mais alargada e um tubérculo facial. Palpos articulados, geralmente duas vezes. Três antenas presentes; a mediana inserida próximo à margem posterior do prostômio, longa e pontuda; antenas laterais menores e mais cônicas que a mediana. Dois pares de olhos, geralmente de coloração avermelhada. Órgãos nucais coalescentes médio-dorsalmente. Labios sem glândulas. Probóscide com um par de dentes ventrais e um par de placas mandibulares dorsais. Cirros dorsais maiores nos segmentos 1 a 5 e cirros ventrais maiores nos segmentos 1 a 4. Cirros dos segmentos 5, 8, 10, 12, 15, 17 e 19 são mais longos e inseridos mais elevadamente. Parapódios unirremes, neurocerdas ausentes nos segmentos 1 a 4, nos demais segmentos neuropódios retangulares e obtusos. Acícula de coloração escura. Cerdas compostas, com lâminas bidentadas, sem dentes prolongados. E cirro ventral sem cirróforo.

\section{Leocratides sp.}

(Figura: $11 \mathrm{a}-\mathrm{g}$ )

Material examinado: 5 espécimes. ECOPROF 1,1 espécime, 655,5m, 40 $10^{\prime}$ 30,33" W- 22 26' 15,57" S, 28/01/2008, em Enallopsammia rostrata; ECOPROF 4, 4

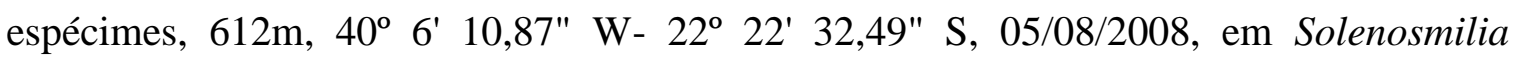
variabilis.

Diagnose: Hesionídeo com quatro pares de cirros tentaculares distribuídos entre o primeiro e o segundo segmento. Prostômio subretangular, com um par de palpos e de antenas articulados, inseridos na região frontal e sem antena mediana. Faringe muscular eversível, dividida em duas regiões: anterior, mais curta e com oito papilas filiformes na borda, e a posterior mais longa e robusta; nenhum dente ou mandíbula presente. Parapódios subbirremes, notocerdas ausentes e neurocerdas compostas falcígeras com pontas fortemente bidentadas.

Descrição: Corpo levemente em forma de fuso, tornando-se um pouco mais fino em direção à região posterior do corpo, achatado ventralmente (figura 11c) e dorso arredondado 
(figura 11b). Apresentam um total de 21 segmentos, sendo que destes apenas 16 são setígeros; terminalmente apresentam o $20^{\circ}$ segmento com parapódio reduzido e sem cerdas, portando apenas um par de cirros dorsais e ventrais; posterior a este segmento está o segmento pigidial com ânus terminal (levemente dorsal em alguns exemplares) e um par de cirros pigidiais inseridos lateralmente ao ânus, podendo variar em alguns exemplares para uma posição mais ventral.

Prostômio com formato subretangular, com um par de órgãos nucais margeando a borda posterior e um pouco da borda lateral (não chega a atingir a metade da borda lateral) (figura 11b); órgãos nucais separados por um sulco, que surge na borda posterior do prostômio. Anteriormente há um par de palpos robustos inseridos ligeiramente para as laterais do prostômio, sem palpóforo aparente, estilódios afinando para a ponta gradualmente com apenas uma articulação completa próximo à base e outra articulação na região mediana incompleta (figura 11c). Um par de antenas articuladas inseridas frontalmente ao prostômio, com estilódios ligeiramente mais longos que os palpos, articulação na região mediana do estilódio, após essa começam a afinar gradualmente em direção à extremidade (figura 11c). Nenhum dos exemplares possui antena mediana ou cicatriz desta. Dois pares de olhos ovais presentes, sendo o par anterior mais largo e o posterior mais longo. Sem tubérculos faciais.

Faringe muscular eversível, cilíndrica, dividida em duas regiões: a região anterior, curta e com oito papilas filiformes, sendo quatro papilas de cada lado da borda da probóscide (figura 11c); já a região posterior é mais longa e robusta que a primeira; nenhum dente ou mandíbula presente.

Nas laterais do segundo e terceiro segmento, juntos, há oito cirros tentaculares, inseridos sobre cirróforos robustos (estes aumentam de tamanho posteriormente) (figura 11c), cirróforos lisos e longos, arranjados em três linhas paralelas: três cirros dorsais e longos, três no meio de tamanho mediano e dois ventrais curtos. Boca surgindo no segundo segmento, lábios com bordas lisas e arredondadas, dorsalmente apresentando um formato mais inflado, assemelhando-se a uma almofada.

Parapódios sub-birremes, com notopódios reduzidos a uma pequena região dorsal, abaixo da inserção do cirro dorsal, internamente com três acículas translúcidas e bem delicadas, localizadas próxima à base do cirro dorsal (figura 11d). Neuropódio subretangular, sustentado por duas acículas nas regiões anteriores e medianas e três posteriormente; neuroacículas de tamanhos diferentes, uma é sempre o dobro do diâmetro da outra. 
Neurocerdas compostas heterogonfas falcígeras, com hastes longas e lisas; lâminas com pontas bífidas e suavemente serrilhada internamente, tamanho variando ao longo do corpo, anteriores mais longas, diminuindo de tamanho posteriormente (figura $11 \mathrm{e}-\mathrm{g}$ ). Cirro dorsal, inserido sobre um curto cirróforo, com estilódios longos, filiformes e apresentando fracas articulações (figura 11d); já os cirros ventrais são mais curtos que os dorsais, ultrapassando ligeiramente a borda do neuropódio, com base robusta e afinando para as extremidades (figura 11d).

Discussão: O gênero Leocratides é bem pequeno, composto apenas por duas espécies: L. filamentosus Ehlers, 1908 e L. ehlersi (Horst, 1924). Pettibone (1970) sinonimizou a espécie de Ehlers porque considerou que muitos caracteres foram negligenciados pelo autor ao descrever L. filamentosus, principalmente aqueles referentes à morfologia dos lábios e quanto ao número de dentes presentes na probóscide. Entretanto, Pleijel (1998) considera as espécies válidas e distintas entre si, não justificando a sinonímia proposta por Pettibone mas ressalta que uma revisão taxonômica deve ser feita para o gênero.

A espécie aqui descrita diferencia-se das outras duas espécies por não apresentar dentes ou mandíbulas na probóscide, além de não possuir antena mediana. Segundo a diagnose proposta por Pleijel (1998) estas são características marcantes do gênero e, uma vez que a espécie aqui descrita não apresenta tais características, acredita-se que um estudo taxonômico detalhado possa vir a elucidar essas questões sobre as características diagnósticas do gênero.

Comparando a região anterior da probóscide desta espécie com as outras duas, esta possui apenas oito papilas, enquanto que nas outras apresentam 10. Além destas características, o lábio dorsal em L. filamentosus e L. ehlersi apresentam lobos que se projetam da região mais inflada, enquanto na espécie aqui descrita essa região é totalmente lisa, apresentando-se mais como uma almofada do que nas outras duas espécies. Os palpos de Leocratides sp. diferem do das demais espécies do gênero ao apresentarem articulação com um anel completo e outro incompleto, entretanto Horst (1924), Pettibone (1970) e Pleijel (1998), não deixam claro em seus trabalhos se todas as articulações são completas ou não, considera-se aqui que os autores observaram anéis completos nas articulações.

A morfologia das cerdas é um caracter que deve ser reavaliado nas outras espécies já descritas, pois segundo Horst (1924) e Pettibone (1970) essas apresentam cerdas heterogonfas falcígeras, como a descrita para Leocratides sp.. Entretanto, quando descrevem as lâminas das cerdas ambos os autores citam que são unidentadas podendo apresentar uma leve dentição 
secundaria distalmente, sendo que ilustram em seus trabalhos o que seria uma clara lâmina bidentada, com o segundo dente muito pequeno. A espécie Leocratides sp.apresenta as lâminas claramente bífidas. Ainda com relação à região parapodial, o número de acícula também é diferente enquanto L. filamentosus e L. ehlersi apresentam apenas duas acículas notopodiais e uma neuropodial, Leocratides sp. apresenta três notoacícula e duas neuroacículas.

Esta e a primeira ocorrência do gênero na costa brasileira, assim como no Oceano Atlântico, uma vez que espécies deste gênero só haviam sido encontradas na Indonésia, Japão e Malásia.

Habitat: Leocratides sp. não estava associada diretamente a uma espécie de coral. $\mathrm{Na}$ verdade os cinco espécimes, encontravam-se no interior de uma esponja Hexactinellida (popularmente chamadas esponjas de vidro) (figura 11a), a qual ainda não foi identificada, esta sim associada aos corais $S$. variabilis e E. rostrata. Como as outras espécies do gênero também foram encontradas associadas a esponjas provavelmente essa seja uma característica ecológica do grupo.

Distribuição batimétrica: $612-655 \mathrm{~m}$.

Distribuição: Sudoeste do Oceano Atlântico, Bacia de Campos, estado do Rio de Janeiro - Brasil. 


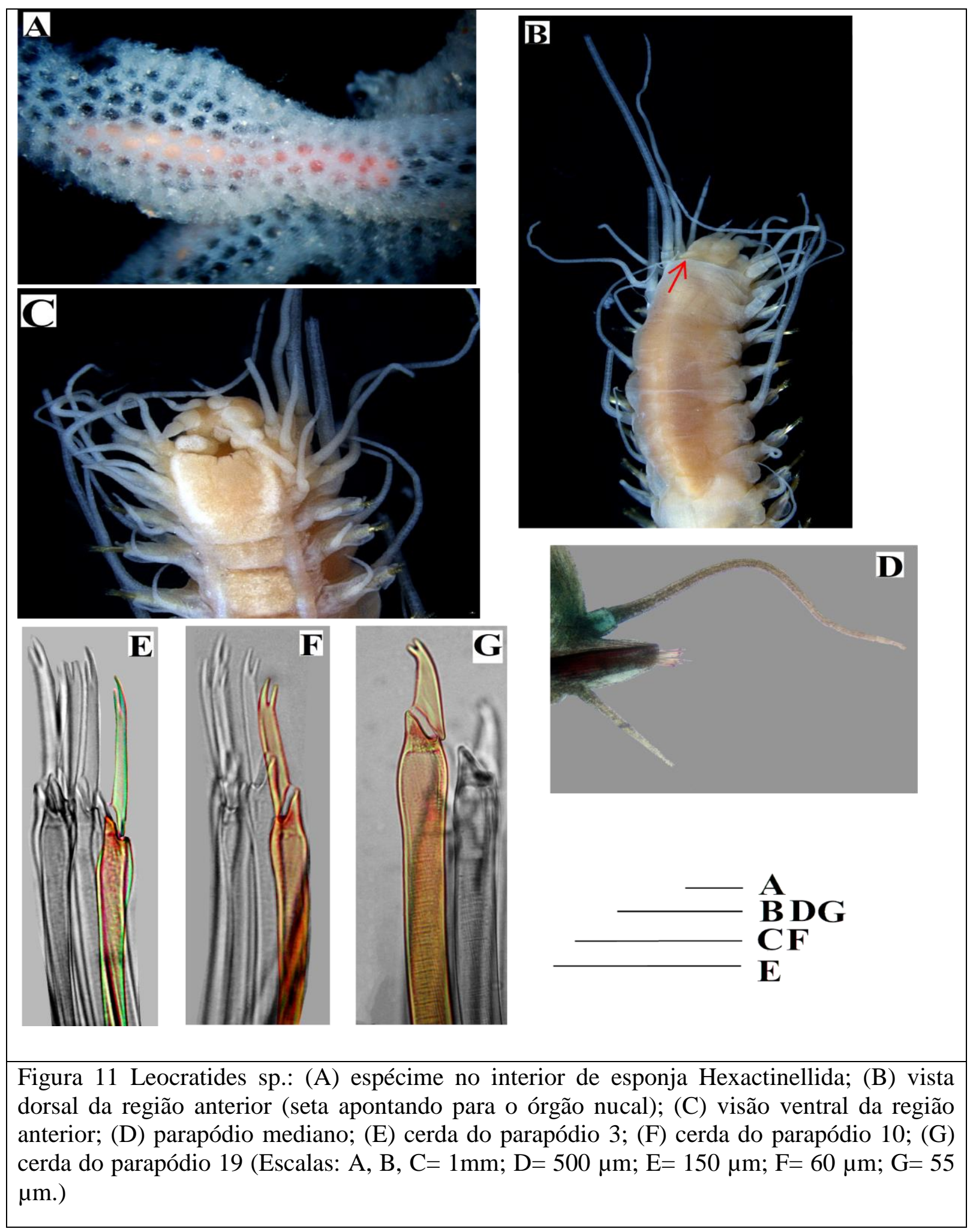


Família Nereididae Blainville, 1818.

Gênero Nicon Kinberg, 1866

Espécie tipo: Nicon maculata Kinberg, 1866.

Diagnose: Prostômio mais ou menos cônico, com dois pares de olhos localizados posteriormente e um par de antenas inseridas anteriormente. Palpos articulados inseridos lateralmente ao prostômio. Faringe lisa, sem paragnatas ou papilas, mas com um par de mandíbulas inseridas anteriormente. Segmento tentacular com quatro pares de cirros tentaculares, inseridos sobre cirróforos robustos e sem parapódios. Primeiros dois setígeros com parapódios sub-birreme, notopódio limitado a uma curta região ligular (com uma acícula interna) e inserção do cirro dorsal. Demais setígeros com parapódios birremes, notopódios divididos em duas lígulas e lobo pré cerdal entre elas; já o neuropódio é composto por um lobo acícular cônico ou bilobado, lobo pós cerdal cônico e lígulas ventrais. Cirro dorsal inserido sobre o dorso da lígula notopodia, e o cirro ventral na base do lobo acícular ou da lígula ventral. Cerdas notopodiais homogonfas espinígeras; neurocerdas homogonfas espinígeras, heterogonfas falcígeras e podendo também apresentar heterogonfas espinígera. Segmento pigidial com um par de cirros anais.

\section{$\underline{\text { Nicon maculata Kinberg, } 1866}$}

(Figura: 12 a - f)

Nicon maculata Kinberg, 1866: 178. Pettibone, 1971: 8-11, figs 1-2. Wu \& Sun, 1979: 101-102, fig. 4a-k. Wu, et al., 1985: 55-56, fig. 28a-k. Hutchings \& Reids, 1990: 73

Nereis loxechini Ehlers, 1908:73, pi. 8: figs. 8-12. Benham 1921:65, pl. 8: figs. 67$75 ; 1927: 50$.

Leptonereis loxechini. Monro 1930:107; 1936:138.

Nicon ehlersi Hartman, 1953: 29.

Nicon benhami Hartman, 1967:66, pi. 18: figs. A-C.

Material examinado: 17 espécimes. ECOPROF 1, 1 espécime, 620m, 40 6' 5,27" W- 22 22' 35,92" S, 29/01/2008, em Enallopsammia rostrata; ECOPROF 1,1 espécime, 658,2m, 40 10' 25,79" W-22 ${ }^{\circ} 26^{\prime}$ 21,9" S, 28/01/2008, em Solenosmilia variabilis; ECOPROF 2, 1 espécime, 612m, 40 6' 6,77" W-22 22' 39,19" S, 10/06/2008, 
em Solenosmilia variabilis; ECOPROF 4, 3 espécimes, 612m, 40 6' 6,06" W-22 22' 38,71" S, 05/08/2008, em Solenosmilia variabilis; ECOPROF 7, 1 espécime, 608m, 40 6' 14,36" W-22 22' 31,21" S, 25/10/2008, em Errina sp.; ECOPROF 9, 1 espécime, 606m, $40^{\circ} 5^{\prime}$ 56,92" W-22 22' 49,47" S, 21/12/2008, em Solenosmilia variabilis; ECOPROF 10, 4 espécimes, 622m, $40^{\circ} 5^{\prime}$ 16,95" W-22 22' 9,55" S, 17/01/2009, em Errina sp.; ECOPROF 11, 2 espécimes, 607m, 40 7' 30,72" W-22º 23' 14,48" S, 14/02/2009, em

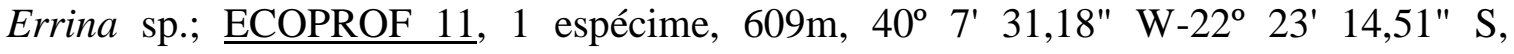
14/02/2009, em Lophelia pertusa; ECOPROF 14, 1 espécime, 623,5m, 40 7' 41,6" W$22^{\circ} 23^{\prime} 41,53 "$ S, 22/05/2009, em Enallopsammia rostrata.

Diagnose: Espécimes apresentendo probóscide sem papilas ou paragnathas. Cirros tentaculares longos (alongando-se até o $10^{\circ}$ setígero) Neurocerdas apenas dos tipos homogonfas espinígeras e heterogonfas falcígeras, tanto infra- quanto supra-acícular. Notopódio arredondado, com lígula dorsal subulada e sem lobo pré-cerdal (Adaptado da tabela fornecida por Leon-Gonzales \& Trovant, 2013).

Descrição: Espécimes com tamanho variável, apresentando em torno de 40 setígeros. Prostômio em formato de pera, com a parte mais larga localizada posteriormente; um leve sulco mediano se prolonga desde a borda anterior até a metade do prostômio (figura 12a). Localizados dorsalmente, na região mais larga do prostômio, há dois pares de olhos sendo o par anterior maior que o par posterior. Antenas pequenas, afiladas e com pontas arredondadas, inseridas frontalmente, ao lado de onde inicia o sulco mediano. Palpos robustos, subcilíndricos e articulados anteriormente, surgindo nas laterais do prostômio (figura 12b). Probóscide armada com duas fortes mandíbulas, em forma de foice; sem papilas ou paragnathas recobrindo a superfície.

Segmento tentacular com comprimento e largura ligeiramente maior que os demais segmentos, formando uma espécie de colar ao redor do prostômio (figura 12a). Parapódios e cerdas ausentes. Anteriormente com três pares de cirros tentaculares, inseridos sobre cirróforos robustos e bem próximos (figura 12b). Tamanho dos cirros variando, o dorsal atingindo a metade do terceiro setígero, o mediano indo até o final do segundo setígero e o ventral prolongando-se até o meio do primeiro setígero, ambos os estilódios apresentando um aspecto articulado distalmente. Os setígeros anteriores (até o sétimo) são, em geral, mais estreitos que os demais. 
Parapódio dos dois primeiros setígeros com cirro dorsal e lígula notopodia simples. Neuropódio similar ao dos demais setígeros; neurocerdas homogonfas espinígeras (figura 12f) e heterogonfas falcígeras (figura 12e).

Parapódio da região anterior com cirros dorsais cirriformes, prolongando-se além da lígula dorsal. Notopódio composto por duas lígulas notopodiais cônicas pré-cerdais e um lobo pós-cerdal oval muito reduzido. Neuropódio formado por um lobo acícular conico e lobo póscerdal digitiformes, lígula neuropodia ventral arredondada; cirro ventral curto e afilado, com o mesmo tamanho da lígula ventral. Notocerdas do tipo homogonfa espinígera, laminas serrilhadas e afinando rapidamente para uma ponta aguda (figura 12f). Neurocerdas do tipo homogonfas espínigeras, semelhantes às notopodiais, e heterogonfas falcígeras, com lâminas curtas, largas, com borda interna serrilhada e ponta curta e afiladas, recurvando-se em direção à base (figura 12e).

Parapódios medianos e posteriroes com os ramos mais separados (figura 12d). Cirro dorsal um pouco mais longo em direção à região posterior do corpo. Notopódios formados por duas ligulas pós-cerdais, de formato mais cônico que as anteriores, e lobo pré-cerdal arredondado. Notocerdas compostas, homogonfas espinígeras; com haste apresentado estrias perpendiculares ao longo de todo o comprimento; lâminas longas, algumas com a metade do comprimento da haste, com borda interna serrilhada e uma longa ponta aguda e delgada (figura 12f). Neuropódio formado por dois lobos pos-cerdais conicos e uma lígula subconicas ventral, menor que as anteriores. Neurocerdas heterogonfas falcígeras e espinigeras, em ambos os tipos a haste também apresentam estrias transversais; as lâminas das falcígeras são curtas, largas, serrilhadas internamente e com a ponta aguda e delgada, recurvando em direção à base (figura 12e); as neurocerdas espinígeras são semelhantes às notocerdas (figura 12f). $\mathrm{O}$ feixe de cerdas acima da acícula neuropodial apresenta mais cerdas espinígeras do que falcígeras, já o feixe subacícular essa razão se inverte. Cirro ventral cirriforme, de tamanho igual ou ligeiramente maior que a lígula neuropodia.

Discussão: Morfológicamente todos os espécimes, coletados e analizados, são compatíveis com a descrição de Pettibone (1971), havendo assim, pouco a se acrescentar a respeito da morfologia dos mesmos. Os espécimes aqui analisados apresentaram os setígeros anteriores mais estreitos que os demais, assim como alguns indivíduos apresentaram alguns setígeros anteriores muito mais largos que os demais. Essas diferenças morfológicas podem ser explicadas devido ao fato de os animais não terem sido tratados com nenhum anestésico, o 
que pode ter promovido alguma modificações morfológicas durante a fixação como ocorre em outros poliquetas estudados. (Costa-Paiva et al., 2007; Oliveira et al., 2010).

$\mathrm{Na}$ costa brasileira podem ser encontradas outras duas espécies desse gênero: $N$. moniloceras (Hartman, 1940) e N. pictus Kinberg, 1866, no entanto apenas a última já havia sido reportada para o Rio de Janeiro. A espécie N. moniloceras, registrada para ao Rio Grande do Sul, quando comparada com N. maculata, apresenta cirro tentacular ligeiramente menor (alongando-se até o nono setígero), além de possuir neurocerdas infra-acículares heterogonfas espinígeras e falcígeras, enquanto que em $N$. maculata, as cerdas desta região são homogonfas espinigeras e heterogonfas falcígeras; em $N$. moniloceras a lígula notopodia dorsal é digitiforme enquanto em N. maculata é subulada.

A espécie $N$. pictus foi descrita com base em material coletado, por Kinberg (1866), na costa do Rio de Janeiro. No entanto essa espécie não possui nenhuma descrição detalhada e faltam ilustrações da mesma, essas lacunas descritivas somadas ao fato de o material tipo se encontrar em péssimas condições, levaram Pettibone (1971) a considerar a espécie como duvidosa. A falta de uma descrição ou diagnose de $N$. pictus, não permite compará-la com $N$. maculata, mas é valido ressaltar que todos os espécimes descritos aqui, apresentam as características morfológicas de $N$. maculata.

Habitat: Neste trabalho foi encontrada dentro da base morta de corais (figura 12a) ou sobre os corais S. variabilis, E. rostrata, L. pertusa e Errina sp. Contudo, esta espécie já foi coletada em diversos tipos de substrato desde rochoso, coralíneo, carcaça em decomposição, até sedimento lamoso ou arenoso (Pettibone, 1971).

Distribuição batimétrica: 137 - 658,2m.

Distribuição: Atlântico Sul: Argentina e Rio de Janeiro (Bacia de Campos) - Brasil. Em vários pontos do continente Antartico, assim como nas costas sul e leste da China. 


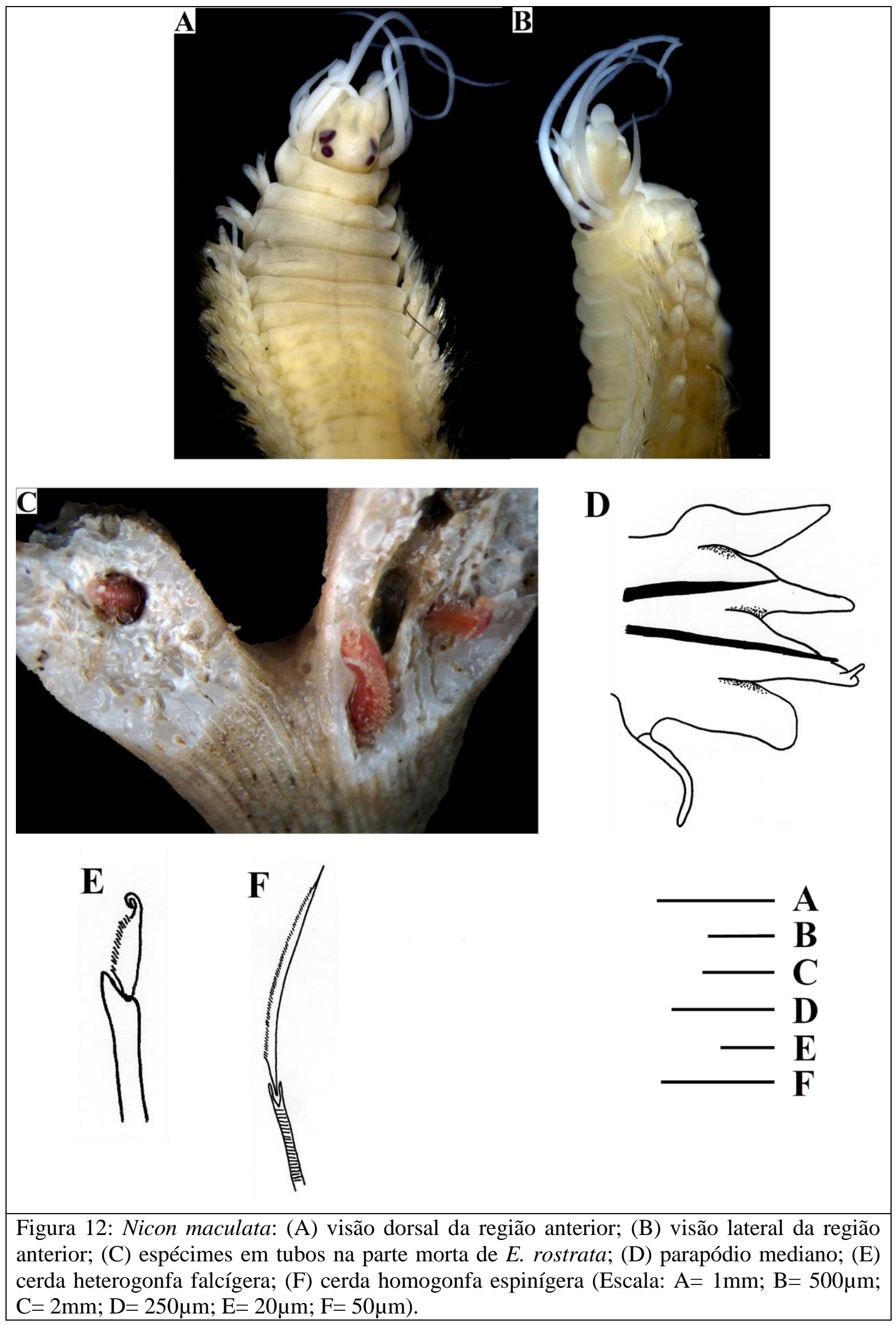


Família Syllidae Grube, 1850

Sub-família: Syllinae Grube, 1850

Gênero Haplosyllis, Langerhans, 1879

Espécie tipo: Haplosyllis (Syllis) spongicola (Grube, 1855).

Diagnose: Sylíneos de corpo cilíndrico, podendo chegar a grandes tamanhos. Prostômio, com dois pares de olhos; três longas antenas articuladas; palpos robustos, triangular ou subtriangular, localizados anteriormente ao prostômio e fundidos na base. Dois pares de cirros tentaculares no primeiro segmento. Cada parapódio contendo um cirro ventral, digitiforme, e outro dorsal, moniliforme. Tanto os cirros tentaculares, cirros dorsais e antenas, são articulados moniliformemente; em alguns casos as articulações podem não ser completamente visíveis (segmentos mais jovens ou indivíduos juvenis). Farínge armada com apenas um dente, circundado por papílas (entre 9 e 12); trepan pode ou não estar presente (se presente com 10 pequenos dentes). Cerdas todas simples e ocorrendo, geralmente, em pequenos números nos parapódios (1 a 3), entretanto algumas espécies apresentam até 12 cerdas. Este gênero não apresenta cerdas capilares. Reprodução ocorrendo, principalmente, por estolões sexuais.

\section{Haplosyllis ohma (Imagima \& Hartman, 1964)}

(Figura: $13 \mathrm{a}-\mathrm{g}$ )

Haplosyllis ohma: Lattig \& Martin, 2009: 25-26, Figs 15A-D e 16A-F.

Trypanosyllis (Trypanoseta) ohma: Imajima \& Hartman, 1964: 129 - 130, pl. 31, fig. A-D.

Geminosyllis ohma: Imajima, 1966: 233 - 235, fig. 43 A-G. Kudenov \& Harris, 1995: 71, fig. 1.26 .

Material examinado: 3 espécimes. ECOPROF 2, 2 espécimes, 623m, 40 6' 9,65" W- 22 $22^{\circ}$ 32,5" S, 10/06/2008, em Solenosmilia variabilis; ECOPROF 8, 1 espécime, 606m, 40 6' 14,37" W- 22 22' 24,47" S, 21/11/2008, em Solenosmilia variabilis.

Diagnose: Haplosylídeo com corpo moderadamente longo, apresentando corpo opaco. Faringe e proventriculo se estendendo por mais que 12 setígeros; faringe apresentando um pequeno dente triangular por volta do segundo segmento. Cerdas em 
pequeno número, com dente secundario distalmente bidentado. Subdistalmente com um forte dente lateral, com 1/3 da largura da cerda; superfície do dente lateral levemente serrilhada. Parapódios anteriores com mais cerdas que os posteriores, estas também são mais robustas.

Descrição: Indivíduo com 67 segmentos, com um estolão reprodutivo de 20 segmentos (figura 13e), localizado na porção final do corpo. Corpo cilíndrico, em algumas regiões do corpo um pouco achatado ventralmente; indivíduos preservados com coloração branca opaca anteriormente e translúcidos posteriormente (figura $13 \mathrm{a}, \mathrm{b}, \mathrm{e}$ ). Prostômio em formato de semicírculo (figura 13b), com dois pares de olhos arranjados de forma trapezoidal, os dois anteriores maiores e mais afastados um do outro do que os posteriores; Antena mediana e laterias quebradas, a mediana inserida bem no meio do prostômio (entre os dois pares de olhos) e as laterais inseridas no bordo anterior do prostômio (alinhadas com os olhos posteriores). Dois palpos fusionados na base e inseridos ligeiramente abaixo do prostômio, ambos um pouco maiores que o prostômio (figura 13b).

Faringe cilíndrica se estendendo por 15 setígeros, com um pequeno dente triangular ocorrendo por volta do segundo setígero. Trepano não observado. Proventriculo (Barrilete) cilíndrico com 54 fileiras de células musculares, se extendendo por 13 setígeros, porém difícil de visualizar devido à opacidade do corpo. Peristômio bem definido, com a metade do comprimento dos demais setígeros (figura 13b).

Cirros tentaculares presentes e afinando em direção às pontas, os dorsais com 39 articulações, já os cirros ventrais, apresentavam-se partidos em todos os espécimes, no espécime analisado estes possuíam 29 articulações, até a região partida. Cirros dorsais longos (figura 13d), com tamanho variando ao longo dos setígeros: os do primeiro setígero com 49 articulações, os do segundo com 33, terceiro com 56, quarto com 50 (no esquerdo este era um pouco maior, com 55 artículos, porém ambos estão completos), quinto com 30, sexto com 56, sétimo com 37, setígeros medianos com média de 42 artículos (variando em \pm 2 artículos de um cirro para outro entre os setígeros) nos posteriores com 38 (também variando com \pm 1 artículo entre os setrígeros), nestes setígeros, diferentemente dos anteriores e medianos, o último artículo é mais longo que os demais (em comprimento igual a três artículos basais) e em formato filiforme (figura 13d). Cirros ventrais digitiformes, com pontas obtusas e mais longas que o parapódio.

Cerdas variando, ligeiramente, de tamanho ao longo do corpo, se tornando mais robustas. Todas com dente secundario distalmente bidentado, com dentes pequenos e de 
mesmo tamanho (figura 13f). Subdistalmente as cerdas apresentam um alargamento, formando um forte dente lateral principal, com $1 / 3$ da largura da cerda; superfície do dente lateral levemente serrilhada. Parapódios anteriores com seis cerdas e quatro acículas, medianos com cinco cerdas e duas a três acículas, posteriores com cinco cerdas e três acículas. As acículas tornam-se mais largas em direção à região posterior do corpo e, em cada parapódio, as inferiores são mais finas e menores; em todos os segmentos as acículas apresentam um alargamento distalmente dando, à ponta, um aspecto de losango (figura 13c).

Espécime analisado com um estolão na região posterior, com 20 segmentos e coloração branca translúcida (figura 13e), mais opaca que no restante do indivíduo. Entretanto não foi possível determinar o sexo do estolão, pois não haviam gametas desenvolvidos. Os indivíduos sem estolão apresentam um par de cirros pigidiais, entretanto em todos os espécimes eles estavam quebrados, o maior dos fragmentos continha cinco artículos.

Discussão: Dentre as espécies descritas para o gênero, apenas duas foram reportadas para águas brasileiras: H. spongícola (Grube, 1855), ocorrendo em todo o nordeste e sudeste, e H. aberrans (Fauvel, 1939) encontrada apenas em Pernambuco.

A cerda de $H$. aberrans é a principal característica que a difere de $H$. ohma, na primeira o dente principal não é tão proeminente além de possuir o dente secundário trifido, enquanto na segunda o dente secundário é bífido e posterior ao proeminente dente primário.

Com relação à espécie $H$. spongicola, as cerdas são muito semelhantes às de $H$. ohma, porém na primeira espécie possui uma forte variação ao longo do corpo, o que não ocorre na segunda, além de nesta espécie ocorrerem mais cerdas por parapódio (4 a 6) do que em $H$. spongícola (1 a 3). As acículas também são diferentes em ambas as espécies, em $H$. ohma somente ocorrem acículas retas e com pontas rombudas e afinadas, enquanto em $H$. spongicola são encontradas cerdas com a ponta recurvada a partir da região mediana do corpo.

As espécies H. tenhovei Lattig et al. 2010, H. aplysinicola Lattig \& Martin, 2011 e $H$. chaetafusorata Lattig \& Martin, 2011, possuem descrições muito semelhantes a dos espécimes brasileiros de H. ohma. Entretanto estas espécies apresentam menos setígeros além de os cirros dorsais, faringe e proventrículo também serem menores do que H. ohma. Em relação às cerdas, na espécie $H$. tenhovei o dente principal é semelhante ao de $H$. ohma, porém o dente secundário é muito menor, o mesmo ocorre para a espécie $H$. aplysinicola; em H. chaetafusorata, os dentes da bifurcação (no topo do dente secundário) são de tamanhos 
diferentes, além do número de cerdas ser menor (2 a 3) quando comparado com H. ohma (4 a $6)$.

Lattig \& Martin (2009) comparam esta espécie com a espécie H. cratericola Buzhinskaja, 1990, essas espécies apresentam acículas muito parecidas, assim como as cerdas, porém estas são duas vezes mais númerosas em $H$. cratericola, quando comparado com $H$. ohma. Os comprimentos do proventriculo e da farínge são ligeiramente maiores em $H$. ohma, sendo a faringe cinco setígeros mais longa e o proventriculo dois setígeros nos espécimes aqui analisados e, no material analisado por Lattig \& Martin (2009), ambas as estruturas são dois setígeros mais longas. Os cirros ventrais também diferem em tamanho entre as duas espécies, em $H$. ohma eles são mais longos que o comprimento do parapódio, enquanto em $H$. cratericola são menores.

Os espécimes aqui descritos são muito semelhantes a descrição do holótipo de $H$. ohma em Lattig \& Martin (2009). Estes autores ao proporem alocar esta espécie neste gênero ressaltando a existência de certas diferenças em relação à região faringeal entre o holótipo e os parátipos, que podem ou não apresentar um dente faringeal ou lóbulos macios na região terminal da faringe. Estes mesmos autores aceitam que isso possa ser uma variação intrapopulacional como, por exemplo, a variação encontrada em $H$. spongicola por Lattig et al. (2007). Martin (com. pess., 2012) ressalta que esta espécie precisa ser mais bem amostrada e revisada, para determinar se há e quais são as variações que podem ocorrer na região faringeal, como as relatadas acima, e reunir informações a respeito da biologia da espécie.

Habitats: Não há muitas informações ecológicas sobre essa espécie em nenhum dos artigos em que ela foi reportada. Na costa brasileira foi encontrada associada ao coral Solenosmilia variabilis.

Distribuição batimétrica: 606 - 623 m (batimetria válida apenas para os espécimes examinados neste trabalho)

Distribuição: Esta espécie foi reportada no pacífico, norte do Japão, sudeste da Rússia e no sudoeste dos Estados Unidos. Esta é a primeira ocorrência da espécie para o Atlântico, no Rio de Janeiro (Bacia de Campos) - Brasil 

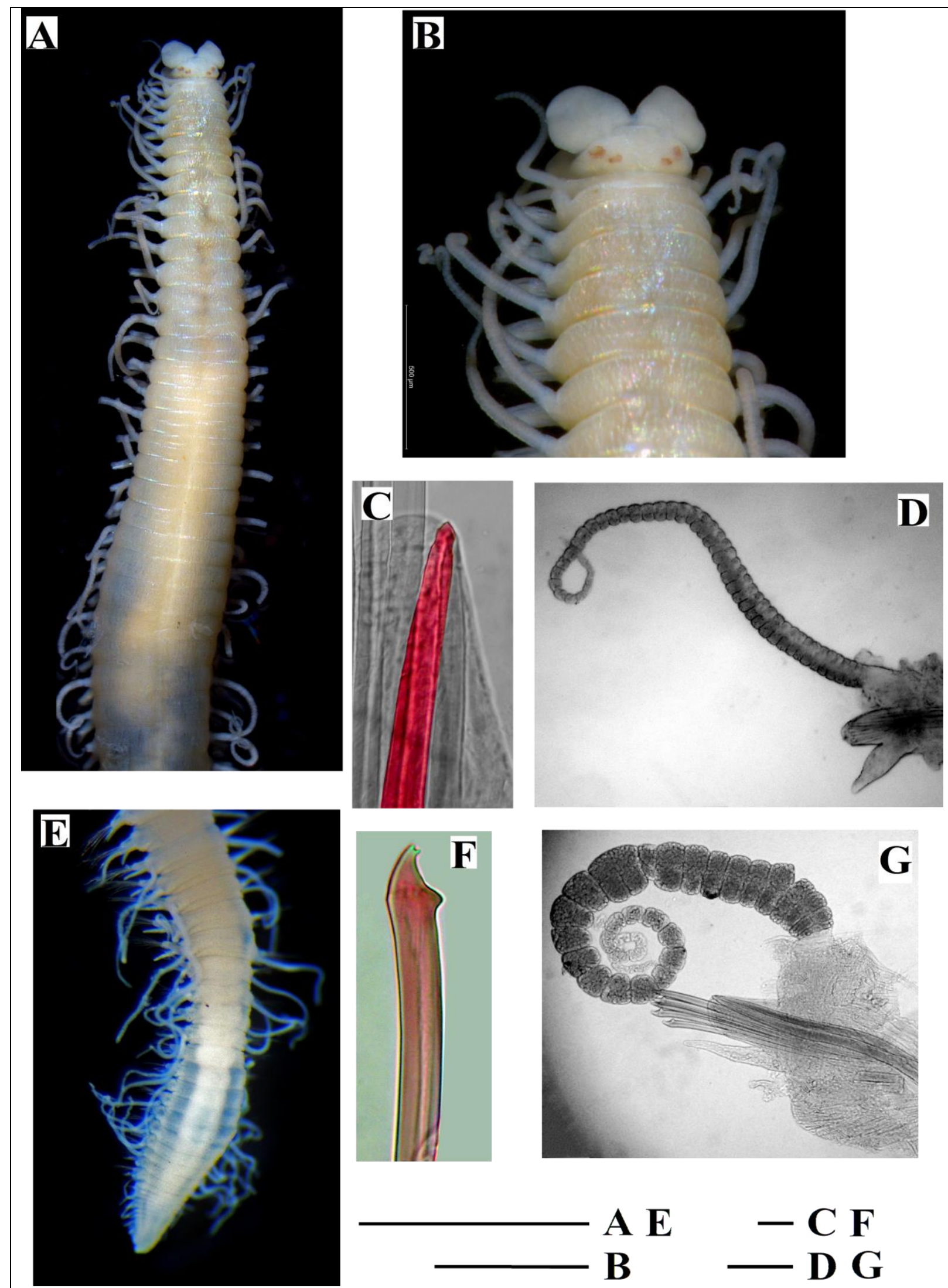

Figura 13: Haplosyllis ohma: (A) visão dorsal da região anterior; (B) detalhes do prostômio; (C) acícula; (D) parapódio do setígero 10; (E) visão dorsal do estolão; (F) cerda; (G) parapódio do setígero 32 (Escalas: $A=2 \mathrm{~mm} ; \mathrm{B}=; \mathrm{C}, \mathrm{F}=5 \mu \mathrm{m} ; \mathrm{D}=60 \mu \mathrm{m} ; \mathrm{E}=1,5 \mathrm{~mm} ; \mathrm{G}=30 \mu \mathrm{m}$ ) 
Gênero Pionosyllis Malmgren, 1867

Espécie tipo: Pionosyllis compacta Malmgren, 1867

Diagnose: Corpo cilíndrico, longo e convexo dorsalmente. Prostômio com dois pares de olhos, antena mediana e um par de antenas laterais. Palpos fusionados na base. Antenas e cirros tentaculares, dorsais e pigidiais, geralmente lisos ou com articulação não muito evidente. Peristômio apresentando dois pares de cirros. Cirros alternando de tamanho, com os mais longos surgindo mais dorsalmente que os menores. Parapódios apresentando lobos précerdais. Cirros ventrais triangulares ou subtriangulares. Acículas presentes, algumas vezes protrundindo do lobo parapodial. Cerdas compostas falcígeras bidentadas, com dois tipos de cerdas em cada parapódio: ventrais mais curtas e robustas e as dorsais delgadas e compridas; nos setígeros posteriores podem ocorrer cerdas capilares ou simples; algumas espécies podem apresentar cerdas pseudoespinígeras. Faringe mais curta que o proventrículo, apresentando um dente anteriormente e uma coroa de papilas moles em torno deste. Reprodução por epigamia (San Martin et al., 2009)

\section{Pionosyllis procera (Hartman, 1965)}

(Figura: $14 \mathrm{a}-\mathrm{h}$ )

Pionosyllis procera: Hartman, 1965: 79-80, fig. 10 C-D. San Martín \& Estapé, 1993: 227-231, figs 1 e 2. Nogueira, 2000: 81-82, fig. 20 A-F. Fukuda, 2010: 81-84, fig. 22 A-H.

Material examinado: 16 espécimes. ECOPROF 1,1 espécime, 617m, 40 6' 5,13" W-22 22' 36,31" S, 28/01/2008, em Enallopsammia rostrata. ECOPROF 1, 1 espécime, 658,2m, 40 $10^{\circ}$ 25,79" W-22 ${ }^{\circ} 26^{\prime}$ 21,9" S, 28/01/2008, em Solenosmilia

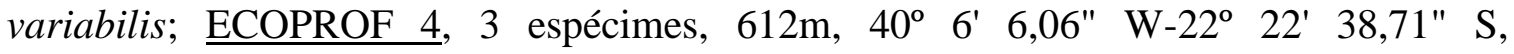
05/08/2008, em Solenosmilia variabilis; ECOPROF 9, 1 espécime, 626m, 40 5' 56,92" W-22 $22^{\circ}$ 49,47" S, 21/12/2008, em Solenosmilia variabilis; ECOPROF 10, 3 espécimes, 614m, 40 4' 53,33" W-22 21' 16,37" S, 18/01/2009, em Madrepora oculata; ECOPROF 11, 1 espécime, 604m, 40 7' 30,61" W-22 23' 13,77" S, 14/02/2009, Enallopsammia

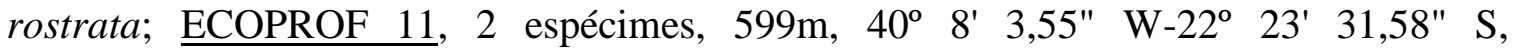
14/02/2009, Lophelia pertusa; ECOPROF 13, 2 espécimes, 626m, 40 6' 41,75" W-22 22' 59,5" S, 23/04/2009, em Errina sp.; ECOPROF 14, 2 espécimes, 617,3m, 40 7' 41,6" W-22 23' 41,53" S, 23/05/2009, em Lophelia pertusa. 
Diagnose: Eusylíneo com corpo longo e tubular, de coloração translucida quando vivo e mais opaco quando fixado. Cirros dorsais alternando de tamanho ao longo do corpo (um grande e um pequeno), aparentemente lisos, mas com fracas articulações quando observados em maiores aumentos. Cerdas compostas falcígeras e pseudoespinígeras em todos os setígeros, ambas com pontas bidentadas e dentes de igual tamanho; lâminas das cerdas serrilhadas internamente. Farínge se extendendo por até 8 segmentos, com um dente anterior rodeado por papilas triangulares e moles; proventrículo com comprimento entre 5 e 11 setígeros. (San Martin et al., 2009; Fukuda, 2010).

Descrição: Espécimes de tamanho variável, menor com 130 setígeros (espécime completo) e o maior com 147 setígeros (este estava incompleto), coloração brancoamarelado no material fixado (figura 14a). Prostômio subpentagonal, com dois pares de olhos avermelhados, localizados bem próximo um do outro, sendo o par anterior maior que o par posterior (figura 14a). Um par de palpos robustos e subcilíndricos inseridos anteriormente ao prostômio, comprimento maior ou igual ao do prostômio. Antenas laterais com 13 artículos, inseridas bem próximas aos olhos anteriores, já a antena mediana possui 41 artículos e inseridas entre o espaço existente entre o par de olhos posteriores, todas as antenas estão inseridas sobre um ceratóforo cilíndrico robusto. Os artículos da antena mediana são mais delgados que os das antenas laterais. Em comprimento total, as antenas laterais chegam a ser $2 / 3$ do tamanho da antena mediana.

Faringe se extendendo por cinco segmentos, borda anterior apresentando uma coroa com até 10 papilas moles e triangulares (figura 14b); dente faríngeo cônico e agudo, localizado logo após a borda anterior da farínge. Proventrículo se extendendo por 11 segmentos, formado por 30 fileiras musculares. Trepano não observado.

Peristômio curto com, aproximadamente, a metade do comprimento dos segmentos posteriores (figura 14a). Cirro peristomial, ou tentacular, dorsal com 40 artículos e o ventral possui entre 17 e 20 artículos. Cirro dorsal com tamanho variando nos segmentos, maiores nos setígeros $1,3,4,6,8,9,11$, quando passa a ocorrer alternadamente até o fim do corpo. Cirro do primeiro setígero com 55 artículos, no segundo com 36; no meio do corpo, o cirro maior com 39 artículos e o menor com 24; já na região posterior o cirro maior possui 56 artículos, esses eram de tamanho irregular, uns mais largos e outros mais finos, e o menor 29 artículos. Nos últimos 15 setígeros o cirro maior possui 27 artículos e o menor 22. No material aqui examinado, o comprimento dos cirros dorsais variou entre os 
exemplares, com até \pm 3 artículos de diferença entre um espécime e outro. Cirro ventral digitiforme e sem articulações, surgindo próximo à base do parapódio e não variando de tamanho ao longo do corpo..

Parapódios cônicos, apresentando até três acículas que, geralmente, não ultrapassam o lobo parapodial; acículas afinando a partir da região mediana, terminando uma ponta aguda ou arredondara (figura 14c). Cerdas compostas falcígeras, no primeiro setígero apenas um tipo de cerda (figura 14d), nos demais segmentos há dois feixes de cerdas distintos, as do feixe superior (localizadas mais próximas às acículas) são mais longas e estreitas que as inferiores, em ambos os casos as hastes são recurvadas e inflam distalmente (na região da articulação), onde são serrilhadas (figura 14 d - h). As lâminas são internamente serrilhadas e terminam em pontas bidentadas (mais proeminentes nas cerdas ventrais), com dentes de igual tamanho; as lâminas das cerdas dorsais são sempre maiores e mais estreitas do que a das ventrais (figura $14 \mathrm{e}-\mathrm{h}$ ). Ao longo do corpo as lâminas das cerdas tornam-se menores, porém nunca chegam a ficar com o mesmo comprimento (figura $14 \mathrm{~g}$-h). O número de cerdas varia ao longo do corpo, a média dos valores encontrados é de 13 cerdas nos parapódios anteriores, nos medianos há 10 cerdas e nos posteriores há nove cerdas. O número de acículas diminui ao longo do corpo, nos parapódios anteriores são encontradas até seis acículas e nos parapódios posteriores até três; o tamanho varia muito pouco, mas as acículas superiores, em geral, eram mais largas que as inferiores; todas com pontas afinadas ou obtusas.

Segmento pigidial com um par de cirros inseridos terminalmente, e o ânus localizado em posição levemente dorsal

Discussão: Esta espécie possui uma morfologia muito peculiar e uma complexa história taxônomica (Fukuda, 2010). Descrita por Hartman (1965) como Pionosyllis procera, apresenta características morfológicas que a posicionam na subfamília Eusyllinae (e.g. cerdas compostas falcígeras e articulações dos cirros e antenas não muito evidentes) (San Martin \& Estapé, 1993; San Martin et al., 2009). No entanto a estratégia reprodutiva apresentada por está espécie (esquizogamia) é característico de outra subfamília: Syllinae, tornando, assim, duvidoso o posicionamento desta espécie no gênero Pionosyllis (San Martin \& Estapé, 1992; San Martin et al., 2009; Fukuda 2010).

San Martin et al. (2009) e Fukuda (2010) ressaltam a necessidade de uma transferência da espécie $P$. procera para outro gênero que melhor englobe seus caracteres 
morfológicos e reprodutivos. San Martin et al. (2008) em seu trabalho sobre as espécies de sylídeos da Australia, criam o gênero Megasyllis, que é muito próximo morfologicamente com o gênero Pionosyllis, apresentando corpos longos e largos, cirros e antenas com articulações não muito evidentes e arranjos de cerdas compostas semelhantes aos de Pionosyllis; mas com reprodução esquizogamica, sendo esta última a principal característica distintiva entre esses dois gêneros (San Martin et al., 2008). Apesar de ainda não haver nenhuma revisão formal para a espécie, Fukuda (com. pess.) acredita que está espécie deva ser tratada como Megasyllis procera, já que este gênero abrange não apenas as características morfológicas como reprodutivas desta espécie. Entretanto, na ausência de um trabalho formal sobre essa mudança de gêneros, opto por tratar a espécie como $P$. procera.

Habitat: Na costa brasileira esta espécie já foi reportada em associação com o coral Mussimilia hispida (Verril, 1901) bem como em bancos de algas em costões rochosos no estado de São Paulo. No Rio de Janeiro, foi encontrada associada aos corais Enallopsammia rostrata, Solenosmilia variabilis, Madrepora oculata, Lophelia pertusa e Errina sp. Nas outras localidades em que a espécie foi encontrada, foi coletada em meio a algas, corais e cascalhos de concha/coral.

Distribuição batimétrica: $1-658 \mathrm{~m}$.

Distribuição: Oceano Atlântico: Cabo Verde, Cuba, Ilhas Bermudas e Brasil (São Paulo e Rio de Janeiro (Bacia de Campos)). 


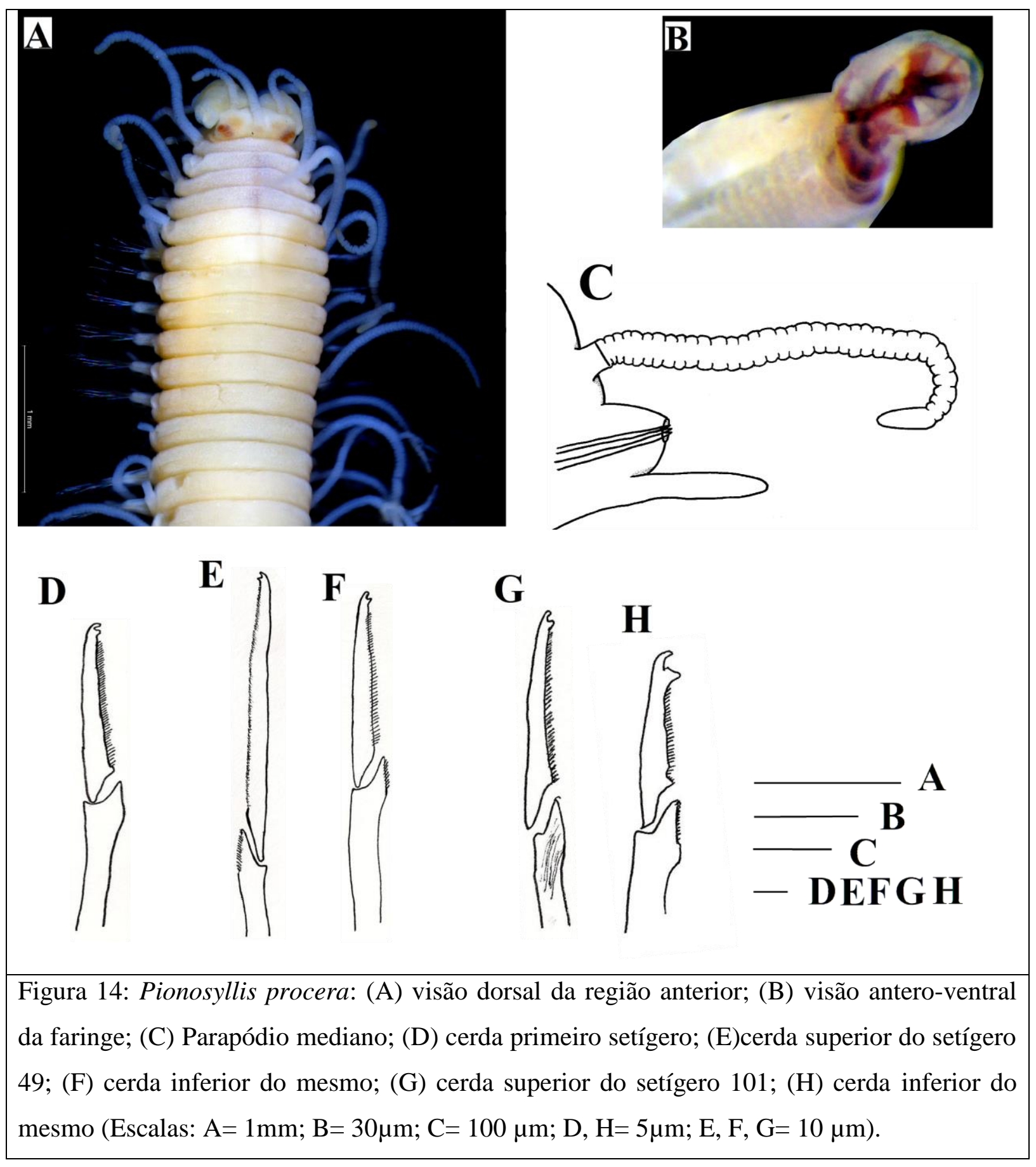




\section{Família Glyceridae Grube, 1850}

Gênero Glycerella Arwidsson, 1899

Espécie tipo: Glycerella magellanica (McIntosh, 1885)

Diagnose: Corpo com númerosos segmentos, alongado e afilando em ambas as extremidades. Segmentos trianelados. Prostômio formado por quatro segmentos, apresentando quatro apêndices relativamente longos. Aileron do tipo rod-like. Primeiros dois parapódios unirremes, apresentando apaenas o neuropódio, com cirro ventral e cerdas compostas. Demais parapódios birremes, com cirros ventral e dorsal, noto- e neuropódios indistintamente separados um do outro, mas cada parapódio apresentando dois lobos pré-cerdais e dois lobos pós-cerdais. Brânquias ausentes. Notopódio com cerdas simples e capilares; neuropódio com neurocerdas compostas, as superiores espinígeras e as inferiores falcígeras. (Boggeman, 2002).

\section{Glycerella magellanica (McIntosh, 1885)}

(Figura: 15 a - q)

Hemipodus magellanicus McIntosh, 1885:349; Pl. 42, Fig.11-15; Pl. 22a, Fig. 12-15; Pl. 35a, Fig. 5 and 7.

Glycerella atlantica Wesenberg-Lund, 1950: 24, Pl. 5 Fig. 22; Pl. 6, Fig. 28.

Pseudolacydonia caeca Rullier, 1964: 151, Fig. 8 a-k.

Glycerella magellanica Böggemann, 2002: 78, Fig.: 124-126.

Material examinado: 1 espécime. CAP-BC (Caratinga) 1 espécime, $745 \mathrm{~m}, 40^{\circ} 14^{\prime}$ 50,57" W- 22 31' 13,47" S, 17/03/2006, em Solenosmilia variabilis (parte morta do coral).

Diagnose: Glycerídeo com corpo fusiforme. Prostômio formado por quatro anéis completos; probóscide muscular, recoberta por papílas digitifores, com um sulco longitudinal; internamente com dois pares de mandíbulas com aileron do tipo rod-like. Primeiro e segundo setígero com parapódios unirremes e neurocerdas compostas. Demais segmentos do corpo, com parapódios birremes, notocerdas capilares e neurocerdas compostas falcígeras e espinígeras.

Descrição: Exemplar com corpo fusiforme, afinando em ambas as extremidades (figura 15a); fragmentado na região posterior, porém completo, com 77 segmentos, todos com coloração marrom. Segmentos anteriores unianelados, passando a bianelados a partir do nono 
setígero e trianulado a partir do $22^{\circ}$ setígero, sendo nestes últimos os ânulos anteriores mais curtos, enquanto que os medianos são os mais longos. Prostômio cônico, formado por quatro anéis completos, no último anel há uma indicação de um quinto anel incompleto (figura 15b); no anel mais anterior há quatro apêndices (porém os dois da direita foram perdidos) comprimidos dorso-ventralmente, os palpos alongando-se até o quinto anél e as antenas passando o quarto anel (figura 15b); no anel mais posterior há um órgão mediano em formato de meia lua.

Probóscide recoberta por númerosas papilas digitiforme (figura 15a), com um sulco mediano e reto mais ou menos distinto; algumas papilas são ligeiramente menores, com base larga e distalmente mais arredondado (figura 15d) do que as outras (figura 15c); todas as papilas apresentando cílios no topo: as maiores dois ou três cílios e, as menores, com apenas um cílio (figura $15 \mathrm{c}-\mathrm{d}$ ). Ailerons em forma de haste (rod-like) ligeiramente ampliada em uma das extremidades; apresentam uma ala translúcida lateral que, provavelmente, trata-se de um remanescente rudimentar da placa interramal (figura 15e).

Os dois primeiros pares de parapódios são unirremes, com lobos pré-cerdais finos e triangulares, enquanto que os lobos pós-cerdais são mais curtos e arredondados (figura 15f). Demais parapódios birremes (figura 15i, n), com lobos pré-cerdais delgados e triangulares, notopódios ligeiramente mais largos e mais compridos que os neuropódios; tanto noto quanto neuropódio tornam-se menores ao longo do corpo. Dois lobos pós-cerdais menores; anteriormente ambos os lobos arredondados; lobo notopodial alongado e mais ou menos triangular nos parapódios seguintes; lobo neuropodial ligeiramente mais longo do que arredondado; os lobos notopodiais mais posteriores geralmente são mais curtos e arredondados. À exceção dos dois primeiros parapódios, todos os outros apresentam noto e neuroacícula.

Notocerdas simples, capilares, margem levemente serrilhada, superfície totalmente áspera nas notocerdas dorsais e, nas medianas e inferiores, apenas a partir da metade (figura 15j). Neurocerdas de dois tipos: as dorsais são espinígeras (figura $15 \mathrm{~g}, \mathrm{k}, \mathrm{o}$ ) e as ventrais falcígeras (figura $15 \mathrm{~h}, 1, \mathrm{p}$ ), em ambos os casos apenas a superfície da lâmina é áspera. Nos segmentos anteriores as neurocerdas espinígeras apresentam lâminas bem longa e distalmente delgadas, ao longo do corpo tornam-se ligeiramente mais curtas e curvas. Neurocerdas falcígeras com lâminas bem longas nos parapódios anteriores, ficando ligeiramente mais curtas e encurvadas nos parapódios posteriores. Todas as hastes das neurocerdas com um dente acessório (figura 15 m, q), localizado próximo à região da articulação. 
Cirro dorsal começa a aparecer a partir do segundo parapódio, de formato cônico a oval; inserido na parede do corpo, logo acima da base do parapódio. Cirro ventral também começando a partir do segundo segmento, localizados próximo à base dos parapódios; os anteriores relativamente largos e cônicos, enquanto que os posteriores são finos e digitiformes, do mesmo tamanho que o lobo pós-cerdal do neuropódio. Não há brânquias e os cirros pigidiais foram perdidos durante a coleta.

Discussão: Morfologicamente não há muitas diferenças entre o espécime encontrado no Brasil e as descrições de McIntosh (1885) e Böggeman (2002). Uma das diferenças observadas foi a presença da placa remanescente interramal, no aileron, característica essa que não é descrita por nenhum dos dois autores, logo esta placa pode vir a desaparecer com o tempo em indivíduos mais desenvolvidos; assim sendo, não é uma variação muito forte para suportar uma nova espécie.

As cerdas também apresentam diferença em relação às outras descrições sendo que neste espécime as neurocerdas apresentam variações ao longo do corpo, com as lâminas se tornando mais curvas e menores em direção à região posterior do corpo. Entretanto de acordo com Böggeman (2002) as cerdas apresentam poucas variações interespecíficas, em Glyceridae, e por isso não deve ser utilizada para diagnósticos a nível específico. Entretanto, estudos recentes com os gêneros Glycera e Hemipodia revelaram diferença na morfologia das cerdas ao longo do corpo (Rizzo et al., 2007; Parapar \& Moreira, 2010). No entanto, Parapar $\&$ Moreira (2010), ressalta que para observara algumas diferenças morfológicas, encontradas nas cerdas, se faz necessário o uso de microscopia electrônica de varredura, uma técnica muitas vezes de difícil acesso para estudos rotineiros, mas que deve ser levada em conta em futuros estudos filogenéticos do grupo.

Como só há um único exemplar não se pode afirmar que se trata de uma nova espécie, uma vez que as divergências acima citadas podem representar variações interpopulacionais.

Para a costa brasileira há 16 espécies, da família Glyceridae, reportadas: 14 do gênero Glycera e duas do gênero Hemipodia (Amaral et al., 2012). Este é o primeiro registro do gênero Glycerella em nossa costa.

Habitat: A respeito do substrato, aparentemente essa espécie tem preferência por sedimento lamoso, mas também ocorre em arenoso-lamoso e com cascalhos. O espécime deste trabalho foi encontrado em um fragmento morto de Solenosmilia variabilis e como 
geralmente as regiões mortas, dos corais, estão mais próximas do solo, isso poderia explicar o fato de a espécie ser encontrada no ambiente coralíneo.

Distribuição batimétrica: entre 45 - 1960m.

Distribuição: Atlâtico Norte (Açores), Mar do Caribe (Barbados), Atlântico Sul (Rio de Janeiro, Bacia de Campos - Brasil); Pacífico Sul (Estreito de Magalhães - Chile), Oceano Indico (Ilhas Edward e Marion). 


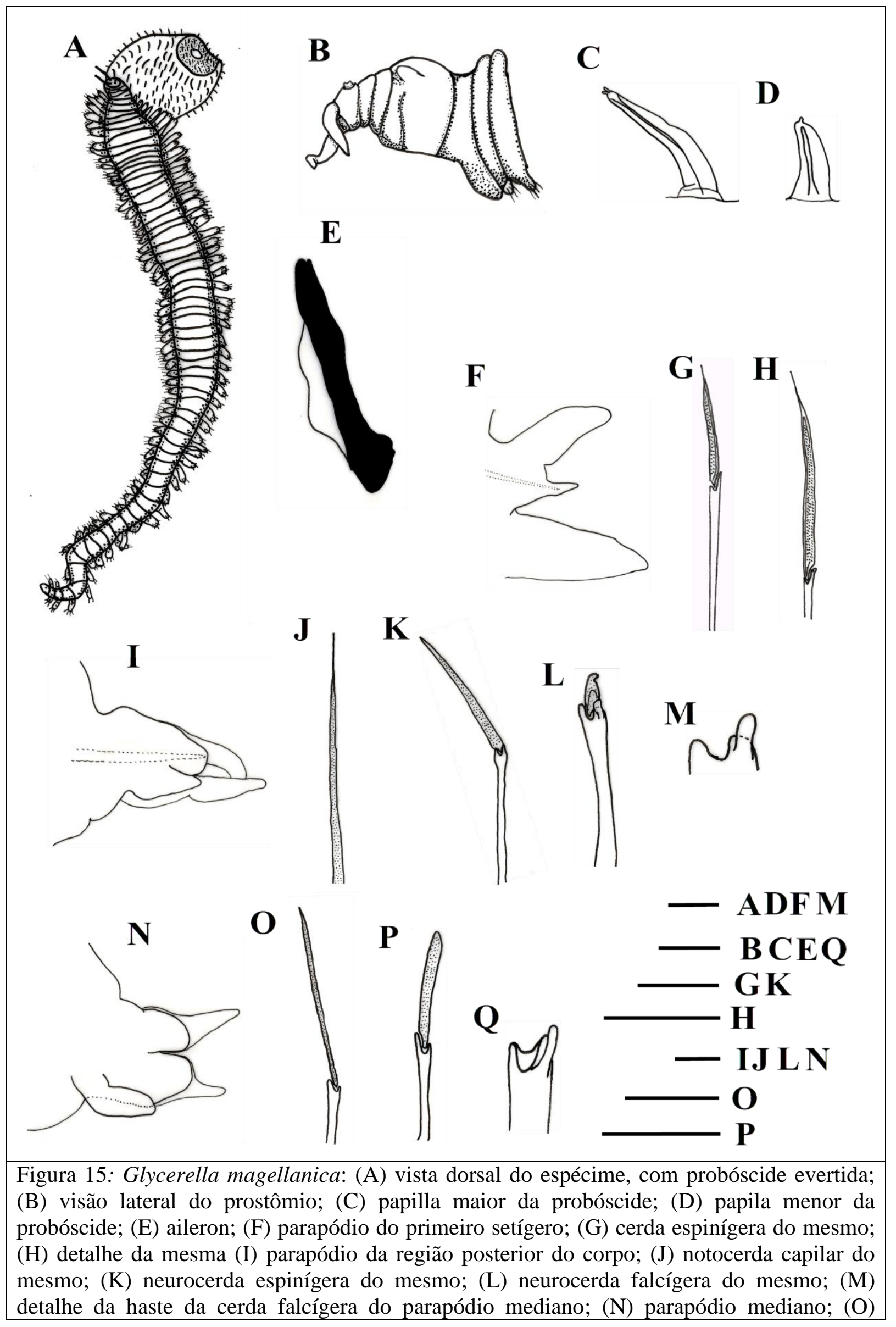


neurocerda espinígera do mesmo; (P) neurocerda falcígera do mesmo (Q) detalhe da haste da neurocerda falcígera do parapódio mediano. (Scalas: $\mathrm{A}=1,55 \mathrm{~mm} ; \mathrm{B}=350 \mu \mathrm{m} ; \mathrm{C}, \mathrm{E}=105 \mu \mathrm{m}$; $\mathrm{D}, \mathrm{K}, \mathrm{O}, \mathrm{P}=: 40 \mu \mathrm{m} ; \mathrm{F}, \mathrm{N}=130 \mu \mathrm{m} ; \mathrm{G}, \mathrm{H}=74 \mu \mathrm{m} ; \mathrm{I}=54 \mu \mathrm{m} ; \mathrm{J}, \mathrm{L}=15 \mu \mathrm{m} ; \mathrm{M}, \mathrm{Q}=4 \mu \mathrm{m})$

\section{Família Amphinomidae Savigni in Lamarck 1818 \\ Gênero Notopygos Grube, 1850 \\ Espécie tipo: Notopygos crinita (Grube, 1855).}

Diagnose: Corpo de um oval alongado, segmentos levemente deprimidos; ânus dorsal (posição variável entre as espécies). Prostômio com dois pares de olhos, um par de antenas e palpos inseridos frontalmente e uma antena mediana inserida sobre o prostômio. Carúncula bem desenvolvida, multipregueada e geralmente ovalada. Parapódio com um par de cirros notopodiais e apenas um cirro ventral; brânquias dorsais, surgindo entre o terceiro e o quinto setígero; cerdas noto- e neuropodiais bifurcadas.

\section{$\underline{\text { Notopygos crinita (Grube, 1855) }}$}

(Figuras: $16 \mathrm{a}-\mathrm{b} ; 17 \mathrm{a}-\mathrm{g}$ )

Notopygos crinita. Treadwell, 1939: 175-176, fig. 9; Ebbs, 1966: 509-512, figs. 6 A-F; Nonato \& Luna, 1970: 66-67, figs. 3 e 4; Salazar-Vallejo, 1996-1997: 384-385, figs. 6, 14 e 15. Liñero-Arana \& Diaz, 2010:113-116 Figs. 4 G-K.

Material examinado: 1 espécime. ECOPROF 4, 1 espécime, 606m, 40 6' 10,97" W-22 22' 31,74" S, 05/08/2008, em Solenosmilia variabilis.

Diagnose: Espécime de porte diminuto, corpo ovóide e levemente achatado dorso-ventralmente. Brânquias aparecendo a partir do quinto setigero. Carúncula robusta, ovoide, ornamentada com fendas transversais no lobo superior. Ânus dorsal, localizado entre o $21^{\circ}$ e o $22^{\circ}$ setígero.

Descrição: Espécime completo, com 22 setígeros. Corpo oval, sem padrões de pigmentação aparente (figura 16a). Prostômio semicircular com dois pares de olhos, localizados de forma trapezoidal, primeiro par um pouco menor que o segundo (figura 16b). Antena mediana em posição central no prostômio, entre o primeiro e o segundo par de olhos, relativamente longa (com a metade do comprimento da carúncula) e afinando em direção à extremidade (figura 16b); Antenas laterais inseridas frontalmente ao prostômio, menores que 
a antena mediana, porém semelhantes em formato a esta (figura 17a). Labios robustos, apresentando um par de palpos inseridos lateralmente; palpóstilos robustos, lisos, digitiforme e com mesmo comprimento que as antenas laterais. Boca ventral, localizada entre os dois primeiros setigeros. Carúncula longa, estendento-se até a metade do terceiro setígero, com um lobo central mais elevado que os laterais, aparentemente todos os lobos são levemente enrugados (figura $16 \mathrm{a}-\mathrm{b}, 17 \mathrm{a}$ ).

Brânquias surgindo a partir do quinto setígero, ocorrendo até o setígero 21. Cada brânquias digitiformes, com até três filamentos por segmento, de tamanho diferenciados, mas sempre com uma predominando sobre as outras e nunca formando tufos.

Parapódios birremes, com notopódio apresentando dois cirros dorsais enquanto o neuropódio apresenta apenas um cirro ventral (figura 17b). Cirros notopodiais inseridos sobre um curto cirróforo, próximo à região mediana do notopódio; o mais ventral é ligeiramente maior, ambos com aspecto cirriforme sendo, facilmente, confundidos com as brânquias; o tamanho varia um pouco ao longo do corpo, maior nos primeiros segmentos e diminuindo de tamanho em direção à região posterior. Cirro ventral menor que os dorsais, robusto e cirriforme, sem cirróforo aparente. Notocerdas maiores que as neurocerdas, longas, delicadas, assimetricamente bifurcadas, com a ponta maior podendo atingir até quatro vezes o comprimento da ponta menor (figura 17e); mais dorsalmente há um feixe de cerdas mais curtas e delgadas, espaçadas umas das outras, muito semelhantes às cerdas menores, mas algumas com a ponta maior em formato sinuoso (figura $17 \mathrm{c}$-d), porém não foi possível observar um padrão na ocorrência desta. Neurocerdas mais númerosas que as notocerdas, o feixe mais dorsal composto por cerdas semelhantes às notopodiais (figura 17e); já o feixe mais ventral apresenta cerdas mais curtas, delgadas, com pontas bifurcadas assimetricamente, com a ponta maior chegando a ser duas vezes o comprimento da ponta menor (figura 17f), na base do neuropódio há cerdas bifurcadas assimetricamente, com o dente maior com o triplo do tamanho do dente menor, este apresenta a ponta arredondada (figura $17 \mathrm{~g}$ ).

Ânus localizado dorsalmente, no setígero 21. Último segmento apresentando um par de cirros curtos, robustos e ovalados.

Discussão: O gênero Notopygos apresenta, ao todo, 18 espécies descritas, das quais apenas as espécies $N$. megalops McIntosh, 1855, N. caribea Yáñez-Rivera \& Carrera-Parra, 2012 e N. crinita Grube, 1855, ocorrem no Oceano Atlântico. Sendo que destas, apenas N. crinita ocorre no Brasil, encontrada na região de infra-litoral no estado de Alagoas (Nonato \& 
Luna 1970). Neste trabalho sua ocorrência foi ampliada um pouco mais ao sul, assim como a primeira ocorrência desta espécie associada a recifes de corais.

Segundo Yáñez-Rivera \& Carrera-Parra (2012), os principais caracteres que distinguem as espécies de Notopygos, são referentes à localização do ânus, o setígero em que iniciam as brânquias, a morfologia da carúncula e padrões de coloração. Com base nisto é possível diferenciar a espécie $N$. crinita das outras duas que ocorrem no Atlântico, apenas com base na carúncula, uma vez que nestas a carúncula apresenta como ornamentação uma série de dobras, enquando em $N$. crinita a carúncula possui uma série de fendas no lobo mais dorsal.

Morfologicamente não há diferenças entre este espécime e as descrições fornecidas por Grube (1885), para a espécie tipo, e por Liñero-arana \& Dias (2010), para as espécies encontradas na Venezuela, pois nestas a carúncula é ornamentada com uma série de fendas transversais e paralelas. Entretanto há algumas diferenças em relação à descrição proposta por Nonato \& Luna (1970), onde a carúncula é descrita como possuindo "uma placa basal multilobada e uma crista longitudinal ligeiramente sinuosa e pregueada”, porém a ilustração desta estrutura no trabalho está de acordo com o que é descrito por Liñero-arana \& Dias (2010); além do problema com a descrição da carúncula faltam outras informações, sobre a morfologia dos espécimes analisados por Nonato \& Luna (1970), como a localização do ânus, além de mais detalhes a respeito das brânquias e das cerdas, que seriam informações relevantes para uma melhor comparação entre os espécimes.

Habitat: Essa espécie pode ser encontrada vivendo sobre algas, rodolitos, recifes de corais, em praias rochosas e sobre o coral Solenosmilia variabilis (neste estudo foi encontrada na cavidade de um pólipo).

Distribuição batimétrica: $4-606 \mathrm{~m}$.

Distribuição: Mar do Caribe, Brasil (Alagoas e Bacia de Campos) e Mar Mediterrâneo. Neste último é tida como uma espécie invasora, porém o total estabelecimento da espécie ainda é considerado duvidoso. 

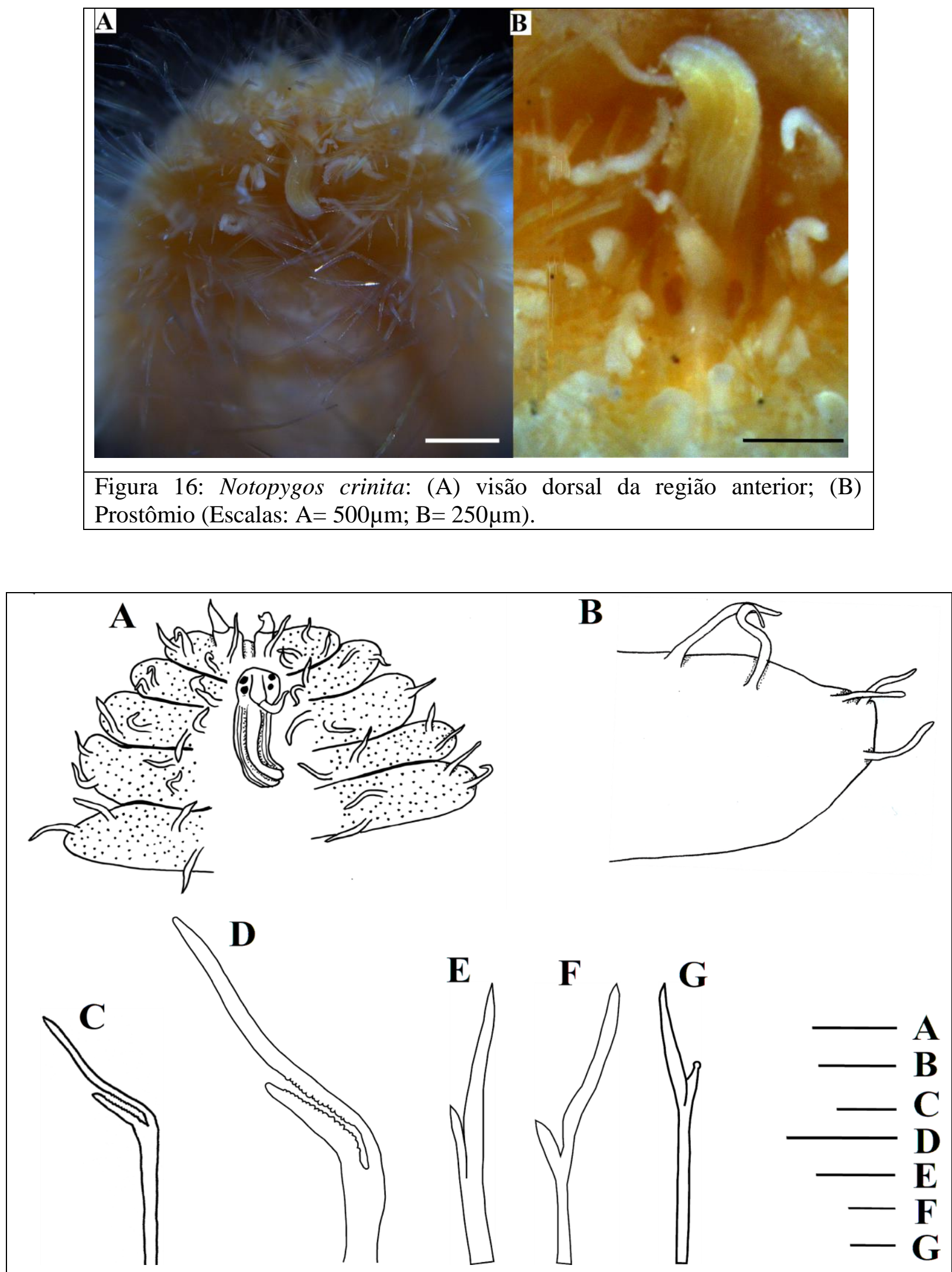

Figura 17: Notopygos crinita: (A) visão dorsal da Região anterior; (B) parapódio anterior; (C) cerda superior recurvada; (D) detalhe da mesma; (E) cerda mediana-superior; (F) cerda mediana-inferior; $(G)$ cerda inferior (Escalas: $A=500 \mu \mathrm{m} ; B=290 \mu \mathrm{m} ; \mathrm{C}, \mathrm{D}=50 \mu \mathrm{m} ; \mathrm{E}=$ $75 \mu \mathrm{m} ; \mathrm{F}=20 \mu \mathrm{m} ; \mathrm{G}=25 \mu \mathrm{m})$ 
Família Dorvilleidae Chamberlin, 1919.

Gênero Ophryotrocha Claparède \& Mecznikow, 1869.

Espécie tipo: Ophryotrocha puerilis Claparède \& Mecznikow, 1869.

Diagnose: Dorvilleideos com antenas e palpos muito reduzidos, digitiformes ou papiliformes. Cirros dorsais presents, podendo ou não apresentar acículas. Cerdas de dois tipos capilares e heterogonfas falcígeras, algumas espécies podem apresentar falcígeras homogonfas. Aparelho mastigatório formado por um par de mandibulas totalmente ou parcialmente fusionadas e com uma placa serrilhada anteriormente, e maxilas formadas por carreiras de placas, em formado de espátulas, fusionadas e semi-articuladas podendo ou não, apresentar dois grandes dentes, em formato de foice, na base.

\section{Ophryotrocha sp.}

(Figura: 18 a - i)

Material examinado: 10 espécimes; 245m, N 7306130.8 E 578756.7, 27/07/2010, em Lophelia pertusa.

Diagnose: Indivíduos com corpo translúcidos enquanto vivos e branco leitoso no material fixado. Maxila $\mathrm{K}$ formada por seis placas dentarias e maxila $\mathrm{P}$ por 7 placas (duas fusionadas e outras cinco semi-fusionadas). Parapódios unirremes com cerdas capilares apenas na região supra-acícular; na região sub-acícular as cerdas são compostas falcígeras heterogonfas, com as borda interna, da lâmina suavemente serrilhada

Descrição: Indivíduos de tamanho variável, o maior com 25 segmentos, fixados de totalmente branco treanslucidos ou levemente opacos (figura 18 a-b). Fêmeas maiores do que os machos.

Corpo curto, robusto, com a superfície dorsal arredondada e ventral achatada, com sulco longitudinal ventral. Prostômio com bandas ciliares presentes na borda frontal, entre as antenas e entre cada antena e os olhos. Bandas ciliares formando anéis completos ao redor dos segmentos peristômiais e setígeros (figura 18a).

Prostômio tão longo quanto largo (figura 18a); portanto um par de antenas laterais cirriformes, inseridas médio-lateralmente e com um tufo de cílios na ponta; com um par de pequenos palpóforos robustos totalmente fusionados à lateral do prostômio, palpóstilos 
retráteis em forma de papila (de difícil visualização após os espécimes serem fixados) (figura 18b). Um par de olhos localizados internamente entre o prostômio e o primeiro segmento peristomial, ambos brilhando quando há luz incidindo (figura 18 a-b). Orgãos nucais não observados. Segmentos peristomiais com a região mediana bem translúcida, sendo possível visualizar a mandíbula e a maxila (figura 18 a-b).

Setígeros bem desenvolvidos, com lobos ventral e dorsal localizados na base dos parapódios, ovais, com a metade do comprimento dos parapódios, projetando-se sobre a base destes (figura 18j). Parapódios unirremes, finos e longos, portanto cirros digitiformes ventral e dorsal (figura 18j); lobo acícular, posicionado medianamente. Feixe de cerdas capilares emergindo acima da acícula (figura $18 \mathrm{c}$ ). Abaixo da acícula despontam cerdas compostas falcígeras heterogonfas, com as borda interna, da lâmina suavemente serrilhada (figura 18 de).

Mandíbulas esclerotinizadas e de coloração marro escuro (figura 18i), localizada dorsalmente à maxila formada por uma base larga anterior, a qual apresenta uma pequena bifurcação, levemente desgastada, assumindo um aspecto serrilhado, denominada placa de corte. Posterior à essa placa de corte, há uma haste longa e curva, com ponta arredondadas.

Maxila $K$ - formada por dois fortes e grandes dentes em forma de foice (figura $18 \mathrm{~g}$ ), estes são articulados posteriormente, anteriormente apresentam uma ponta aguda e única. Entre o meio e a ponta do fórceps sai uma haste relativamente longa e delicada, na qual se articula a primeira de seis placas côncavas e com borda anterior serrilhada, unidas uma a outra por uma membrana basal (figura 18h). As primeiras três placas apresentam a carreira de dentes iniciando por um dente maior e mais curvo que os demais. Primeira placa com oito dentes, quatro grandes e robustos e outros quatro menores, ocorrendo alternadamente; segunda placa com 25 dentes com tamanhos alternando como no primeiro; terceira placa com nove dentes alternando em tamanho; da quarta à sexta placa os dentes são de igual tamanho; quarta placa com 22 dentes, quinta com 19 e sexta placa com 24 .

Maxila $P$ - formada por 5 placas semi-fusionadas, umas as outras, e outras 2 placas completamente fusionadas, formando uma base de sustentação (figura 18f). Todas as placas apresentam um aspecto côncavo e bordas anteriores serrilhadas, sendo que nas três primeiras os dentes são pequenos e uniformes, já nas outras três os dentes são mais robustos e alternam em tamanho: um grande para um a dois pequenos intercalados; a sexta placa, encontra-se 
totalmente fusionada com a setima, que não possui área serrilhada, formando uma base comum à toda a maxila.

Todos os segmentos com um anél ciliar rodeando-os (figura 18 ). Corpo afinando posteriormente, terminando com um par de longos cirros pigidiais, inseridos ventralmente (figura 18a). Ânus ventral, inserido entre os cirros pigidiais.

Discussão: Dentre todas as espécies pertencentes ao gênero Ophryotrocha as que mais se aparentam com a descrita acima são O. puerilis puerilis Claparède \& Metschnikow, 1869, O. adherens Paavo, Bailey-Brock \& Akesson, 2000 e O. eutrophila Wiklund et al., 2009.

O. adherens é uma espécie originalmente do Hawaii morfologicamente são diferenciadas principalmente pela distribuição das cerdas nos parapódios, $O$. adherens possui cerdas capilares simples tando na região supra-acícular quando na subacícular, enquanto que Ophryotrocha $\mathrm{sp}$ as cerdas simples estão presentes apenas na região supra-acícular. Paavo et al. (2000) não descreveram, com detalhes, o aparato bucal da espécie havaiana, mas uma análise das ilustrações observa-se até sete placas dentarias nas maxilas P- e K-, enquanto que os espécimes encontrados na costa brasileira apresentam seis placas dentarias na maxila $\mathrm{K}$ - e cinco na maxila P-.

Assim como em $O$. adherens, $O$. puerilis puerilis, também apresenta cerdas capilares subacilares, diferenciando-se de Ophryotrocha sp . As mandíbulas de O. puerilis puerilis apresentam placas de corte com até 20 diminutos dentículos (Paxton \& Akesson, 2007), esses mesmos autores afirmam que muitas vezes indivíduos amadurecidos apresentam essa placa desgastada e, portanto, não apresentando todos os dentes. Em todos os espécimes, analizados neste estudo, as mandíbulas apresentavam um aspecto gasto na placa de corte, sendo as indentições decorrentes do desgaste. A maxila K- é muito semelhante em ambas as espécies, já a maxila P- possui duas placas dentarias a mais em O. puerilis puerilis. Orensanz (1990) relata a ocorrência da espécie $O$. puerilis em um aquário na região de Mar del Plata (norte da Argentina), no entanto ele afirma que o espécime encontrado é muito semelhante à descrição de Fauvel (1923), e não com a descrição do espécime tipo encontrado por Claparède \& Metschnikow (1869) na Itália. Por falta de descrições mais detalhadas destes espécimes encontrados por Orensanz (1990), é preferível evitar comparações até que os espécimes argentinos sejam reexaminados. 
A espécie $O$. eutrophila talvez seja a espécie mais semelhante, visualmente, a encontrada no presente estudo. Na verdade essa espécie é descrita precariamente, com relação à sua morfologia, e poucos dados são proporcionados por Wiklund et al. (2009) para comparações. Com o pouco que e descrito sobre a morfologia de O. eutrophila, é possível pontuar que ela apresenta a mesma diferença, na distribuição das cerdas, que as outras duas espécies comparadas acima (O. adherens e O. puerilis puerilis). Além disso nas cerdas compostas, de $O$. eutrophila, há um longa projeção da haste, em forma de espinho, que se prolonga até a metade da lamina. Sobre a morfologia das maxilas P- e K- apresentam sete placas dentarias, enquanto que os espécimes brasileiros apresentam seis placas na maxila K- e cinco na maxila P-.

Habitat: associada ao coral Lophelia pertusa a uma profundidade de $300 \mathrm{~m}$.

Distribuição batimétrica: $300 \mathrm{~m}$.

Distribuição: conhecida apenas para o Rio de Janeiro (Bacia de Campos) - Brasil 


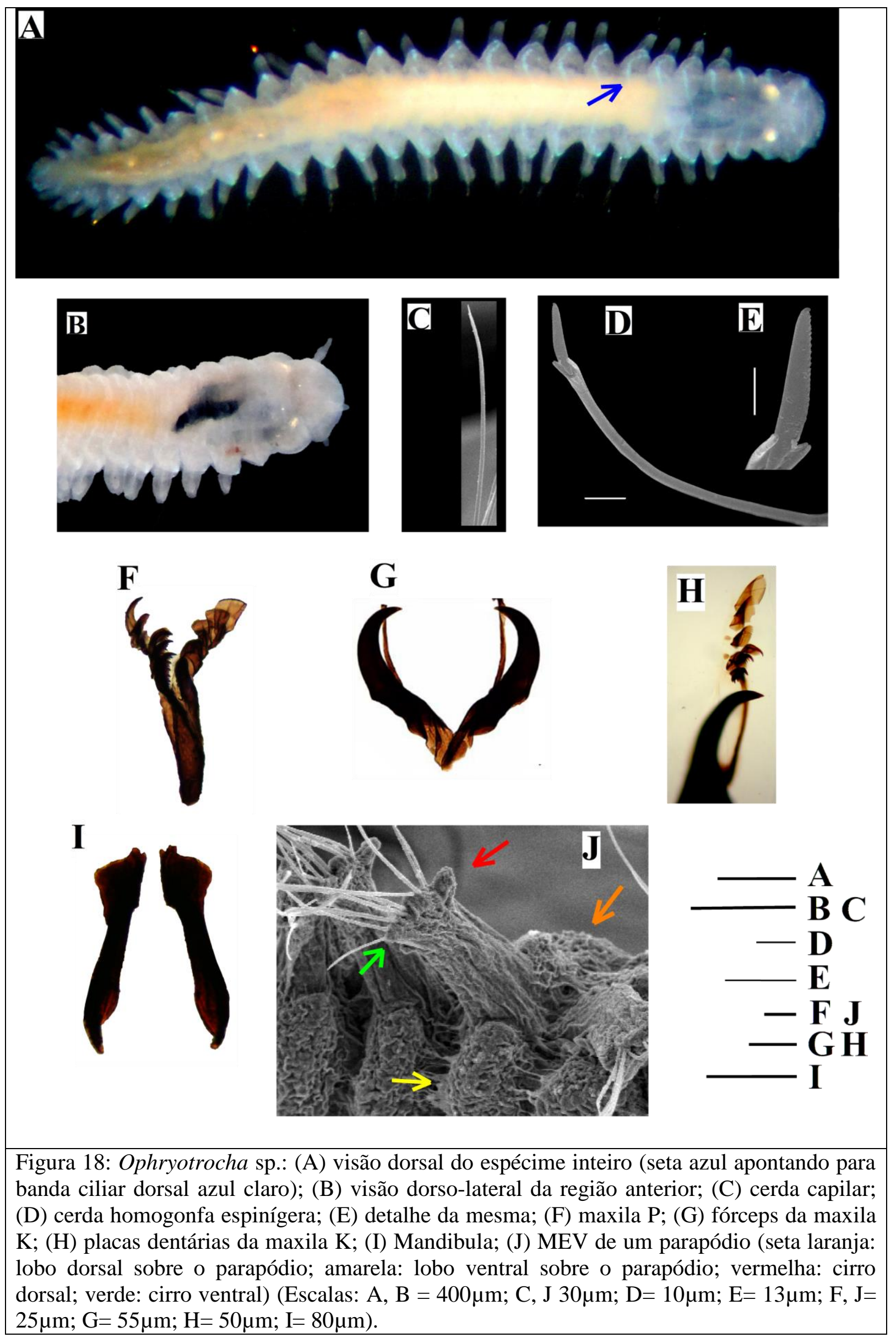


Família Eunicidae Berthold, 1827.

Gênero Eunice Cuvier, 1817.

Espécie tipo: Eunice (Nereis) aphroditois (Pallas, 1788).

Diagnose: Eunicídeos de tamanho variado. Prostômio apresentando dois pares de olhos, cinco antenas (divididas em três grupos: AI, AII e AIII), frontalmente possuem um par de palpos robustos. Peristômio geralmente maior que o prostômio, apresentando um par de cirros peristomiais dorsais. Parapódios sub-birremes, ou seja, o notopódio é reduzido à região acicular. Cerdas neuropodiais de vários tipos: limbadas, pectinadas e compostas falcígeras. Acículas presentes ao longo de todo o corpo. Ganchos aciculares presentes geralmente do meio do corpo para o fim, de coloração amarelo claro ou escuras, uni-, bi- ou tridentadas.

\section{Eunice prognatha McIntosh, 1885}

(Figura: 19 a - i)

Eunice prognatha: Mclntosh, 1885:268-270, figs. 29-31, pi. 37: figs. 16, 17, pi. 19A:figs. 10, 11. Fauchald, 1992: 274-276, fig. 92 A-E.

Material examinado: 63 espécimes. ECOPROF 1, 1 espécime, 658,2m, 40 10' 30,77" W-"22 26 ' 16,72”S, 28/01/2008, em Solenosmilia variabilis; ECOPROF 1, 2 espécimes, 653,4m, 40 10' 30,55"W-22 26' 17,03" S, 28/01/2008, em Enallopsammia rostrata; ECOPROF 1, 1 espécime, 247m, 40 6' 9,94" W-"22 22' 33,8" S, 30/01/2008, em Enallopsammia rostrata; ECOPROF 1, 1 espécime, 658,3m, 40 10' 30,87" W-22 26' 16,52" S, 28/01/2008, em Enallopsammia rostrata; ECOPROF 2, 1 espécime, 617m, 40 6' 11,75" W-22 $22^{\prime}$ 34,02" S, 10/06/2008, em Lophelia pertusa; ECOPROF 2, 1 espécime, 614m, 40 6' 11,54" W-22 22' 33,95" S, 09/06/2008, em Solenosmilia variabilis; ECOPROF 2, 1 espécime, 615m, 40 $6^{\circ} 11,43 " \mathrm{~W}-22^{\circ} \quad 22^{\prime} 33,82^{\prime \prime} \mathrm{S}$, 10/06/2008, em Solenosmilia variabilis; ECOPROF 2, 2 espécimes, 614m, 40 6' 11,47" W-22 22' 33,86" S, 10/06/2008, em Solenosmilia variabilis; ECOPROF 2, 1 espécime, $612 \mathrm{~m}, 40^{\circ} 6^{\prime} 11,75^{\prime \prime} \mathrm{W}-22^{\circ} 22^{\prime} 34,02 " \mathrm{~S}, 10 / 06 / 2008$, em Solenosmilia variabilis; ECOPROF 3, 2 espécimes, 605m, 40 6' 11,63" W-22 22' 32,16" S, 05/07/2008, em Enallopsammia rostrata; ECOPROF 3, 1 espécime, 606m, 40 $6^{\circ} 12,26^{\prime \prime} \mathrm{W}-22^{\circ} 22^{\prime}$ 
32,68" S, 07/07/2008, em Solenosmilia variabilis; ECOPROF 3, 1 espécime, 605m, 40 6' 11,31" W-22 22' 32,13" S, 05/07/2008, em Solenosmilia variabilis; ECOPROF 3, 1 espécime, 605m, $40^{\circ} 6^{\prime} 12,05^{\prime \prime} \mathrm{W}-22^{\circ} 22^{\prime}$ 32,42" S, 05/07/2008, em Solenosmilia variabilis; ECOPROF 3, 1 espécime, 608m, 40 6' $11,66^{\prime \prime} \mathrm{W}-22^{\circ} 22^{\prime} 32,07 " \mathrm{~S}$, 05/07/2008, em Madrepora oculata; ECOPROF 3,1 espécime, 608m, 40 6' 11,73" W$22^{\circ} 22^{\prime}$ 31,84" S, 05/07/2008, em Madrepora oculata; ECOPROF 3, 1 espécime, 620m, $40^{\circ} 6^{\prime} 12,01 " \mathrm{~W}-22^{\circ} 22^{\prime}$ 31,45" S, 03/07/2008, em Lophelia pertusa; ECOPROF 3, 1 espécime, 609m, 40 6' 11,69"W-22 22' 31,9"S, 03/07/2008, em Solenosmilia variabilis; ECOPROF 4, 2 espécimes, 618m, 40 6' 8,13" W-22 22' 31,83" S, 02/08/2008, em Lophelia pertusa; ECOPROF 4, 2 espécimes, 601m, 40 6' 11,84" W-22 $22^{\circ} 32,85^{\prime \prime} \mathrm{S}$, 05/08/2008, em Lophelia pertusa; ECOPROF 4, 3 espécimes, 612m, 40 6' 11,04" W-22º 22 '33,53"S, 05/08/2008, em Solenosmilia variabilis; ECOPROF 5, 1 espécime, 621m, $40^{\circ} 6^{\prime}$ 16,33" W-22 22' 34,54" S, 31/08/2008, em Errina sp; ECOPROF 5, 1 espécime, $603 \mathrm{~m}, 40^{\circ} 6^{\prime} 11,6^{\prime \prime} \mathrm{W}-22^{\circ} 22^{\prime} 32,81 " \mathrm{~S}, 01 / 09 / 2008$, em Solenosmilia variabilis; ECOPROF 5, 1 espécime, 572m, 40 6' 42,74"W-22 21' 51,43" S, 01/09/2008, em Lophelia pertusa; ECOPROF 5, 1 espécime, 604m, 40 6' 11,56"W-22 22' 32,23"S, 01/09/2008, em Solenosmilia variabilis; ECOPROF 5, 1 espécime, 612m, 40 6' 10,53" W-22 22' 31"S, 01/09/2008, em Lophelia pertusa; ECOPROF 5, 1 espécime, 612m, 40 6' 10,46"W-22 22' 30,87" S, 01/09/2008, em Madrepora oculata; ECOPROF 6, 1 espécime, 607m, 40 7' 21,46"W-22 '22' 59,19" S, 25/09/2008, em Solenosmilia variabilis; ECOPROF 6, 2 espécimes, 608m, 40 7' 21,99"W-22 23' 0,36"S, 26/09/2008, em Solenosmilia variabilis; ECOPROF 7, 1 espécime, 609m, 8 5' 45,81"W-19² 26' 10,31"S, 25/10/2008, em Solenosmilia variabilis; ECOPROF 7, 1 espécimes, 605m, 40 6' 18,04"W-22 22' 24,64"S, 25/10/2008, em Solenosmilia variabilis; ECOPROF 7, 1 espécime, 609m, 40 6' 19,1"W-22 ${ }^{\circ}$ 22' 26,03"S, 25/10/2008, em Madrepora oculata; ECOPROF 7, 1 espécime, 609m, 40 6' 18,99"W-22 22' 25,48"S, 25/10/2008, em Solenosmilia variabilis; ECOPROF 7, 1 espécime, 596m, 40 6' 22,34"W-22 22' 7,25"S, 26/10/2008, em Solenosmilia variabilis; ECOPROF 8, 1 espécime, 612m, 40 6' $16,96 " \mathrm{~W}-22^{\circ} 22^{\prime} 25,46 " \mathrm{~S}, 22 / 11 / 2008$, em Enallopsammia rostrata; ECOPROF 8, 1 espécime, 614m, 40 6' 17,17" W-22 ${ }^{\circ}$ 22' 25,75"S, 21/11/2008, em Lophelia pertusa; ECOPROF 8, 1 espécime, 606m, 40 6' 18,04"W-22 22' 25,49"S, 22/11/2008, em Solenosmilia variabilis; ECOPROF 9, 1 espécime, 636m, 40 5' 47,06"W-22 $22^{\circ}$ 42,38"S, 22/12/2008, em Lophelia pertusa; ECOPROF 9, 1 espécime, 639m, 40 5' 
45,24"W-22 22' 42,52" S, 22/12/2008, em Solenosmilia variabilis; ECOPROF 9, 1 espécime, 626m, 40 6' 1,9"W-22 22' 44,3"S, 21/12/2008, em Solenosmilia variabilis; ECOPROF 10, 1 espécime, 614m, 40 4' 58,31"W-22 21' 11,2"S, 18/01/2009, em Madrepora oculata; ECOPROF 10, 1 espécime, 613m, 40 5' 42,39"W-22 22' 4,07"S, 17/01/2009, em Solenosmilia variabilis; ECOPROF 11, 1 espécime, 585m, 40 8' 34,47"W-22 23' 25,48"S, 13/02/2009, em Enallopsammia rostrata; ECOPROF 11, 1 espécime, 608m, 40 7' 35"W-22 23' 9,34"S, 14/02/2009, em Solenosmilia variabilis; ECOPROF 11, 1 espécime, 599m, 40 8' 8,53"W-22 23' 26,41"S, 14/02/2009, em Lophelia pertusa; ECOPROF 12, 1 espécime, 621m, 40 6' 46,76"W-22 22' 53,97"S, 12/03/2009, em Lophelia pertusa; ECOPROF 12, 1 espécime, 628m, 40 6' 47,5"W-22º 22' 54,36"S, 13/03/2009, em Solenosmilia variabilis; ECOPROF 12, 1 espécime, 625m, $40^{\circ} 6^{\prime} 47,71 " \mathrm{~W}-22^{\circ} 22^{\prime}$ 54,45"S, 13/03/2009, em Solenosmilia variabilis; ECOPROF 14, 1 espécime, 624,4m, 40 7' 47,77"W-22 ${ }^{\circ}$ 23' 35,46"S, 23/05/2009, em Solenosmilia

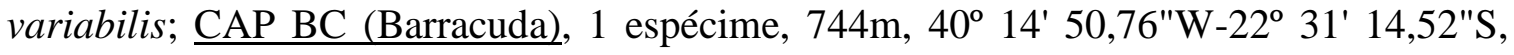
17/03/2006, em Solenosmilia variabilis; CAP BC (Marlin Leste), 1 espécime, 1079m, 39º 57' 40,28" W-22 25' 49,18"S, 22/07/2005, em Solenosmilia variabilis; CAP BC (Marlin

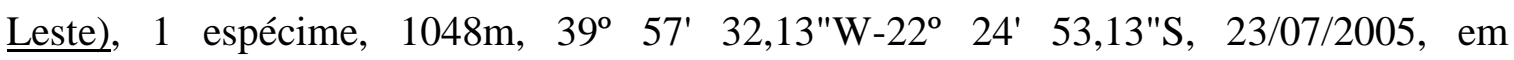
Solenosmilia variabilis; CAP-BC (Malin Leste), 1 espécime, 1054m, 39 57' 48,3"W-22º 25' 45,33"S, 07/11/2004, em Enallopsammia rostrata; CAP-BC (Marlin Leste), 1

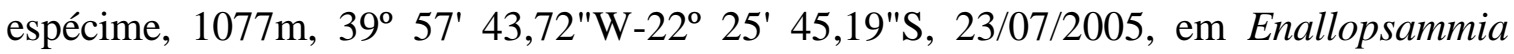
rostrata; CAP-BC (Marlin Leste), 1 espécime, 848m, 40 4' 44,74"W-22 21' 10,18"S, 12/11/2004, em Lophelia pertusa.

Diagnose: Eunicídio de médio porte $( \pm 12 \mathrm{~cm}$ de comprimento e até $1 \mathrm{~cm}$ de largura). Apresentando brânquias palmadas a partir do $10^{\mathrm{a}}$ setígero e prolongando-se por todo o corpo até bem próximo do segmento pigidial. Parapódios sub-birremes, com cerdas homogonfas falcígeras, apresentando de uma a duas acículas nos setígeros anteriores e de duas a três nos posteriores. Ganchos aciculares surgindo a partir do $35^{\circ}$ setígero. Cirros ventrais ao longo de todo o corpo, porém entre o quinto e o $58^{\circ}$ setígero apresentam a base inflada.

Descrição: Indivíduos com prostômio distintamente mais curto e arredondado que o peristômio, com comprimento igual à metade deste (figura 19a). Lobos prostomiais frontalmente arredondados, inflados dorsalmente e com um raso sulco mediano. Dobra 
peristomial larga, cobrindo os olhos e a base das antenas. Antenas inseridas em semicírculo, com a antena I (AI) mais afastadas de AII e AIII, por um espaço igual à base do ceratóforo. Ceratóstilo fino, com articulações cilíndricas, que diminuem de tamanho em direção à ponta (figura 19a); essas articulações por vezes podem se apresentar bem fracas, com antena aparentando ser lisa. Comprimento das antenas variando de uma para outra, AI atingindo o inicio do terceiro setígero, AII o setígero dois e AIII entre o segundo e terceiro setigero. Peristômio largo, com comprimento igual a 1,5 vezes a largura dos setígeros anteriores; cirros peristomiais mais curto que as antenas, inseridos diretamente no dorso do peristômio, com estilódios lisos e afilados, em alguns espécimes a ponta é articulada até 3 vezes. Fórmula maxilar: $1+1,6+6,8+1,5+10,2+2$ e $1+1$.

Os segmentos com setígeros robustos eseparações bem delimitadas. Parapódios birremes, com cirros dorsais de tamanho variável ao longo do corpo, em geral apresentam o comprimento igual à altura dos parapódios (na região da base deste), robustos e afilados terminando em uma ponta obtusa e arredondada (figura 19 d-f). Brânquias inseridas entre o cirro dorsal e a base do parapódio, começando em torno do décimo setígero e se prolongando até bem próximo do final do corpo, geralmente terminando em torno de dez setígeros antes do segmento pigidial. De formato predominantemente palmado (figura 19f), com até quatro filamentos brânquiais curtos e cilíndricos, contudo as primeiras 15 brânquias e as últimas dez são simples filamentos branquiais (figura 19e), muito semelhantes ao cirro dorsal; em comprimento possuem em torno de $2 / 3$ do comprimento do cirro dorsal.

Lobos parapodiais pós-cerdais maiores que os lobos pré-cerdais. Notopódio restrito à região acicular, sem cerdas e localizado imediatamente abaixo da base do cirro dorsal, acículas delgadas e pontudas, de coloração amarelada a levemente avermelhada, variando entre seis e oito, entre os parapódios. Neuropódio mais desenvolvido que o notopódio, com número de acículas variando ao longo do corpo, em torno de duas nos parapódios anteriores e três nos posteriores; acículas com tamanhos e formatos iguais, muito robustas e terminando em uma ponta arredondara, de coloração marrom escuro (figura 19i). Ganchos subaciculares começam a ocorrer entre os setígeros 35 e 39, estando presente em todos os setígeros até a final do corpo; de coloração marrom escuro ou marrom-avermelhado, terminando em pontas bidentadas (em alguns setígeros aparenta ser ponta arredondada, mas isso se deve ao desgaste por conta do atrito), com dentes de igual tamanho; logo abaixo da base do dente mais inferior surge uma cápsula que irá envolver toda a ponta do gancho (figura 19c). Cirro ventral 
digitiforme, com a metade do comprimento do parapódio, apresentando uma base inflada entre o sexto (com variação de \pm 1 ) e o $58^{\circ}$ setígero (com variação de \pm 5 ) (figura 19 e-f).

Cerdas divididas em dois feixes distintos: supra-aciculares e subaciculares. Feixe supra-acicular com cerdas capilares simples e ligeiramente ásperas (figura 19h), e cerdas pectinadas, planas e em forma de leque, um dente marginal cerca de 1/3 maior que o outro e, entre estes até 15 dentes menores (figura 19g). Feixe de cerdas subaciculares compostas falcígeras (figura 19b); hastes longas e robustas, alargando levemente na região próxima à articulação, neste local a superfície aparenta ser áspera; lâminas bidentadas, com dente superior recurvado e pontiagudo, o inferior menor e mais robusto, a partir da base da lâmina sai um capuz com borda externa serrilhada e superfície levemente áspera.

Discussão: Morfologicamente todos os espécimes observados neste estudo são semelhantes às descrições propostas por McIntosh (1885) e Fauchald (1992). Inicialmente, os espécimes coletados entre os corais da Bacia de Campos foram identificados como E. collini Augener, 1906 por Brasil et al.(2007). No entanto a espécie é E. prognatha já que as mesmas apresentam a mesma relação das posições das brânquias e dos ganchos subaciculares. $E$. collini apresenta antenas e antenóforos lisos, assim como brânquias terminando bem antes da região final do corpo e ganchos subaciculares ocorrendo a partir do $26^{\circ}$ setígero. Em contrapartida, todos os exemplares observados neste estudo apresentavam antenas e antenóforos com articulações e aspecto anelado, quanto às brânquias, em ambas as espécies são palmadas, porém em E. prognatha elas não mais ocorrem bem próximo do segmento pigidial; já os ganchos subaciculares apresentam pontas bidentadas em ambas as espécies, porém há diferença no setígero de origem, enquanto em E. collini aparecem a partir do $26^{\circ}$ setígero, todos os exemplares observados apresentam esta estrutura por volta do $35^{\circ}$ setígero confirmando a espécie E. prognatha.

Habitat: Encontrado em meio a sedimento vulcânico na Ilha Ascencion. Na costa brasileira foi encontrada associada aos corais Solenosmilia variabilis, Enallopsammia profunda, Lophelia pertusa e Madrepora oculata.

Distribuição batimétrica: 585 - 1058m.

Distribuição: Ilha Ascencion (ou St. Helena, localizado no meio do Oceâno Atlântico) e Rio de Janeiro (Bacia de Campos) - Brasil 


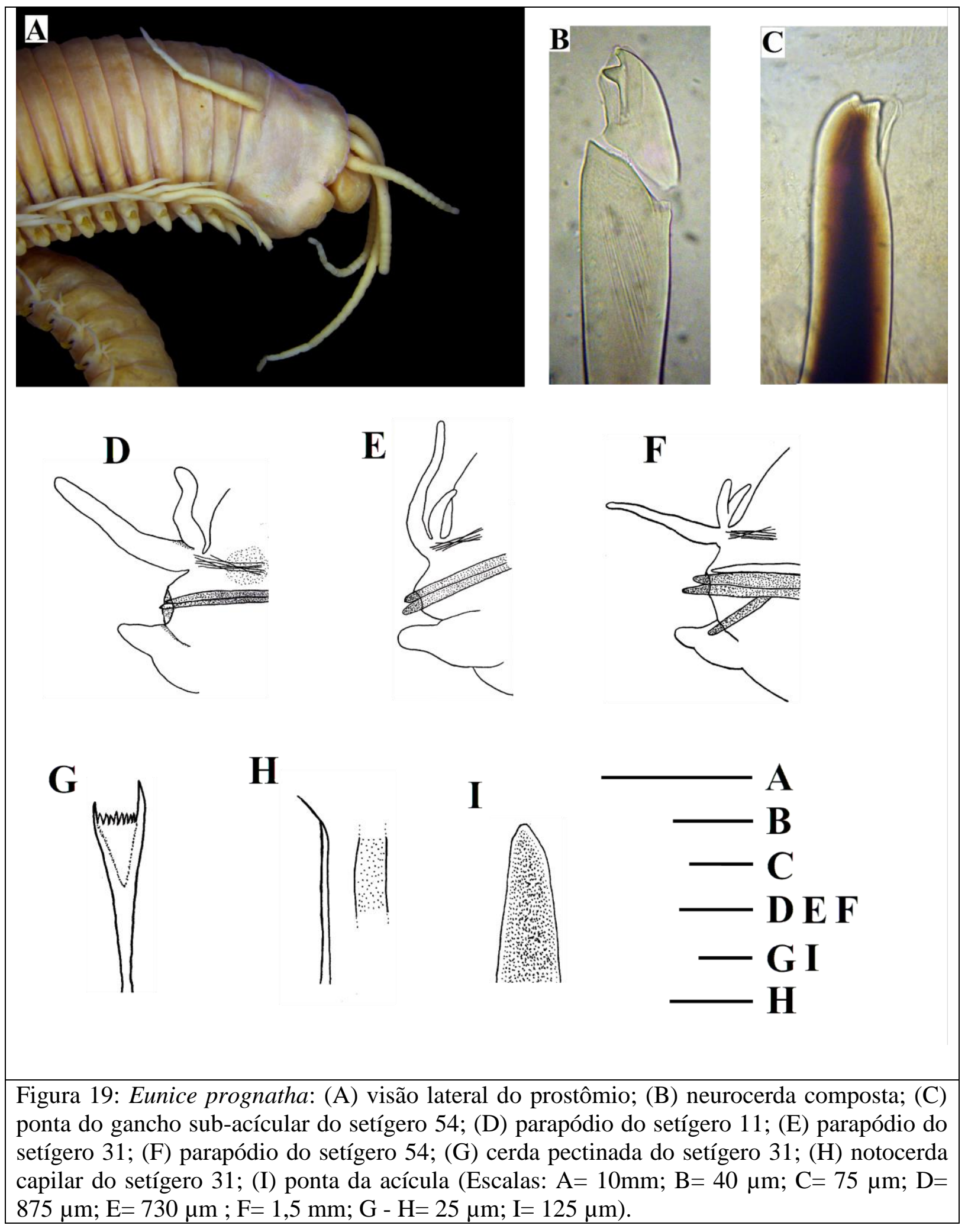




\section{Eunice gracilicirrata (Treadwell, 1922).}

(Figura: 20 a - i)

Liodice gracili-cirrata Treadwell, 1922:149-150, figs. 36-38, pi. 5: figs. 1-8.

Eunice armillata.-Hartman, 1956:282

Eunice gracilicirrata Fauchald, 1992: 169-171, fig. 51 a-g.

Material examinado: 2 espécimes. CAP-BC (Barracuda), 1 espécime, 750m, 40 10' 30,33" W- 22 26' 15,57" S, 18/03/2006, em Solenosmilia variabilis; CAP-BC (Caratinga) 1 espécime, 1058m, 40 13' 31,33" W- 22³9' 35,8" S, 11/03/2006, em Lophelia pertusa.

Diagnose: Eunicídio de corpo longo e fino. Apresentando brânquias pectinadas a partir do sexto setígero e prolongando-se até a metade do corpo. Cirros dorsais anteriores afinados. Parapódios sub-birremes, com cerdas homogonfas falcígeras, apresentando de uma acícula nos setígeros anteriores a duas ou três nos posteriores. Ganchos aciculares amarelos claros, surgindo a partir do $24^{\circ}$ setígero. Cirros ventrais ao longo de todo o corpo, porém entre o quarto e o $48^{\circ}$ setígeros apresentam a base inflada.

Descrição: Espécimes incompletos, o maior com 88 segmentos. Prostômio cordiforme, com lobos arredondados frontalmente, separados por um curto sulco mediano (figura 20b). Antenas disposta em meia-lua, com AI e AII mais próximas e a AIII um pouco mais afastada (figura 20b); ceratóforos, de todas as antenas, em formato de anel, não articulados; estilódios das antenas basalmente cilíndricos, afinando em direção à ponta e levemente articulados, ao menos 5 vezes próximo a ponta. Antenas AI e AIII com igual comprimento, ambas atingindo a região anterior do primeiro setígero, AII faltando (figura 20a).

Corpo apresentando segmentação, com separação entre os segmentos bem definidas. Peristômio duas vezes mais largo que os demais segmentos do corpo; cirro peristomial atingindo a região posterior do primeiro setígero (figura 20a). Demais segmentos apresentando parapódios birremes (figura $20 \mathrm{c}$-d). Brânquias surgindo a partir do sexto setígero e ocorrendo até o $33^{\circ}$, de formato pectinado, com até 14 filamentos secundários saindo da haste principal (figura $20 \mathrm{~d}$ ); com comprimento igual ou ligeiramente maior que o cirro dorsal. Cirros dorsais cirriformes, ocorrendo a partir do segundo segmento e ocorrendo até a região fragmentada do corpo (figura 20 c); inseridos entre as brânquias e a base do 
parapódio Cirro ventral inserido próximo à base do neuropódio, ocorrendo em todos os setígeros, os com base inflada surgindo no quarto setígero e ocorrendo até o $48^{\circ}$, a partir destes tornam-se digitiformes.

Parapódios com lobos pós-cerdal maiores que os lobos pré-cerdal; apresentando até três acículas neuropodiais nos setígeros posteriores; as acículas superiores tendem a ser mais robustas que as inferiores (figura 20e), todas aumentam de diâmetro em direção à região posterior do corpo. Os ganchos sub-aciculares surgem a partir do $24^{\circ}$ setígero, apresentando uma coloração amarela, ocorrendo até dois ganchos por parapódios; com ponta bidentada (figura $20 \mathrm{f}-\mathrm{g}$ ), sendo o dente inferior mais robusto que o superior (figura 20g), abaixo do dente inferior surge uma espécie de cápsula que envolve a ponta do gancho.

As cerdas supra-aciculares são de dois tipos, capilar lisa (figura 20h) e pectinada, com até 10 dentes menores e dois dentes maiores nas laterais, com o dobro do tamanho dos menores. As cerdas subaciculares são compostas falcígeras, na base das lâminas surge um capuz que envolve a mesma, com a borda interna levemente serrilhada (figura 20i). Laminas bidentadas, com o dente superior ligeiramente maior que o dente inferior, todas com bordas lisas. As hastes das lâminas tornam-se mais largar próximo à articulação, nesta região mais larga apresentam pequenos dentículos, dando um aspecto serrilhado.

Discussão: Morfologicamente os espécimes são muto semelhante ao que foi descrito por Treadwell (1922) e Fauchald (1992).

Fauchald (1992) agrupa a espécie E. gracilicirrata com outras seis espécies, todas com gancho subacicular de coloração amarelada e com ponta dupla e a divisão entre os dois segmentos peristomiais parcial ou totalmente visível, porém das citadas pelo autor apenas $E$. stigmatura (Verril, 1900) é reportada para o Brasil. Dentre as espécies deste agrupamento proposto pelo autor, as duas espécies acima citadas, são as únicas que apresentam peristomial longo (indo até a metade do prostômio) e ceratóstilos com articulações longas; mas diferem quanto ao tamanho das brânquias, maiores que o cirro dorsal em E. gracilicirrata e do mesmo tamanho que o cirro dorsal em E. stigmatura.

Duas espécies morfologicamente aparentadas com E. gracilicirrata já foram encontradas na Bacia de Campos por Attolini (1997): E. websteri Fauchald, 1969 e E. vittata (delle Chiaje, 1828). Entretanto, em E. websteri os ganchos subaciculares possuem ambos os dentes de igual tamanho, além de as cerdas pectinadas possuírem os dentes com igual 
tamanho, enquanto que em E. gracilicirrata o dente proximal do gancho subacicular é menor que o distal e as cerdas pectinadas apresentam um dente externo maior que os internos. Já a espécie E. vittata apresenta até três ganchos subaciculares, além de estes possuírem cada um pontas tridentadas; enquanto que em E. gracilicirrata ocorrem no máximo dois ganchos subaciculares com pontas duplas.

Habitat: O material coletado no Pacifico foi encontrado no interior de tubos formados por conchas e pedras, assim como espécimes sobre corais, porém sem a formação e tubos. No Brasil a espécie foi encontrada estando associadas aos corais Solenosmilia variabilis e Lophelia pertusa e, assim como o material do Pacífico, estavam sobre os corais, sem construírem tubos.

Distribuição batimétrica: 750 - 1060m

Distribuição: Fiji (Oceâno Pacífico sul), Japão e Brasil (Bacia de Campo, Rio de Janeiro) (Oceano Atlântico Sul). 


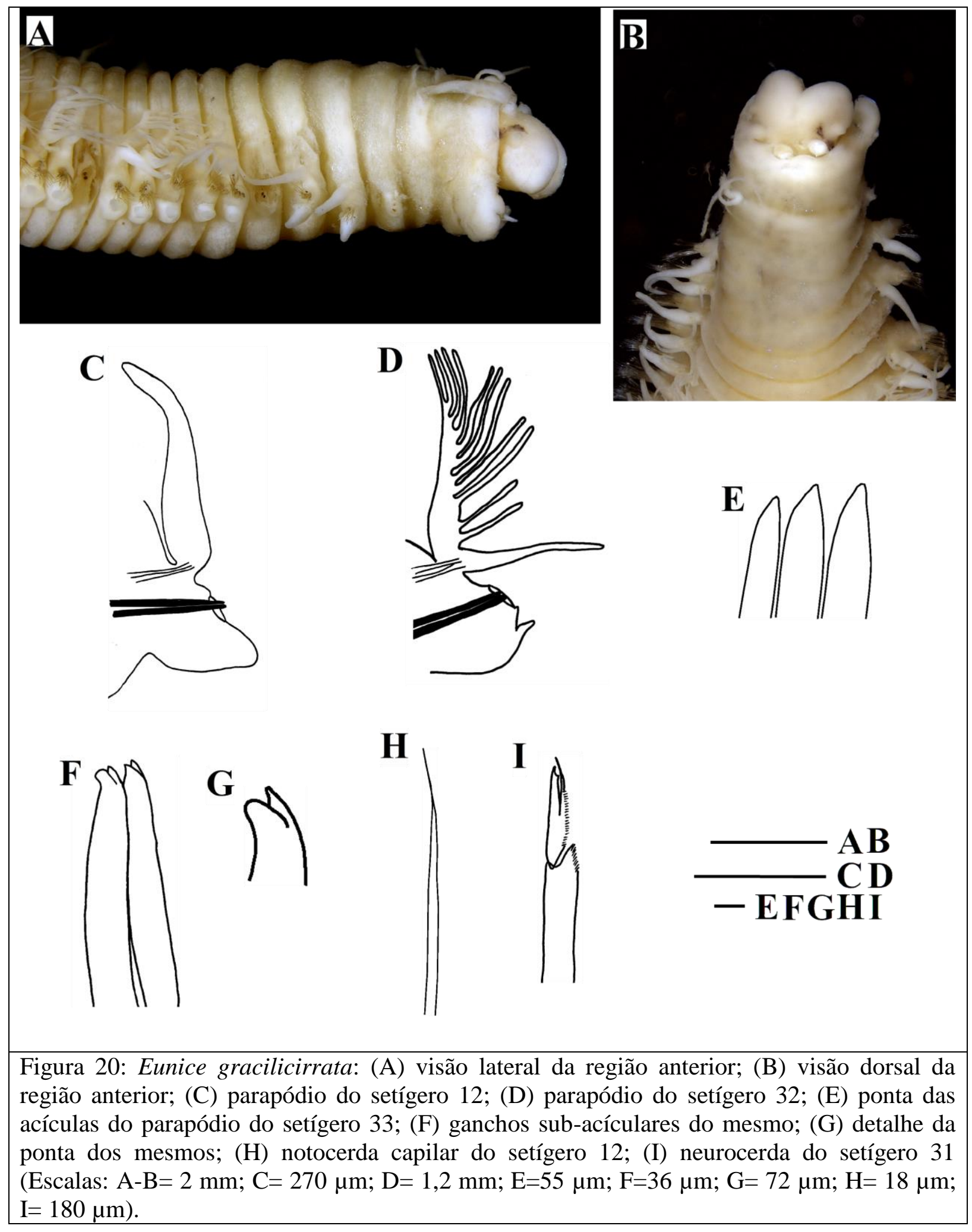




\section{Família Sabellidae}

Sub-família: Sabellinae

Gênero Euchone, Malmgren, 1866

Espécie tipo: Euchone (Sabella) analis (Kröyer, 1856)

Diagnose: Sabelíneos com, no mínimo, 3 pares de radíolos, esqueleto radiolar apresentando duas linhas de células. Algumas espécies podem apresentar membrana palmada, assim como franjas. Lábios dorsais com apêndices radiolares dorsais, possuem também os lábios ventrais. Apêndices radiolares ventrais presentes. Cintura glândular no segundo setígero. Notocerdas torácicas formando dois grupos transversais em baioneta e/ou encapuzadas. Neurocerdas abdominais limbadas, dispostas em duas fileiras transversais de tamanhos diferenciados. Uncini da região torácica no neuropódio; do tipo acícular. Notopódios abdominais anteriores com uncini não acículares, com peito bem desenvolvido e manúbrio ausente. Depressão anal anterior ao pigídio, ocupando, no mínimo, três setígeros abdominais.

\section{Euchone sp.}

(Figura: $21 \mathrm{a}-\mathrm{j}$ )

Material examinado: 3 espécimes. ECOPROF 11, 1 espécime, 604m 40 $7^{\prime}$ 35,41" W - 220 23' 7,55" S, 14/02/2009, em Enallopsammia rostrata; ECOPROF 11, 1 espécime, 599m, 40 8' 8,36" W - 220 23' 25,37", 14/02/2009, em Lophelia pertusa; ECOPROF 11, 1 espécime, 585m, 40 8' 34,29" W - 22 23' 24,43" S, 13/02/2009, em Enallopsammia rostrata.

Diagnose: Espécime com 16 radíolos, com pínulas filiformes. Três pares de apêndices radiolares ventrais. Corpo com 8 segmentos toráxicos e 20 segmentos abdominais, sendo que destes 8 formam a depressão anal. Cerdas toráxicas e abdominais apenas limbadas sendo o feixe superior sempre maior que o inferior. Uncinis toráxicos acículares com cinco a seis fileiras de dentes secundários sobre o dente principal; uncinis abdominais não acículares, em formato de "u" e também com cinco a seis fileiras de dentes secundários sobre o principal. Número de uncinis variando entre ao longo do abdômen, nos parapódios anteriores há entre sete e outo uncinis, já nos posteriores de 10 a 11 uncinis.

Descrição: Espécimes com 28 setígeros, radíolos $(12 \mathrm{~mm})$ mais longos que o corpo (10 mm) (figura 21a). Constrição mediana desde os setígeros torácicos até os abdominais, 
porém fica mais fraca em direção à região posterior do corpo (figura 21a). Coroa branquial formada por oito parés de radíolos, arranjados em dois feixes, cada um com duas fileiras de células esqueléticas. Três pares de apêndices radiolares ventrais e um par dorsal, presentes. Pinulas longas, maiores com $1 / 4$ do comprimento dos radíolos e as menores (mais ventrais) com 1/5 do comprimento dos radíolos; ponta dos radíolos filiformes (figura 21b). Anel peristomial formando um colar, com um par de lamelas ventrais sobrepondo-se levemente, ambas se fundindo à goteira fecal na região dorsal; ventralmente é mais curto que na região dorsal, porém em ambas as faces deixa exposta a base dos radíolos (figura 21a).

Torax composto por oito setígeros (figura 21a). Segundo setígero apresetando uma cintura glandular. Parapódios apresentando notocerdas limbadas (figura 21e), sendo as dorsais mais longas (figura 21c) e com limbo mais estreito que as ventrais (figura 21d). Neuropódio apresentando uma fileira de até 10 uncinis aciculares (figura 21g); cada uncini apresentando cinco a seis fileiras de dentes menores e secundários sobrepondo-se ao dente principal, sendo esses dentes menores de igual tamanho (figura 21h), manúbrio longo e terminando em ponta bifida.

Região abdominal composta por 20 setígeros (figura 21a). Parapódios anteriores (setigero nove) com notopódios apresentando entre sete e oito uncinis em formato de " $u$ " com peito bem desenvolvido, sem manúbrio e cinco a seis fileiras de dentes secundários sobre o dente principal (figura 21i), estes dentes secundários tornam-se maiores em direção ao dente principal; neuropódios com dois tipos de cerdas, as dorsais mais longas (dobro do tamanho das ventrais) e com limbo mais estreito (figura 21f), as ventrais em maior quantidade menores e com limbo mais largo. Parapódios posteriores ( $19^{\circ}$ setígero) com notopódios apresentando entre 10-11 uncinis, também em formato de " $u$ ", porém com o peito menos desenvolvido que o dos parapódios anteriores (figura $21 \mathrm{j}$ ), também sem manúbrio, cada uncini possui entre cinco ou seis fileiras de dentes secundários sobre o dente principal, que também torna-se maior em direção ao dente principal; neuropódio apresentando apenas um tipo de cerda, limbada e levemente recurvada. Útimo segmento abdominal sem cerdas ou uncinis.

Depressão anal iniciando no pigídio e se prolongando por 8 segmentos abdominais (figura 21a). Sem ocelos pigidiais.

Discussão: O gênero Euchone possui, atualmente, 33 espécies consideradas válidas. Neste gênero o número de segmentos abdomais se mantêm constante, apenas aumentam de tamanho ao longo do desenvolvimento (Cochrane, 2003; Fitzhugh, 2002). Estes mesmos 
autores destacam ainda que a proporção entre o número de segmentos abdominais, localizados anteriormente à prega anal, em relação ao número que forma a prega anal, apresentam um importante caráter taxonômico. Assim sendo, muitas espécies são identificadas baseando-se nesta combinação do número de segmentos (e.g.: 17 anteriores à prega/ 9 formando a prega anal em E. analis).

Levando-se em conta tal afirmação, apenas duas espécies, possuem a mesma proporção de segmentos (12 segmentos abdominais anteriores/8 segmentos posteriores formando a depressão anal) que Euchone sp., E. elegans Verril, 1873 e E. papillosa (Sars, 1851). No entanto na descrição de E. elegans é dito que essa espécie possui segmentos bianelados, característica essa que não é encontrado nos espécimes coletados na Bacia de Campos, além disso o sulco anal se prolonga por 10 setígeros em E. elegans, dois setígeros a mais do que os dos exemplares examinados neste trabalho. O mesmo autor descreve um tufo de cerdas maiores no último setígero, em Euchone sp, todas as cerdas abdominais desta região são de igual tamanho.

A espécie E. papillosa é a que mais se assemelha ao material coletado na Bacia de Campos, apresenta um número maior de setígeros abdominais que Euchone sp., os menores indivíduos analizados por Banse (1972) apresentaram 21 setígeros abdominais, este mesmo autor cita ainda um exemplar com 54 setígeros abdominais coletados no mar Báltico. Em adição, E. papillosa apresenta cerdas toráxicas espatuladas, esse tipo de cerda não foi encontrado em nenhum exemplar analisado neste estudo, todos os espécimes coletados possuem apenas cerdas limbadas ao longo do corpo. Os uncinis abdominais também diferem em ambas as espécies, já que em E. papillosa cada uncini pode apresentar de 10 a 15 fileiras de dentes secundários sobre o dente principal, um número muito maior que o encontrado em Euchone sp., que apresentou de cinco a seis dentes secundários.

Rossi (2008) registrou a primeira ocorrência do gênero Euchone na costa brasileira, no entanto a espécie ainda não foi formalmente descrita. Os espécimes analisados pela autora diferem dos exemplares analisados neste trabalho, por possuírem apenas cinco pares de radíolos, no espécime da Bacia de Campos há oito pares. Além disso, os uncinis toráxicos são recobertos por um pequeno capuz, característica não encontrada em nenhum dos exemplares analisados neste estudo. Os uncinis abdominais também são diferentes, nos exemplares da Bacia de Campos, pois possuem um peito retangular, podendo apresentar uma dentição em direção ao dente principal, já Rossi (2008) descreve seus exemplares como possuindo um peito triangular. Além destas 
características os espécimes observados pela autora, apresentam apenas 12 e 13 setígeros abdominais, dos quais cinco a seis formam a depressão anal, enquanto que todos os exemplares da Bacia de Campos apresentaram 20 setígeros abdominais, sendo oito formando a depressão anal.

Habitat: Espécie encontrada associada aos corais Enallopsammia rostrata e Lophelia pertusa, em tubos anexados ao esqueleto dos corais.

Distribuição batimétrica: 585 - 604m.

Distribuição: Conhecida apenas para a Bacia de Campos, noroeste do Rio de Janeiro, Brasil. 


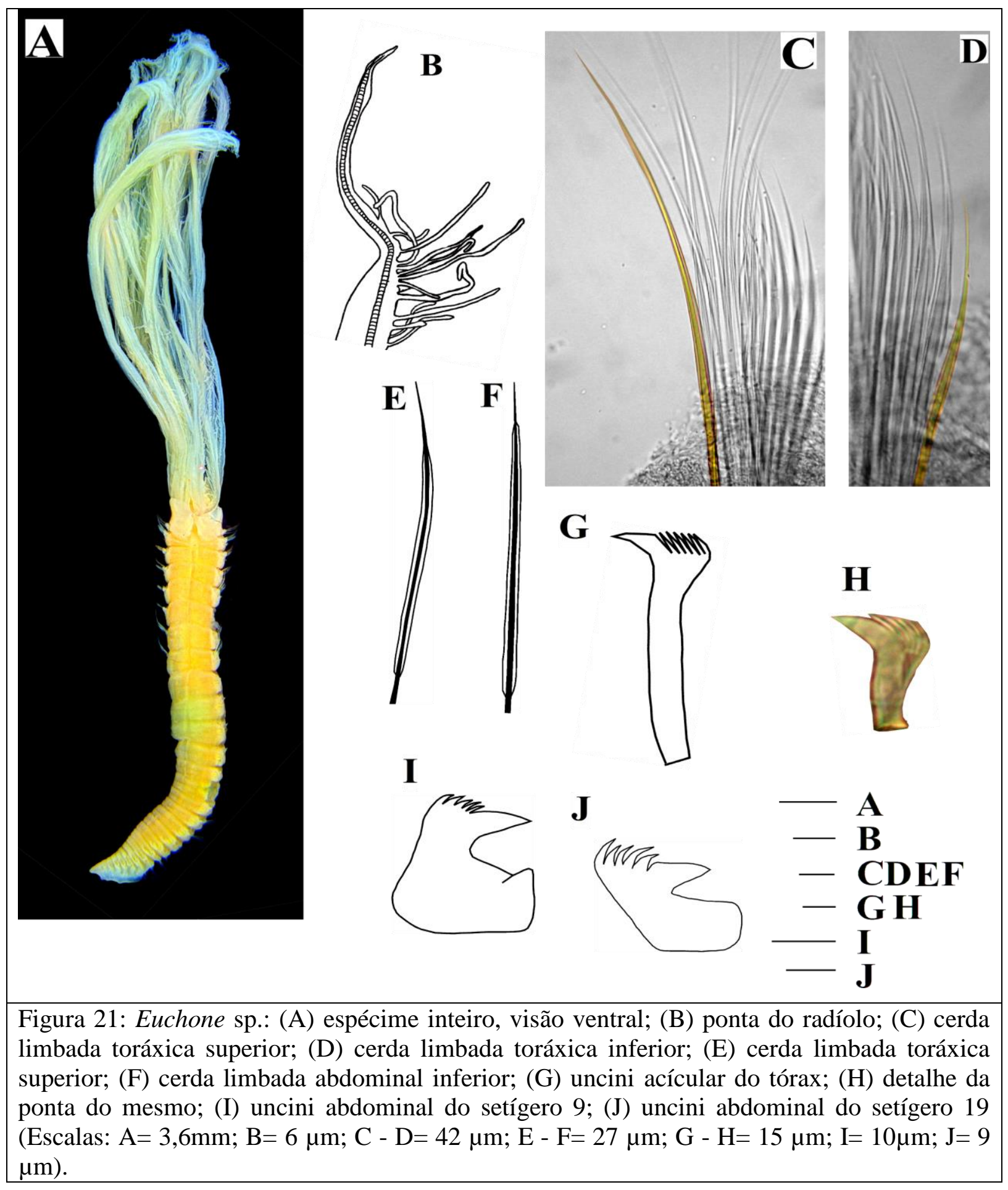




\section{Família Serpulidae}

Gênero Filogranula, Langerhans, 1884

Espécie tipo Filogranula gracilis, Langerhans, 1884

Diagnose: Tubo branco e opaco, com quilhas presentes. Opérculo com uma placa superficial quitinosa, podendo apresentar um espinho adicional ao centro da mesma; apresenta constrição opercular. Pedúnculo cilíndrico, liso e sem asas laterais, inserido como segundo radíolo dorsal. Pseudo-opérculo ausente. Os radíolos arranjados em dois semi-circulos, até sete por lobo. Não há membrana inter-radiolar e nem estilódios.

Sete setígeros toráxicos. Colar com bordas inteiras e dando segmento com a membrana torácica, terminando no segundo setígero torácico. Linguetas ("tonguelets") ausentes. Cerdas do colar, do tipo "fin-and-blade" e limbadas. Cerda do tipo apomatos presente em um ou mais segmentos torácicos. Unicini do toráx total ou parcialmente serrilhado, apresentando entre 12 e 14 dentes em perfil e, em linha, até cinco dentes acima da projeção anterior; dentes de formato obtusos. Cerda abdominal curta e triangular. Uncinis abdominais de bordo liso. Apresentam a região anterior do abdomem sem cerdas, mas posteriormente apresentam cerdas capilares.

\section{Filogranula revizee Nogueira \& Abbud, 2009}

(Figura: 22 )

Filogranula revizee: Nogueira \& Abbud, 2009: Fig. 1E-I, 9; Table 4.

Omphalopoma sp. Zibrowius, 1970: 12, plate I: 18-23.

Material examinado: 3 espécimes. ECOPROF 2, 1 espécime, 614m, 40 $6^{\prime}$ 51,13" W- 22 33' 43,51" S, 10/06/2008, em Solenosmilia variabilis; ECOPROF 9, 1

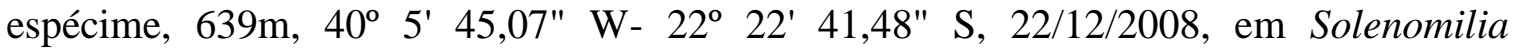
variabilis; ECOPROF 13, 1 espécime, 624m, 40 6' 11,36" W- 22 22' 32,91" S, 22/04/2009, em Enallopsammia rostrata.

Diagnose: Tubo branco, de formato semi-triangular, com as laterais lisas e com uma quilha central lisa. Espécimes com radíolos arranjados em dois semicírculos; opérculo distalmente em formato de bulbo, com uma leve concavidade superior, de onde surge um espinho liso e pontiagudo. Membrana toráxica se prolongando até a região posterior do segundo setígero toráxico. Parapódios toráxicos com uncini em formato de serra (com apenas uma linha de dentes) e cerdas limbadas. 
Descrição: Tubo quase triangular em vista transversal, com quilhas e laterais lisas. Espécime inteiro (Figura 22a), com a haste do opérculo derivada do segundo radíolo, com comprimento igual aos radíolos. Opérculo em forma de taça, com base carnosa e translucida, distalmente quitinizado, Dorsalmente apresenta uma coluna central recurvada de coloração amarelo escuro com a ponta quebrada rombuda (Figura 22a).

Coroa branquial com sete radíolos organizados em dois semicírculos. Colar com um par de lobos dorso-laterias e três lobos ventrais (lobo ventral direito um pouco menor que os outros dois). Membrana torácica atingindo o início do segundo setígero torácico. Não foi observada a presença de um escudo torácico ventral. Em ambos os lados do tórax uma linha delimita a porção final do neuropódio.

Colar apresentando dois tipos de cerdas, as limbadas (Figura 22d) e as do tipo "finand-blade” (Figura 22e), com lâmina levemente serrilhada. Cerdas limbadas presentes entre os setígeros dois e sete. Cerdas do tipo apomatus, aparecem entre o terceiro e sétimo setígero, porém estavam quebradas no material analizado. Neuropódios do tórax com uncinis serrilhados, apresentando entre 13 e 15 dentes (Figura 22b), a projeção anterior possui um aspecto que lembra um trapézio.

Neuropódios abdominais apresentando um par de cerdas geniculadas, com lâminas serrilhadas (Figura 22f). Últimos quatro a seis setígeros apresentando cerdas capilares. Notopódios abdominais com uncinis de dentição muito pequena e fina (Figura 22c); os notopódios abdominais anteriores visivelmente com menor quantidade de linhas de dentições do que os localizados posteriormente. No último segmento uma pequena almofada glândular está presente acima do orifício do ânus.

Discussão: O material aqui examinado é semelhante a espécie descrita por Nogueira \& Abbud (2009). Estes mesmos autores relatam, algumas variações morfológicas encontradas no seu material examinado variações estas também encontradas nos exemplares da Bacia de Campos. Entretanto, como possuímos apenas um único exemplar completo e em bom estado optou-se por não analisa-lo utilizando microscopia eletrônica de varredura, podendo assim ter perdido algumas características como o número de dentições nas cerdas do tipo "fin-and-blade”, bem como de detalhes maiores dos uncinis.

Habitat: O presente espécime foi encontrado associado aos corais Solenosmilia 


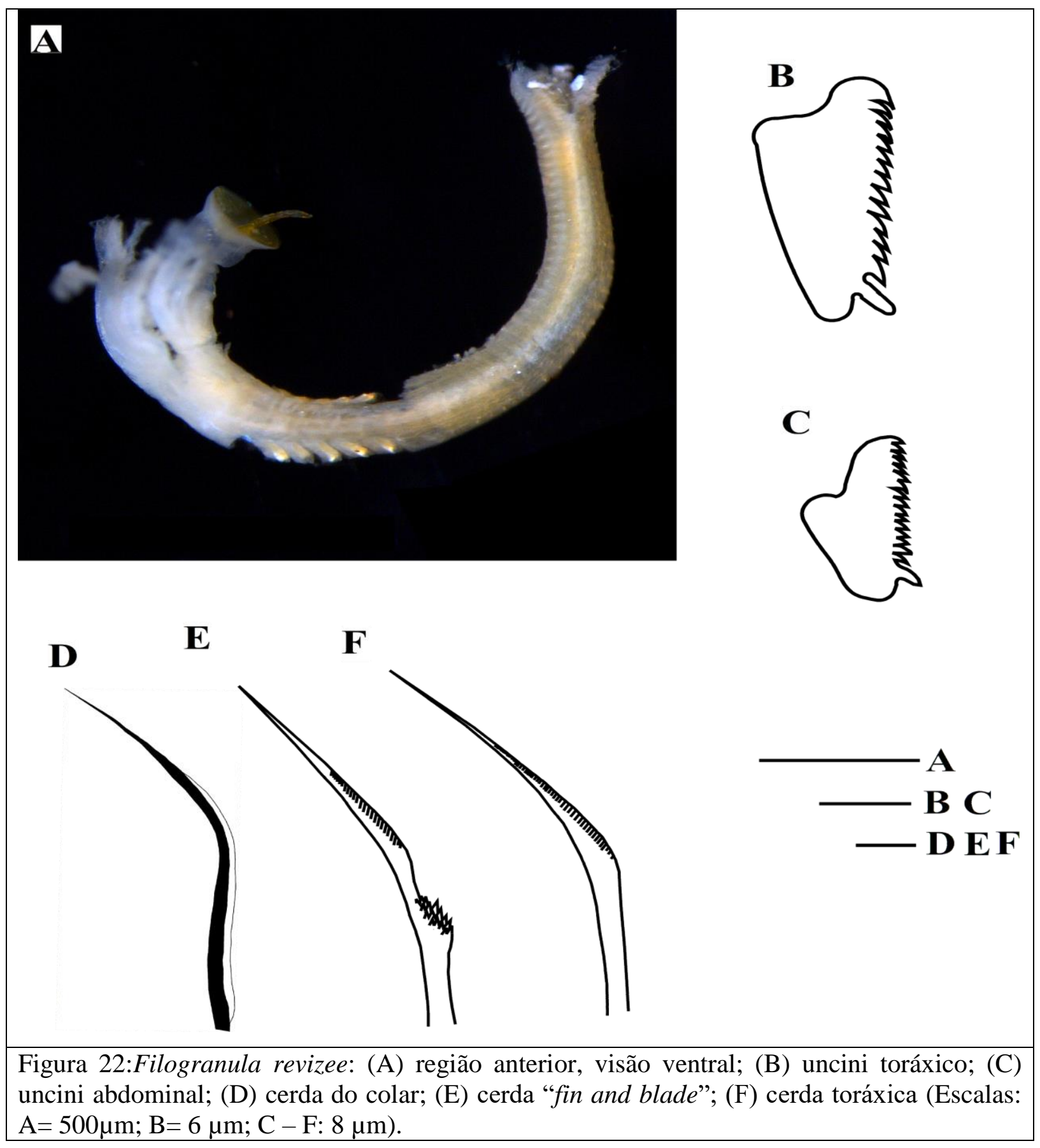

variabilis e Enallopsammia rostrata. Infelizmente Nogueira \& Abbud (2009) não informaram o tipo de substrato a que estavam associados os espécimes por eles descritos.

Distribuição batimétrica: 100 - 639m.

Distribuição: Atualmente só é registrada a ocorrência da espécie para o Brasil, primariamente só era conhecida para a região entre Paraná e São Paulo, essa é a primeira ocorrência desta espécie no Rio de Janeiro, na Bacia de Campos. 


\section{DISCUSSÃO}

O ambiente bentônico profundo, do Atlântico Sul, é um dos menos estudados e amostrados em todo o planeta, podendo abrigar uma grande diversidade de espécies ainda não descobertas (Rex et al., 2006; Fiege et al., 2010). Os bancos de corais dessa parte do Atlântico são ainda menos conhecidos em termos de diversidade associada, com poucos trabalhos abordando a diversidade e a ecologia desse ambiente coralíneo (e.g. Sumida et al., 2004; Brasil et al., 2007). O Brasil possui a quarta maior diversidade de corais de profundidade do planeta (Roberts et al., 2009), apesar disso ainda estamos começando a entender esse importante ambiente de profundidade e suas associações faunísticas. Em contrapartida pesquisas sobre esse ambiente, conduzidas por outros países, é diferente, as pesquisas atualmente buscam compreender como funciona este ambiente, as adaptações das espécies para a vida nestes locais, assim como a real conectividade entre as populações (Roberts et al., 2006; 2009).

Esta dissertação apresenta o primeiro estudo realizado sobre a fauna de poliquetas associados aos bancos de corais de profundidade da costa brasileira, assim como do Atlântico Sul. A diversidade de poliquetas associados aos bancos de corais, se comparado com outros trabalhos, foi muito baixa. Em um levantamento sobre a fauna associada ao coral L. pertusa, Jensen \& Frederiksen (1992), registram 67 espécies de poliquetas, Cordes et al. (2008), Mastrototaro et al.(2010) registram em torno de 24 espécies, números mais próximos dos encontrados para os corais da Bacia de Campos. Porém esses trabalhos foram feitos apenas com L. pertusa, enquanto que o projeto ECOPROF coletou cinco espécies e o projeto CAPBC todas as espécies coralíneas encontradas nos transectos (incluindo as cinco do ECOPROF). O baixo número de espécies encontradas, em relação aos trabalhos citados, pode ser devido a um menor esforço amostral dos projetos CAP-BC e ECOPROF quando comparados com outras campanhas realizadas nos outros projetos. Jensen \& Frederiksen (1992), Cordes et al. (2008) e Mastrototaro et al. (2010) por exemplo, realizam mais de uma campanha em um mesmo banco de corais, com uso de metodologia mais adequadas para coleta de espécies associadas e obtendo como uma maior diversidade. Apesar dos projetos CAP-BC e ECOPROF terem amostrado uma área muito maior que os trabalhos acima citados, o esforço de coleta em cada banco foi menor, por vezes um banco era amostrado uma única vez, retirando um exemplar de cada coral encontrado, sem que houvesse uma replicação da 
amostra em cada espécie de coral ou preocupação com padronização das amostras, já que os objetivos desses projetos eram diferentes dos trabalhos acima citados.

A metodologia de coleta aplicada é outro fator que pode influenciar a diversidade encontrada. Mortensen \& Fosså (2006) comparam os métodos de coletas de corais de profundidade mais comuns: uso de ROVs, arrasto de fundo e uso de busca fundo (Van veen), esses autores desaconselham o uso de ROVs, pois essa técnica apesar de possibilitar uma escolha de melhores corais, mas não permite uma coleta homogênea dos corais, além de não preservar a fauna associada na sua totalidade, que muitas vezes são perdidos durante o transporte até os recipientes e ao navio. O uso de redes de arrasto, apesar de coletar uma grande quantidade de corais e das faunas pelágica e bentônica associada (e.g. Jensen \& Frederiksen, 1992) não proporciona uma amostragem com a mesma quantidade de corais, além do fato de as amostras acabarem todas juntas no interior da rede, podendo até mesmo causar danos a mesma por conta dessa mistura, além de causar um grande dano ambiental. A alternativa, segundo eles, seria o uso de busca fundo (Van-veen) com uma câmera acoplada que garante a acurácia e homogeneidade da coleta e a integridade da fauna associada, o que não é possível ao se utilizar as outras técnicas. Cordes et al. (2008) faz uso de uma outra técnica muito parecida, na qual utiliza um corer adaptado ("bushmaster") para ser usado por ROVs que apresenta resultados muito próximo dos encontrados com uso do Van-veen no trabalho de Mastrototaro et al. (2010). Os projetos CAP-BC e ECOPROF utilizaram apenas ROVs, sem qualquer adaptação para a coleta de amostras biológicas que podem ter resultado numa perda muito grande de fauna associada, tanto na hora de coleta, espantando alguns espécimes com maior poder de deslocamento quanto durante o transporte até o recipiente.

A morfologia do banco de coral está diretamente relacionada com a riqueza de espécies que ele abriga, já que em bancos mais tridimensionais, ou seja, com corais em forma de arbustos, o ambiente é mais protegido de predadores e das correntes marinhas (Roberts et al. 2006; Fiege \& Barnich, 2009). Dos corais analisados neste trabalho, as espécies L. pertusa, $S$. variabilia e $M$. oculata, são as que possuem um formato arbustivo (com ramos crescendo em altura, largura e profundidade), resultando numa elevada complexidade espacial e tridimensional, além de poderem atingir atingirem até $10 \mathrm{~m}$ de altura no Mar do Norte (Roberts et al., 2009). Já os corais Errina sp. e E. rostrata, possuem uma complexidade estrutural menor, com um formato mais bidimensional já que os ramos crescem apenas em altura e largura, resultando em uma área menos abrigada quando comparados com os outros corais. Essa diferença de conformação estrutural pode influenciar na associação dos 
poliquetas encontrados como observado por Berlandi et al. (2012) em seu trabalho com bancos de rodolitos, onde diferentes morfologias dos rodolitos (com estruturas espaciais mais ou menos complexas) abrigam diferentes espécies de poliquetas. Entre os corais essa diferença pode ser observada, por exemplo, nos fato de em gorgônia e hidrocorais apresentarem um maior número de polynoideos e syllideos, endêmicos, do que outras espécies de corais como L. pertusa ou M. oculata (corais com conformação tridimensional) (Pettibone, 1991 a,b; Martin et al., 2002; Buhl-Mortensen \& Mortensen, 2004; Fiege \& Barnich, 2009).

Dentre os corais formadores de recifes na Bacia de Campos, em termos de poliquetafauna, S. variabilis foi a espécie que apresentou uma tendência a maior diversidade, além de sustentar também uma maior abundância das espécies (à exceção da espécie $N$. maculata, que foi mais abundante em Errina sp.). Em segundo E. rostrata também apresentou grande diversidade, sendo que em abundância de espécies isso foi verificado para L. pertusa. Esses dados vão de encontro a trabalhos prévios sobre a comunidade associada aos corais de profundidade (e.g. Jensen \& Frederiksen (1992), Cordes et al. (2008) e Mastrototaro et al. (2010)), os quais apontam o coral L. pertusa como detentor de uma grande diversidade, porém nos locais amostrados nestes trabalhos esse era o coral com a maior densidade na área amostrada. O fato de, na Bacia de Campos, L. pertusa não possuir a maior diversidade de poliquetas, pode estar relacionado tanto aos problemas de amostragens discutidos acima, quanto pelo fato de, provavelmente, não ser o coral mais abundante na área de coleta. Essa diferença de diversidade entre os corais é mais um motivo, pelo qual estudos mais detalhados e com uma metodologia mais adequada para análises quantitativas, precisam ser realizados para se compreender a associação entre os poliquetas e os corais, já que esta é uma lacuna existente não apenas para a costa brasileira, mas em todos os trabalhos sobre comunidade associada aos corais de profundidade.

Apesar de ser um dos grupos mais abundantes, muito pouco se sabe sobre o papel dos poliquetas nas associações com os corais (Buhl-Mortensen \& Mortensen, 2004; Roberts et al., 2006), as espécies deste grupo apesar de terem sido encontradas no ambiente recifal podem não possuir uma relação íntima com os corais mas sim com o ambiente criado por estes. Essa afirmação é reforçada pelo fato de todas as espécies descritas neste trabalho não terem sido reportadas em nenhum outro trabalho, realizado na Bacia de Campos, nos quais amostrou-se o sedimento (e.g. Attolini 1997, 2002; Barroso, 2010), essas espécies ocorreram apenas em meio aos corais. Além disso, os espécimes de Leocratides, por exemplo, neste trabalho 
estavam no interior de esponjas, que usavam os corais como substrato para incrustação, esses poliquetas não possuem relação direta com o coral e sim com a esponja que utiliza o coral como suporte. Outra espécie, G. magellanica, é encontrada predominantemente em sedimento lamoso (Böggemann, 2002), possivelmente, essa espécie tem mais relação com sedimento aprisionado no interior da colônia do que com o coral.

O eunicideo E. norvegica é o poliqueta, associado aos corais de profundidade, mais bem estudado (e.g. Mortensen (2001), Roberts (2005) e Muellet et al. (2013)), no entanto, essa espécie não ocorre nos corais de profundidade da costa brasileira. Porém outras duas espécies de eunicídeos ocorrem em meio aos corais, E. prognatha e E. gracilicirrata, sendo a primeira em maior densidade, e é possível que ambas ou uma das espécies podem estar ocupando o mesmo nicho de E. norvegica nos bancos de corais do Atlântico Sul, atuando da mesma forma já reportada, para essa espécie, em outros estudos no Atlãntico Norte (Mortensen (2001), Roberts (2005) e Muellet et al. (2013)), Os silídeos (H. ohma e P. procera) e os nereidídeos ( $N$. maculata) foram encontrados ou no interior dos esqueletos das colônias, em partes antes ocupados pela parte mole dos corais, ou no interior das cavidades gástricas dos corais. $\mathrm{O}$ fato de estarem em áreas antes ocupadas pelos pólipos não significa que essas espécies se alimentam dos mesmos, pode ser que apenas aproveitaram o espaço vazio para se alojarem. Assim como para Haplosyllis villogorgicola Martin et al. 2002, alguns espécimes de $P$. procera e $N$. maculata também foram retirados de cálices ainda com pólipos vivos entretanto, como apontado por Martin et al. (2002), sem uma observação dos espécimes vivos não é possível afirmar se esses indivíduos se encontravam nesse local para se alimentarem do pólipo, se são cleptoparasitas ou se apenas competem pelo espaço com o cnidário. Esse mesmo questionamento surge a respeito da espécie $N$. crinita, coletada dentro do cálice de um pólipo de S. variabilis, pois Fauchald \& Jumars (1979) descrevem os amphinomídeos como predadores de esponjas e corais, no entanto Ebbs (1966) relata que essa espécie apenas usa os corais como um ambiente, não necessariamente se alimentando destes.

Apesar do foco da amostragem em ambos os projetos (ECOPROF e CAP-BC) não ter sido para o estudo da fauna associada, este estudo ampliou o conhecimento sobre a fauna de poliquetas da costa brasileira, cerca de $50 \%$ das espécies encontradas entre os corais são novas ocorrências para a costa brasileira, outros $30 \%$ são novas espécies para a ciência que necessitam ser formalmente descritas e apenas $20 \%$ são espécies que já se sabiam ocorrer no Brasil. No entanto, é fundamental a observação dos poliquetas ainda vivos em interação com as colônias de corais, como realizado por Mortensen (2001), Roberts (2005) e Mueller et al. 
(2013), de forma a elucidar o papel desempenhado por cada espécie nesta interação, assim como determinar se essas interações são fixas ou livres. Este estudo taxonômico é um início, do que ainda pode ser descoberto em termos de fauna de poliquetas associadas aos corais de profundidade em nossa costa. Novos projetos devem ser realizados, levando-se em conta um aumento do esforço de coleta, com uma ampliação da área estudada, aliado a uma metodologia adequada de coleta tanto dos corais quanto da fauna associada, o que pode ampliar o número de espécies se associando aos corais e prover material para outros estudos de cunho ecológico, taxonômico e molecular. 


\section{CONCLUSÃO}

Há pouquíssimos estudos sobre aos corais de profundidade e para a região do Atlântico Sul apenas dois trabalhos foram encontrados, expondo uma grande lacuna de conhecimento nessa região.

A Bacia de Campos é um dos ambientes de profundidade que atualmente está melhor sendo estudado em toda a costa brasileira. Este trabalho foi o primeiro a abordar a poliquetafauna associada aos bancos de corais em profundidade no Brasil, 50\% das espécies encontradas entre os corais são novas ocorrências para a costa brasileira, outros $30 \%$ são novas espécies para a ciência que necessitam ser formalmente descritas e apenas $20 \%$ são espécies que já se sabiam ocorrer no Brasil

Projetos com novas propostas amostrais e metodológicas adequadas devem ser elaborados para o real conhecimento desse ambiente em conjunto com estudos taxonômicos específicos para cada grupo de táxons coletados. Apenas dessa forma será possível conhecer melhor a diversidade que o ecossistema de corais profundo brasileiro abriga.

O coral S. variabilis apresentou uma diversidade maior de poliquetas associadas, porém como a metodologia de coleta não tinha como objetivo direto o estudo da fauna associada, muitas das relações de diversidade e densidade devem ser observadas com cautela. A diferença de estudos sobre a fauna associada a corais de profundidade no Atlântico Sul quando comparada a outros locais do mundo dificulta discussões mais gerais em termos biogeográficos. Neste trabalho foram reportadas espécies oriundas de províncias biogeográficas distintas, tais como Caribe, extremo sul da America do Sul e Africa. Estudos focados em análises filogeográficas deveriam ser realizados a fim de se elucidar com qual província biogeográfica os corais de profundidade e a fauna de poliqueta possuem maior conectividade. 


\section{REFERÊNCIAS BIBLIOGRÁFICAS}

ALTHAUS, F., WILliAMS, A., SCHLACHER, T.A., KLOSER, R.J., GREEN, M.A., BARKER, B., BAX, N.J., BRODIE, P., HOENLINGER-SCHLACHER, M.A. Impacts of bottom trawling on deep-coral ecosystems of seamounts are long-lasting. Marine Ecology Progress Series 397, 279-294. 2009.

AMARAL A.C. \& NONATO E.F. Anelídeos Poliquetas da Costa Brasileira. Aphroditidae e Polynoidae. CNPq. Brasilia 3. 1982. Pp.: 1-46.

AMARAL, A.C.Z.; LANA, P.C.; RIZZO, A.E.; STEINER, T.M.; PARDO, E.V.; SANTOS, C.S.G.; CARVALHO, A.C.; WAGNER, M.F.R.; GARRAFFONI, A.R.S., BRASIL, A.C.; RIBEIRO, Z.; NOGUEIRA, J.M.M.; ABBUD, A.; ROSSI, M.C.S. \& FUKUDA, M.V. Filo Annelida - Classe Polychaeta. In: Biodiversidade Bentônica da Região Sudeste-Sul do Brasil - Plataforma Externa e Talude Superior. Série Documentos Revizee: Score Sul / Responsável Carmen Lucia Del Bianco Rossi-Wongtschowski, Amaral, A.C.Z. \& Rossi-Wongtschowski, C.L.D.B. (eds.), MMA, 2004. p. 114-125.

AMARAL, A.C.Z.; NALLIN, S.A.H.; STEINER, T.M.; FORRONI, T.O. \& GOMES FILHO, D. Catálogo das espécies de Annelida Polychaeta do Brasil. Disponível em: http://www.ib.unicamp.br/museu_zoologia/files/lab_museu_zoologia/Catalogo_Polyc haeta_Amaral_et_al_2012.pdf. 2006-2012 (consultado em 20/01/2013).

ANDREWS, E. A. Report upon the Annelida Polychaeta of Beaufort, North Carolina. Proceedings of the United States National Museum, 14(852): 277-302. 1891.

ARANTES, R., CASTRO, C., PIRES, D., SEOANE, J. Depth and water mass zonation and species associations of cold-water octocoral and stony coral communities in the southwestern Atlantic. Marine Ecology Progress Series 397, 71-79. 2009.

ARWIDSSON, I. Studien über die Familien Glyceridae und Goniadidae. Bergens museums årbog, 1898(11): 1-69. 1899.

ASSIS, J.E. De, AZEVEDO, E. De, BEZERRA, S., BRITO, R.J. De, GONDIM, I., CHRISTOFFERSEN, M.L. An Association between Hesione picta (Polychaeta: 
Hesionidae) and Ophionereis reticulata (Ophiuroidea: Ophionereididae) from the Brazilian Coast. Zoological Studies 51, 762-767. 2012.

ATTOLINI, F.S. Composição e Distribuição dos Anelídeos Poliquetas na Plataforma Continental da Região da Bacia de Campos, RJ, Brasil. Dissertação de Mestrado, Instituto Oceanográfico, Universidade de São Paulo. 1997. 122p.

ATTOLINI, F.S. Padrões de Distribuição de Poliquetas Macrobentônicos na Região de Plataforma Externa e Talude Superior Entre Cabo Frio (RJ) e Cabo de Santa Marta (SC), Costa Sudeste do Brasil. Tese de Doutorado, Instituto Oceanográfico, Universidade de São Paulo. 2002. 115p.

AUGENER, H. Die bodensässigen Polychäten nebst einer Hirudinee der Meteor-Fahrt. Mitteilungen der Zooologisches Staatinstitut und zoologisches Museum, Hamburg, 44: 279-313. 1931.

AUGENER, H. Polychaeta. Beitrage zur Kenntnis der Meeresfauna Westafrikas, 2(2): 67625. 1918.

AUGENER, H. Reports on the results of dredging, under the supervision of Alexander Agassiz, in the Gulf of Mexico and the Caribbean Sea, and on the east coast of the United States, 1877 to 1880 , by the U.S. Coast Survey Steamer Blake, Lieut. Commander C.D. Sigsbee, U.S.N., and Commander J.R. Bartlett, U.S.N. commanding. 42. Westindische Polychaeten. Bulletin of the Museum of Comparative Zoology 43(4): 91-196. 1906.

AVERINCEV, V.G. The Polychaetous Annelids of the Aphroditiformia of the Shelf and Upper Bathial of Australian and New Zealand Region and of Macquarie Island (on the Base Data of 16th Cruise of R/V DM. Mendeleev). Transactions of the P.P.Shirov Institute of Oceanology Academy of Sciences of the USSR, Moscow 113: 51-72. 1978.

BANSE, K. Redescription of some species of Chone Kroyer and Euchone Malmgren, and three new species (Sabellidae, Polychaeta). Fishery Bulletin, v. 70, n. 2, p. 459-495, 1972. 
BARNICH, R.; FIEGE, D. Revision of the Mediterranean species of Harmothoe Kinberg, 1856 and Lagisca Malmgren, 1865 (Polychaeta: Polynoidae: Polynoinae) with descriptions of a new genus and a new species. Journal of Natural History, v. 34, n. 10, p. 1889-1938, out. 2000.

BARNICH, R.; FIEGE, D. The Aphroditoidea (Annelida:Polychaeta) of the Mediterranean Sea. 1. ed. Frankfurt a. M.: Abhandlungen der Senckenbergischen Naturforschende Gesellschaft, 2003. p. 167

BARROSO, R. \& PAIVA, P. C. A new deep-sea species of Chloeia (Polychaeta: Amphinomidae) from southern Brazil. Journal of the Marine Biological Association of the United Kingdom, v. 91, p. 419-423. 2011.

BARROSO, R. \& PAIVA, P.C. 2008. A new deep sea species of Paramphinome (Polychaeta: Amphinomidae) from southern Brazil. Journal of the Marine Biological Association of the United Kingdom, v. 88, p. 743-746.

BARROSO, R. \& PAIVA, P.C. Polychaeta de mar profundo do Sudeste do Brasil, 2o Simpósio Latino-Americano de Polychaeta, Argentina, p. 96. 2009.

BARROSO, Rômulo Baptista. Anelídeos poliquetas das famílias Amphinomidae, Opheliidae, Syllidae e Paraonidae de oceano profundo da Bacia de Campos , Sudeste do Brasil. Universidade Federal do Rio de Janeiro, 191p. 2011.

BENHAM, W. B. Polychaeta. Australian Antarctic Expedition 1911-14, under the leadership of Sir Douglas Mawson, D.Sc.B.E. Scientific Reports, series C. Zoology and Botany, 6(3): 1-128, plates 5-10. 1921.

BERLANDI, Raquel Meihoub. Biodiversidade de Poliquetas em três bancos de algas calcárias (rodolitos) na costa leste brasileira. Universidade Federal do Rio de Janeiro, 197p. 2010.

BLAINVILLE, H. Mémoire sur la classe des Sétipodes partie des Vers á sang rouge de M. Cuvier, et des Annélides de M. de Lamarck. Bulletin des Sciences par la Société Philomatique de Paris: 77-85. 1818.

BÖGGEMANN, M. Revision of the Glyceridae Grube 1859 (Annelida: Polychaeta). Abhandlungen der Senckenbergischen naturforschenden Gesellschaft 555: 1-249. 2002. 
BONGIORNI, L., MEA, M., GAMBI, C., PUSCEDDU, a., TAVIANI, M. and DANOVARO, R. Deep-water scleractinian corals promote higher biodiversity in deep-sea meiofaunal assemblages along continental margins. Biological Conservation 143, 1687-1700. 2010.

BRASIL, A.C.S., PAIVA, P.C., CAVALCANTI, G.H. \& FERNANDEZ, M.P.C. Deep-sea polychaetes associated with coral banks of Campos Basin: first records for the Brazilian continental margin, Southwest Atlantic. 9th International Polychaete Conference, p.101. 2007.

BRITAYEV, T. A., KRYlOVA, E. M., MARTIN, D., COSEL R. von, AKSIUK T. S. Symbiont - host interraction in the association of the scaleworm Branchipolynoe aff . seepensis ( Polychaeta: Polynoidae) with the hydrothermal mussel , Bathymodiolus spp . ( Bivalvia : Mytilidae ) Internation. International Research : Biological Studies, v. 12, n. 2, p. 13-16, 2003.

BRITAYEV, T.A., ZAMISHLIAK, E.A. Association of the commensal scaleworm Gastrolepidia clavigera ( Polychaeta : Polynoidae ) with holothurians near the coast of South Vietnam. Ophelia 45, 175 - 190. 1996.

BRITO, M. C., NUÑES, J. and BACALLADO, J. J. Polynoidae (Polychaeta) from the Canary Islands, Bulletin Marine Sciences, 48(2), 180 - 188pp. 1991.

BUHL-MORTENSEN P. Aquarium observations on the deep-water coral Lophelia pertusa (L., 1758) (scleractinia) and selected associated invertebrates. Ophelia 54: 83-104. 2001.

BUHL-MORTENSEN, L., MONRTENSEN, P.B. Distribution and diversity of species associated with deep-sea gorgonian corals off Atlantic Canada. Cold-water Corals and Ecosystems. 849-879. 2005.

BUHL-MORTENSEN, L., MORTENSEN, Pal, B. Symbiosis in Deep-Water Corals. Symbiosis 37, 33-61. 2004.

BUZHINSKAJA, Galina N. Polychaetes off the coast of Jankich Island (Ushishir Islands, Kuril Islands). Trudy Zoologicheskogo Instituta Akademiia Nauk SSSR, 218: 18-35. 1990. 
CARNEY R.S. Zonation of Deep biota on continental margins. Oceanography and Marine Biology: An Annual Review, 43: 211-278. 2005

CARRANZA, A., RECIO, A.M., KITAHARA, M., SCARABINO, F., ORTEGA, L., LÓPEZ, G., FRANCO-FRAGUAS, P., MELlO, C., ACOSTA, J., FONTAN, A. Deepwater coral reefs from the Uruguayan outer shelf and slope. Marine Biodiversity 42, 411-414. 2012.

CASTRO CB, PIRES DO, MEDEIROS MS, LOIOLA LL, ARANTES RCM, THIAGO CM, BERMAN E Cnidaria. In: Lavrado HP, Ignacio BL (eds) Biodiversidade bêntica da costa central da Zona Econômica Exclusiva Brasileira. Museu Nacional, Rio de Janeiro, Livro 14. 2006. p 147-192

CHAMBERLIN, Ralph V. The Annelida Polychaeta [Albatross Expeditions]. Memoirs of the Museum of Comparative Zoology at Harvard College, 48: 1-514. 1919.

CHIAJE, S. delle. Memorie sulla sioria e notomia degli animali senza vertebre del Regno di Napoli. Volume 3, 232 pages. Naples. 1928

CLAPARÈDE, É., METSCHNIKOW, E. Beitraege zur Kenntnis der Entwicklungsgeschichte der Chaetopoden. Zeitschrift für wissenschaftliche Zoologie, 19: 163-205,6plates. 1869.

COCHRANE, S. J. Snowflakes and feather-dusters - some challenges for soft-bottom fanworm systematics. Hydrobiologia. 497: 49-62. 2003.

CORDES, E. E.; MCGINLEY, M. P.; PODOWSKI, E. L.; BECKER, E. L.; LESSARDPILON, S.; VIADA, S. T.; FISHER, C. R. Coral communities of the deep Gulf of Mexico. Deep-Sea Research I, v. 55, p. 777- 787, 2008.

COSTA-PAIVA, E. M.; PAIVA, P. C.; KLAUTAU, M. Anaesthetization and fixation effects on the morphology of sabellid polychaetes (Annelida: Polychaeta: Sabellidae). Journal of the Marine Biological Association of the United Kingdom, n. 87, p. 1127$1132,2007$.

CUVIER, G. Le Regne animal distribue d'apres son organisation, pour servir de base a I'hisloire naturelle des animaux et d'introduction a Vanatomie comparie: Les 
Reptiles, les Poissons, les Mollusques et les Annilides. Volume 2, 532 pages. Deterville Libraire, Paris. 1817.

DAY, J.H. Polychaeta of Southern Africa. Part 1. Errantia. British Museum (Natural History), London. 1967. 458pp

DAY, J.H. The Polychaet [sic] fauna of South Africa. Part 5. Errant species dredged off Cape coasts. Annals of the South African Museum, 45(3): 261-373. 1960.

DI CAMILlO, C.G., MARTIN, D., BRITAYEV, T.A. Symbiotic association between Solanderia secunda (Cnidaria, Hydrozoa, Solanderiidae) and Medioantenna variopinta sp . nov . (Annelida, Polychaeta, Polynoidae) from North Sulawesi (Indonesia). Helgol Marine Research 495-511. 2010.

DUNCAN, P.M. A description of the Madreporaria dredged up during the expeditions of H.M.S. "Porcupine" in 1869 and 1870. Transactions of the Zoological Society of London, 8(5), 303-344, pls. 39-49. 1873.

EBBS, N. The coral-inhabiting polychaetes of the northern Florida reef tract. Pt.1. Aphroditidae, Polynoidae, Amphinomidae, Eunicidae and Lysa- retidae. Bulletim of Marine Science, 16(3): 484-555. 1966.

EHLERS, E. Die bodensassigen Anneliden aus dern Sammlungen der deutschen TiefseeExpedition. Wissenschaftliche Ergebnisse der deutschen Tiefsee-Expedition auf dem Dampfer 'Valdivia' 1898-1899. 16, 1-168. 1908.

FAUCHALD, K. A Review of the Genus Eunice (Polychaeta: Eunicidae) Based upon Type Material. Smithsonian Contributions to Zoology, n. 523, p. 1-422, 1992.

FAUCHALD, K. A Revision of Six Species of the Flavus -Bideniatus Group of Eunice (Eunicidae: Polychaeta). Smithsonian Contributions to Zoology, 6: 15 pages, 6 figures, 1 table. 1969.

FAUCHALD, K., JUMARS, P.A. The diet of worms : a study of POLYCHAETE feeding guilds. Oceanography and Marine Biology, Annual Review 193-284. 1979.

FAUVEL, P. Annélides Polychètes de l'Indochine receuillies par M. C. Dawydoff. Commentationes, Pontificia Academia Scientiarum, annual, 3: 243-368. 1939. 
FAUVEL, P. Polychètes errantes. Faune de France. Volume 5. 1-488. Librairie de la Faculte des Sciences. Paris. 1923.

FIEGE, D.; BARNICH, R. Polynoidae ( Annelida : Polychaeta ) associated with cold-water coral reefs of the northeast Atlantic and the Mediterranean Sea. Zoosymposia 2, p. 149-164. 2009.

FITZHUGH, K. Fan worm polychaetes (Sabellidae: Sabellinae) collected during the ThaiDanish Bioshelf Project. Phuket Marine Biology Research Bulletim. 24: 353-424. 2002.

FITZHUGH, K. A systematic revision of the Saellidae-Caobangidae-Sabellongiidae complex (Annelida: Polychaeta). Bull. Am. Mus. Nat. Hist. 192: 1-104. 1989.

FOSSÅ, J.H., MORTENSEN, P.B., FUREVIK, D.M., The deep-water coral Lophelia pertusa in Norwegian waters : distribution and fishery impacts. Hydrobiologia 471, 1-12. 2002.

FREIWALD, A., BEUCK, L., RÜGGEBERG, A., TAVIANI, M., R/V Meteor M70-1 participants. The white coral community in the central Mediterranean revealed by ROV surveys. Oceanography 22, 58-74. 2009.

FREIWALD, A., FOSSÅ, J.H., GREHAN, A., KOSLOW, T., ROBERTS, J.M. Cold-water Coral Reefs. UNEP-WCMC, Cambridge, UK. 2004.

FUKUDA, M. V. Contribuição ao conhecimento taxonômico dos silídeos ( Polychaeta : Syllidae ) da região sudeste-sul do Brasil Contribuição ao conhecimento taxonômico dos silídeos ( Polychaeta : Syllidae ) da região sudeste-sul do Brasil. Universidade de São Paulo, 2010.

GLOVER, A. G.; SMITH, C. R. The deep-sea floor ecosystem : current status and prospects of anthropogenic change by the year 2025. Environmental Conservation, v. 30, n. 3, p. 219-241, 2003.

GRUBE, A. E. Die Familien der Anneliden. Arch for Nat- uugeschichte, 16,249-364. 1850.

GRUBE, A.E. Beschreibungen neuer oder wenig bekannter Anneliden. Archiv für Naturgeschichte, Berlin, 21(1): 81-136, pls 3-5. 1855. 
HALL-SPENCER, J., ALLAIN, V., FOSSÅ, J.H. Trawling damage to Northeast Atlantic ancient coral reefs. Proceedings of the Royal Society of London, Biological sciences 269, 507-511. 2002.

HARTMAN, O. Catalogue of the Polychaetous Annelids of the World. Parts 1 and 2. Occasional Papers of the Allan Hancock Foundation, 23: 628pp. 1959.

HARTMAN, O. Deep-water benthic polychaetous annelids off New England to Bermuda and other North Atlantic areas. Occasional Papers of the Allan Hancock Foundation, 28: 1-378. 1965.

HARTMAN, O. Non-pelagic Polychaeta. Further Zoological Results of Swedish Antarctic Expedition 1901-1903, 4 (11): 1-83, 21 figures. 1953.

HARTMAN, O. Polychaetous Annelids Collected by the USNS Eltanin and Staten Island Cruises, chiefly from Antarctic Seas. Allan Hancock Monographs in Marine Biology, 1967, 2:1-387, 51 plates.

HARTMAN, O. Polychaetous Annelids Erected by Treadwell, 1891 to 1948, Together with a Brief Chronology. Bulletin of the American Museum of Natural History, 109(2):239-310. 1956.

HARTMAN, O. Polychaetous Annelids. Part II. Chrysopetalidae to Goniadidae. Allan Hancock Pacific Expeditions, 7:173-286, plates 31-44. 1940.

HENRY, L.-A., ROBERTS, J.M. Biodiversity and ecological composition of macrobenthos on cold-water coral mounds and adjacent off-mound habitat in the bathyal Porcupine Seabight, NE Atlantic. Deep Sea Research Part I: Oceanographic Research Papers 54, 654-672. 2007

HILBIG, B., BLAKE, J.A. Dorvilleidae (Annelida: Polychaeta) from the U.S. Atlantic slope and rise. Description of two new genera and 14 newspecies, with a generic revision of Ophryotrocha. Zoologica Scripta 20, 147-183. 1991.

HORST, R. Polychaeta Errantia of the Siboga-Expedition. Part 3. Nereidae and Hesionidae. Siboga Expeditie. 99, 145-198. 1924. 
HUMASON, G. L. Animal tissue techniques. 4th ed. W. H. Freeman and Company, San Francisco, CA, USA. Pp. 661. 1979.

HUTCHINGS, P.; REID, A. The Nereididae (Polychaeta) from Australia-Gymnonereidinae sensu Fitzhugh, 1987: Australonereis, Ceratocephale, Dendronereides, Gymnonereis, Nicon, Olganereis and Websterinereis. Records of the Australian Museum, v. 42, n. 1, p. 69-100, 23 mar. 1990.

IMAJIMA, M. and O. HARTMAN. The Polychaetous annelids of Japan, Part I. Occasional Papers of the Allan Hancock Foundation Papers, 26: 1-452. 1964.

IMAJIMA, M. The Syllidae (Polychateous Annelids) from Japan (IV) Syllinae (1). Publication of Seto Marine Biology Laboratory, XIV: 218-252. 1966.

JENSEN, A., FREDERIKSEN, R. The fauna associated with the bank-forming deepwater coral Lophelia pertusa (Scleractinaria) on the Faroe Shelf. Sarsia 77, 53-69. 1992.

JOHNSON, Herbert P. A preliminary account of the marine annelids of the Pacific coast, with descriptions of new species. Proceedings of the California Academy of Sciences, Ser. 3, 1(5): 153-199. 1897.

KINBERG, J. G. H. Annulata nova. Öfversigt af Königlich Vetenskapsakademiens förhandlingar, Stockholm 22(2): 167-179. (Leitura em 1865 e publicado em 1866)

KINBERG, J. G. H. Annulata nova. Öfversigt af Königlich Vetenskapsakademiens förhandlingar, Stockholm, 23(4): 97-103. 1866.

KINBERG, J.G.H. Nya slägten och arter af Annelider, Öfversigt af Kongl. VetenskapsAkademiens Förhhandlingar, Stockholm, 12 (9-10), 381-388 (read 1855; printed 1856)

KITAHARA, M. V, CAPÍTOLI, R.R., FILHO, N.O.H. Distribuição das espécies de corais azooxantelados na plataforma e talude continental superior do sul do Brasil. Iheringia 99, 223-236. 2009.

KITAHARA, M. V. Novas ocorrências de corais azooxantelados ( Anthozoa , Scleractinia ) na plataforma e talude continental do sul do Brasil ( 25-34 o S ). Biotemas, v. 19, n. 3, p. 55-63, 2006. 
KITAHARA, $\mathrm{M}$. V. SPECIES RICHNESS AND DISTRIBUTION OF AZOOXANTHELLATE SCLERACTINIA IN BRAZIL. BULLETIN OF MARINE SCIENCE, v. 81, n. 3, p. 497-518, 2007.

KITAHARA, M.V. A pesca demersal de profundidade e os bancos de corais azooxantelados do sul do Brasil. Biota Neotropica vol. 9, no. 2. Pp. 11-19. 2009. (Disponível online: http://www.biotaneotropica.org.br/v9n2/pt/abstract?article+bn00409022009).

KRØYER, H. Meddelelser af en Afhandling Ormeslaegten Sabella Linn., isaer med Hensyn til dens nordiske Arter. Oversigt over det Kongelige Danske videnskabernes selskabs forhandlinger 1856: 1-36. 1856.

KUDENOV, J.D. and L.H. HARRIS. Family Syllidae Grube, 1850. In: Blake, J.A., B. Hilbig, and P.H. Scott (eds.) Taxonomic atlas of the benthic fauna of the Santa Maria Basin and western Santa Barbara Channel, vol. 5, part 2. Santa Barbara Museum of Natural History, Santa Barbara, California. 1995. pp. 1-99.

LANGERHANS, P. Die Wurmfauna von Madeira. IV. Zeitschrift für wissenschaftliche Zoologie, 40(2): 247-285. 1884.

LANGERHANS, P. Die Wurmfauna von Madeira. Zeitschrift für Wissenschaftliche Zoologie, 32: 513-592. 1879.

LATREILlE P. A. FAMILlES NATURELlES DU RÈGNE ANIMAL, EXPOSÉ SUCCINCTEMENT ET DANS UN ORDRE ANALYTIQUE AVEC L'INDICATION DE LEURS GENRES. J. B. BAILLIÈREPARIS PP. 570. 1825.

LATTIG, P. MARTÍN, D. Sponge-associated Haplosyllis (Polychaeta: Syllidae: Syllinae) from the Caribbean Sea, with the description of four new species. Scientia Marina, v. 75, n. 4, p. 733-758. 2011.

LATTIG, P.; MARTIN, D. A taxonomic revision of the genus Haplosyllis Langerhans, 1887 (Polychaeta: Syllidae: Syllinae). Zootaxa 2220: 1-40. 2009.

LATTIG, P.; MARTIN, D.; AGUADO, M. T. Four new species of Haplosyllis (Polychaeta: Syllidae: Syllinae) from Indonesia. Journal of the Marine Biological Association of the United Kingdom, v. 90, n. 04, p. 789-798. 2010. 
LATTIG, P.; MARTÍN, G. S. A. N.; MARTIN, D. Taxonomic and morphometric analyses of the Haplosyllis spongicola complex ( Polychaeta: Syllidae: Syllinae ) from Spanish seas, with re-description of the type species and descriptions of two new species. Scientia Marina, v. 71, n. 3, p. 551-570. 2007.

LAVRADO, H.P. \& BRASIL, A.C.S. Biodiversidade da região oceânica profunda da Bacia de Campos: macrofauna. $1^{a}$ ed. Rio de Janeiro: SAG Serv, 2010. 232p

LAVRADO, H.P. \& VIANA, M.S. Atlas de Invertebrados Marinhos da Região Central da Zona Econômica Exclusiva Brasileira - parte 1, Vol. 1, $1^{\text {a } e d ., ~ M u s e u ~ N a c i o n a l ~}$ da UFRJ, Rio de Janeiro, 2007, 258p.

LEON, J. DE; TROVANT, B. A new species of Nicon Kinberg, 1866 (Polychaeta, Nereididae) from Ecuador, Eastern Pacific, with a key to all known species of the genus. ZooKeys, v. 269, p. 67-76. 2013.

LINERO ARANA I, DIAZ O. Amphinomidae y Euphrosinidae (Annelida: Polychaeta) de la costa nororiental de Venezuela. Latin American Journal of Aquatic Research 38:107-120. 2010.

LINNAEUS, C. Systema Naturae per regna tria naturae, secundum classes, ordines, genera, species, cum characteribus, differentiis, synonymis, locis. Editio decima, reformata. Laurentius Salvius: Holmiae. Ii. 1758. 824 pp.

LINNAEUS, C. Systema naturae sive regna tria naturae, secundum classes, ordines, genera, species, cum characteribus, differentiis, synonymis, locis. Laurentii Salvii, Holmiae. 12th ed. v. 1 (pt 2): 533-1327. 1767

MALMGREN, A. J. Annulata polychaeta Spetsbergiae, Groenlandiae, Islandiae et Scandinaviae hactenus cognita, Öfversigt af Kongl. Vetenskaps-Akademiens Förhhandlingar Stockholm, 24, 127- 235pp. 1867

MARENZELLER, E. von. Berichte der Commission für Oceanographische erforschung des Östlichen mittelmeeres. Zweite Reihe. VI. Zoologische Ergebnisse II. Polychäten des Grundes, gesammelt 1890, 1891, 1892. Denkschriften der Akademie der Wissenschaften, Wien 60: 25-48,4plates. 1893. 
MARTIN D., BRITAYEV T.A. Symbiotic polychaetes: review of known species. Oceanograph Marine Bioloçy Annual Review 36:217-340. 1998.

MARTIN, D., MARIN, I., BRITAYEV, T. Features of the first known association between Syllidae (Annelida, Polychaeta) and crustaceans. Organisms Diversity \& Evolution 8, 279-281. 2008.

MARTIN, D., NÚÑEZ, J., RIERA, R., GIL, J., AL, D.M.E.T. On the associations between Haplosyllis (Polychaeta, Syllidae) and gorgonians (Cnidaria, Octocorallaria), with the description of a new species. Biological Journal of the Linnean Society 77, 455-477. 2002 .

MASTROTOTARO, F., D’ONGHIA, G., CORRIERO, G., MATARRESE, a., MAIORANO, P., PANETTA, P., GHERARDI, M., LONGO, C., ROSSO, a., SCIUTO, F., SANFILIPPO, R., GRAVILI, C., BOERO, F., TAVIANI, M., TURSI, A. Biodiversity of the white coral bank off Cape Santa Maria di Leuca (Mediterranean Sea): An update. Deep Sea Research Part II: Topical Studies in Oceanography 57, 412-430. 2010.

McINTOSH, W.C. 1885. Report on the Annelida Polychaeta collected by H.M.S. Challenger during the years 1873-1876. Report on the Scientific Results of the Voyage of H.M.S.Challenger during the years 1872-76, Serie Zoology, 12: 1-554.

McINTOSH, W.C. On British Annelida. Part I. Euphrosynidae, Amphinomidae, Aphroditidae, Polynoidae, Acoetiidae, and Sigalionidae. Transactions of the Zoological Society of London, 9(7): 371-394. 1876.

MONRO, C. C. A. 1930. Polychaete Worms. Discovery Reports, 2:1-222, 91 figures.

MORTENSEN, P. B.; BUHL-MORTENSEN, L.; GEBRUK, A.V.; KRYLOVA, E.M. Occurrence of deep-water corals on the Mid-Atlantic Ridge based on MAR-ECO data. Deep Sea Research Part II: Topical Studies in Oceanography, v. 55, n. 1-2, p. 142-152, 2008.

MORTENSEN, P.B. Aquarium observations on the deep-water coral Lophelia pertusa (L., 1758) (scleractinia) and selected associated invertebrates. Ophelia 54, 83-104. 2001. 
MORTENSEN, P.B., FOSSÅ, J.H. Species diversity and spatial distribution of invertebrates on deep - water Lophelia reefs in Norway. Proceedings of the 10th International Coral Reef Symposium 1849-1868. 2006.

MUELLER C.E., LUNDA T., MIDDELBURG J.J., van OEVELEN D. The Symbiosis between Lophelia pertusa and Eunice norvegica Stimulates Coral Calcification and Worm Assimilation. PLoS ONE 8(3): e58660. 2013.

MUNIZ, P., PIRES-VANIN, A.M.S., BURONE, L. \& SILVA, J.P. Density and distribution of polychaetes in the infralitoral of Mar Virado Bight (Ubatuba, SP) southeastern brazilian coast. Anais Academia Brasileira de Ciências, 68(3): 453-462. 1996.

NOGUEIRA, J. M. M.; ABBUD, A. Three new serpulids ( Polychaeta : Serpulidae ) from the Brazilian Exclusive. Zoosymposia, n. 2, p. 201-227, 2009.

NOGUEIRA, J.M.M. 2000. Anelídeos poliquetas associados ao coral Mussismilia hispida (Verrill, 1868) em ilhas do litoral do Estado de São Paulo. Phyllodocida, Amphinomida, Eunicida, Spionida, Terebellida, Sabellida. Tese de Doutorado - Instituto de Biociências, Universidade de São Paulo. 265 p.

NONATO, E. \& A. LUNA. Anelídeos poliquetas do nordeste do Brasil. I. Poliquetas bentônicos da costa da Alagoas e Sergipe. Bolm. Inst. Oceanogr. São Paulo, 19: 57130. 1970.

OLIVEIRA, Verônica M; SANTOS, Cinthya S G; LANA, Paulo Cet al. Morphological variations caused by fixation techniques may lead to taxonomic confusion in Laeonereis ( Polychaeta : Nereididae ). Zoologia, v.27, n.1, p.146-150, 2010.

ORENSANZ, J. M. L. The Eunicemorph Polychaete annelids from Antartic and Subantartic seas. Antartic Research Series, v. 52, p. 1-183, 1990.

PAAVO, B., BAILEY-BROCK, J., AKESSON, B. Morphology and life history of Ophryotrocha adherens sp nov (Polychaeta, Dorvilleidae). Sarsia, 85(3): 251-264. 2000.

PALLAS, P. S. Marina varia nova et rariora. Nova acta Academiae Scientiarum imperialis Pelropolitanea, 2:229-249, plates 5-8. 1788. 
PARAPAR, J. \& MOREIRA, J. Aproximación al estudio de la morfología setígera en algunas especies ibéricas de los géneros Glycera Savigny, 1818 y Glycerella Ardwidsson, 1899 (Polychaeta, Glyceridae). Graellsia, 66(2): 119-130. 2010.

PAXTON, H., DAVEY, A. A new species of Ophryotrocha (Annelida: Dorvilleidae) associated with fish farming at Macquarie Harbour, Tasmania, Australia. Zootaxa $2509,53-61.2010$.

PAXTON, H.; ÅKESSON, B. Redescription of Ophryotrocha puerilis and O. labronica (Annelida, Dorvilleidae). Marine Biology Research, v. 3, n. 1, p. 3-19, 2007.

PETTIBONE, M. H. Contribution to the polychaete family Pholoidae Kinberg. Smithsonian Contributions to Zoology, n. 532, p. 24, 1992.

PETTIBONE, M. H. New species of polychaete worms of the family Polynoidae from the east coast of North America. Journal of the Washington Academy of Sciences, 45(4): 118-126. 1955.

PETTIBONE, M. H. Polychaeta Errantia of the Siboga-Expedition. Part IV: Some additional polychaetes of the Polynoidae, Hesionidae, Nereidae, Goniadidae, Eunicidae and Onuphidae, selected as new spec- ies by the late Dr. Hermann Augener with remarks on other related species. Siboga Expeditie, 24, 1-72. 1970.

PETTIBONE, M. H. Polynoid polychaetes commensal with antipatharian corals. Proceedings of the Biological Society of Washington, v. 104, n. 4, p. 714-726, 1991 b.

PETTIBONE, M. H. Polynoids commensal with gorgonian and stylasterid corals, with a new genus, new combinations, and new species (Polychaeta: Polynoidae: Polynoinae). Proceedings of the Biological Society of Washington, v. 104, n. 4, p. 688-713, $1991 \mathrm{a}$.

PETTIBOnE, M. H. Revision of some species referred to Antinoe, Antinoella, Antinoana, Byglides, and Harmothoe (Polychaeta: Polynoidae: Harmothoinae). Smithsonian Contributions to Zoology, 545: 1-41. 1993.

PETTIBONE, M. H. Revision of Some Species Referred to Leptonereis, Nicon, and Laeonereis (Polychaeta: Nereididae). Smithsonian Contributions to Zoology, n. 104, p. 53, 1971. 
PETTIBONE, M. H. Some Scale-bearing Polychaetes of Puget Sound and Adjacent Waters. University of Washington Press, Seattle. 1953, 89 pp.

PLEIJEL, F. Phylogeny and classification of Hesionidae (Polychaeta). Zoologica Scripta, v. 27, n. 2, p. 89-163. 1998.

PLYUSCHEVA, M., MARTIN, D., BRITAYEV, T. Diet analyses of the scale-worms Lepidonotus squamatus and Harmothoe imbricata (Polychaeta, Polynoidae) in the White Sea. Marine Biology Research 6, 271-281. 2010.

POURTALÈS, L.F. de. Report of the results of dredging, under the supervision of Alexander Agassiz, in the Gulf of Mexico, by the U.S. Coast Survey Steamer Blake. Corals. Bulletin of the Museum of Comparative Zoölogy, Harvard 5(9): 197-212, $1 \mathrm{pl}$. 1878.

PRUVOT, G. [Polychaeta context] Coup d'oeil sur la distribution général des invertébrés dans la région de Banyuls (Golfe du Lion). Archives de zoologie expérimentale et générale 3(3): 629-658. 1895.

REX M.A., ETTER R.J., MORRIS J.S., COUSE J., MCCLAIN C.R., JOHNSON N.A., STUART C.T., DEMING J.W., THIES R. \& AVERY R. Global bathymetric patterns of standing stock and body size in the deep-sea benthos. Marine Ecology Progress Series, 317: 1- 8. 2006.

RIZZO, A. E., STEINER, T. M. \& AMARAL, A. C. Z. Glyceridae Grube, 1850 (Annelida: Polychaeta) from Southern and Southeastern Brazil, including a new species of Glycera.

Biota Neotropica, 7 (3): 41-59. 2007.

ROBERTS J. M. Reef-aggregating behaviour by symbiotic eunicid polychaetes from coldwater corals: do worms assemble reefs? Journal of the Marine Biological Association of the United Kingdom 85: 813-819. 2005.

ROBERTS, J M.; WHEELER, Andrew J; FREIWALD, A. Cold-water corals: the biology and geology of deep-sea coral habitats. 1.ed. New York: Cambridge University Press, 351pp. 2009,

ROBERTS, J.M., WHEELER, A.J., FREIWALD, A. Reefs of the deep: the biology and geology of cold-water coral ecosystems. Science, 312, 543-7. 2006 
ROSSI, M. C. S. Contribuição ao conhecimento taxonômico dos poliquetas sabelídeos (Polychaeta: Sabellidae) da região sudeste do brasil. Universidade de São Paulo, 2008 .

RULLIER, F. Resultats scientifique des campagne de la 'Calypso': Iles du Cap Vert. 5. Annélides Polychètes. Annales de l'Institut océanographique, 41(6): 113-218. 1964.

SALAZAR-VALLEJO, S. Anfinómidos y eufrosínidos (Polychaeta) del Caribe mexicano con claves para las espécies reconocidas del Gran Caribe. Revista Biologia. Tropical, 44(3)/45(1): 379-390. 1997.

SAN MARTÍN, G. \& ESTAPÉ, S. Redescription of Pionosyllis procera (Polychaeta: Syllidae) with comments on its reproduction and systematic position. Revista de Biología Tropical, 41(2): 227-231. 1993.

SAN MARTÍN, G., HUTCHINGS, P. \& AGUADO, M.T. Syllinae (Polychaeta, Syllidae) from Australia. Part 2. Genera Inermosyllis, Megasyllis n. gen., Opisthosyllis, and Trypanosyllis. Zootaxa, 1840: 1-53. 2008.

SAN MARTÍN, G.; LÓPEZ, E.; AGUADO, M. T. Revision of the genus Pionosyllis (Polychaeta: Syllidae: Eusyllinae), with a cladistic analysis, and the description of five new genera and two new species. Journal of the Marine Biological Association of the United Kingdom, v. 89, n. 07, p. 1455. 2009.

SARS, M. Beretning om en i Sommeren 1849 foretagen zoologisk Reise i Lofoten og Fimarken. Nyt Magazin for Naturvidenskaberne 6: 121-211. 1851.

SAVIGNY, J.S. Section on Annelida in LAMARCK, 1818. System des Annelides, principalement de celles des cones de I'Egypte et de la Syrie, offrant les caracteres tant distinctifs que naturelles des orders, familles et genres, avec Ia description des especes. Descr. de I'Egypte, Paris. Hist. Nat. 21:325-472. 1818.

SUMIDA, P. Y. G. et al. Seabed pockmarks associated with deepwater corals off SE Brazilian continental slope, Santos Basin. Marine Geology, v. 207, p. 159 - 167, 2004. 
TABOADA, S., WIKLUND, H., GLOVER, A.G., DAHLGREN, T.G., CRISTOBO, J., AVILA, C. Two new Antarctic Ophryotrocha (Annelida: Dorvilleidae) described from shallow-water whale bones. Polar Biology (DOI: 10.1007/s00300-013-1326-4). 2013.

TREADWELL, A. L. 1922. Leodicidae from Fiji and Samoa. Carnegie Institute of Washington Publication, 312: 127-170. 1922.

TREADWELL, A. Polychaetous annelids of Porto Rico and vicinity. Scientific survey of Porto Rico and the Virgin Islands. New York Academy of Science, 16(2): 151-319. 1939.

VERRILL, A.E. Additions to the Turbellaria, Nemertina, and Annelida of the Bermudas, with revisions of some New England genera and species. Transactions of the Connecticut Academy of Arts and Sciences, 10(2): 595-671. 1900

VERRILL, A.E. Report upon the invertebrate animals of Vineyard Sound and the adjacent waters, with an account of the physical characters of the region. Report of the United States Commission for Fisheries, 1871-72: 295-778. 1873.

VIANA AR, FAUGÈRES JC, KOWSMANN RO, LIMA JAM, CADDAH LFG, RIZZO JG. Hydrology, morphology and sedi- mentology of the Campos continental margin, offshore Brazil. Sediment Geol 115:133-157. 1998.

WESENBERG-LUND, E. Polychaeta. Danish Ingolf-Expedition, 4(14): 1-92. 1950.

WIELGUS, J.; GLASSOM, D.; CHADWICK, N. E. Patterns of polychaete worm infestation of stony corals in the northern Red Sea and relationships to water chemistry. BULLETIN OF MARINE SCIENCE, v. 78, n. 2, p. 377-388, 2006.

WIENBERG, C., HEBBELN, D., FINK, H.G., MIENIS, F., DORSCHEL, B., VERTINO, A., CORREA, M.L., FREIWALD, A. Scleractinian cold-water corals in the Gulf of Cádiz-First clues about their spatial and temporal distribution. Deep Sea Research Part I: Oceanographic Research Papers 56, 1873-1893. 2009.

WIKLUND, H., GLOVER, A.G., DAHLGREN, T.G. Three new species of Ophryotrocha (Annelida: Dorvilleidae) from a whale-fall in the North-East Atlantic. Zootaxa 2228, 43 $-56.2009$. 
WU, B. \& R. SUN R. Revision of the genera Nicon and Rullierinereis with descriptions of a new genus Sinonereis (Polychaeta: Nereidae). Oceanic Selections (2): 95-112. Vol. 2 No. 2. 1979.

WU, B., SUN R. \& Yang, D.J. The Nereidae (Polychaetous Annelids) of the Chinese Coast. China Ocean Press, Beijing 234 pp. Tokyo. 1985.

YANEZ, B.; CARRERA, L. F. Reestablishment of Notopygos megalops McIntosh, description of $\mathrm{N}$. caribea sp. $\mathrm{n}$. from the Greater Caribbean and barcoding of "amphiamerican" Notopygos species (Annelida, Amphinomidae). ZooKeys, v. 223, p. 69-84, 28 set. 2012.

ZIBROWIUS, H. Contribution à l'étude des Serpulidae (Polychaeta Sedentaria) du Brésil. Boletim do Instituto Oceanográfico, 19, 1-32. 1970. 


\section{ANEXO I}

\section{A PROTOCOL FOR PREPARING POLYCHAETES FOR SEM USING HMDS}

\section{Kirk Fitzhugh Natural History Museum of Los Angeles County}

kfitzhug@nhm.org

I follow a three-step process for preparing polychaetes for SEM: (1) water removal through an ethanol (EtOH) series, (2) replacement of EtOH with HMDS through a graded series, and (3) evaporation of HMDS.

1. Removal of water. Our specimens are preserved in $70 \% \mathrm{EtOH}$, so to remove water I place specimens in a series of 70, 80, and $90 \% \mathrm{EtOH}$, and finally into absolute $\mathrm{EtOH}$. I do not keep stock solutions of the mixtures, but rather mix each concentration at the time it is needed, using enough to sufficiently cover the specimens. Since most specimens I work with are from 0.5 to $8 \mathrm{~mm}$ long, I use small glass blocks that have shallow wells. For the EtOH concentrations, I withdraw the appropriate amount of absolute EtOH with a syringe, place it in a well, add the necessary amount of water, mix, then transfer the specimen into that well and cover it with a glass slide. Because of the small size of specimens, I transfer them from one well to another using an 'Irwin loop' rather than using forceps. This minimizes the transfer of water from one well to another and reduces the risk of specimen damage. For small specimens, I leave them in each EtOH concentration for about 10 minutes (you might need longer times depending on the sizes of your specimens). I do all of these transfers, including those in HMDS (see below) using a stereo microscope, again because of the small size of specimens. After the specimen is transferred to absolute EtOH for 10 minutes, I then transfer it to another well with absolute EtOH for another 10-15 minutes to ensure that all water is removed.

2. Removal of EtOH using HMDS. The techniques mentioned in step 1 are applied here. The specimen in absolute EtOH is sequentially transferred to mixtures of absolute EtOH and HMDS with the following ratios 2:1, 1:1, 1:2, and then into pure HMDS. As with the EtOH keep specimens in each concentration for about 10-15 minutes. If you are working with very small specimens, ensure that each well is free of dust, especially for the final HMDS step that will evaporate.

3. Evaporation of HMDS. After the specimen has been in pure HMDS for 10-15 minutes in step 2, I transfer it to another well with fresh HMDS, where it will sit until the HMDS has completely evaporated, your specimen will look almost completely white, leaving the specimen completely dry and ready to be mounted onto the SEM stub. 